\title{
Analyzing the Costs of Nontraditional Choices: Role Congruity Theory and College Student's Perception of Attractiveness
}

\author{
Brittany M. Kowalski
}

Follow this and additional works at: https://researchrepository.wvu.edu/etd

\section{Recommended Citation}

Kowalski, Brittany M., "Analyzing the Costs of Nontraditional Choices: Role Congruity Theory and College Student's Perception of Attractiveness" (2017). Graduate Theses, Dissertations, and Problem Reports. 6009.

https://researchrepository.wvu.edu/etd/6009

This Thesis is protected by copyright and/or related rights. It has been brought to you by the The Research Repository @WVU with permission from the rights-holder(s). You are free to use this Thesis in any way that is permitted by the copyright and related rights legislation that applies to your use. For other uses you must obtain permission from the rights-holder(s) directly, unless additional rights are indicated by a Creative Commons license in the record and/ or on the work itself. This Thesis has been accepted for inclusion in WVU Graduate Theses, Dissertations, and Problem Reports collection by an authorized administrator of The Research Repository @ WVU. For more information, please contact researchrepository@mail.wvu.edu. 
Analyzing the Costs of Nontraditional Choices:

Role Congruity Theory and College Student's Perception of Attractiveness

\title{
Brittany M Kowalski
}

Thesis submitted

to the Eberly College of Arts and Sciences

at West Virginia University

in partial fulfillment of the requirements for the degree of

Master of Arts in

Sociology

\author{
Lisa Dilks, Ph.D., Chair \\ Melissa Latimer, Ph.D. \\ Rachel Stein, Ph.D. \\ Department of Sociology and Anthropology
}

\section{Morgantown, West Virginia}

2017

Keywords: roles, role congruity, gender, gender roles, attraction Copyright 2017 Brittany M Kowalski 


\author{
ABSTRACT \\ Analyzing the Costs of Nontraditional Choices: \\ Role Congruity Theory and College Student's Perception of Attractiveness \\ Brittany M Kowalski
}

Researchers have shown that both women and men with traits incongruent to their gender roles are viewed as less competent and are less acceptable than those whose traits conform to their gender roles. The present study looks at the effect of role congruity between gender, occupational status and personality traits and the effect that this has on the evaluation of potential romantic partner attractiveness. Little research has looked at the effect of both status characteristics such as occupation or college major and personal traits such as personality, likesdislikes or hobbies. A vignette experiment was conducted in which college students were asked to read a paragraph about a hypothetical peer and then answer survey questions that assessed whether or not they find the person to be an attractive romantic partner. Analysis of this data helps to show the effect that role congruence or incongruence in both occupational status and personality traits has on evaluations of attraction. 


\section{TABLE OF CONTENTS}

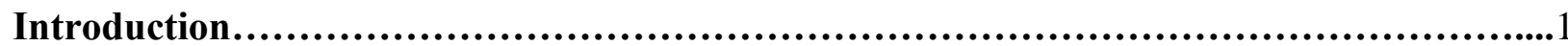

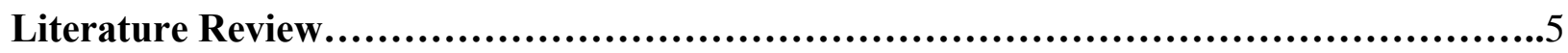

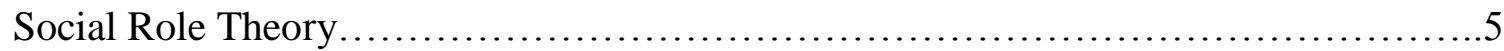

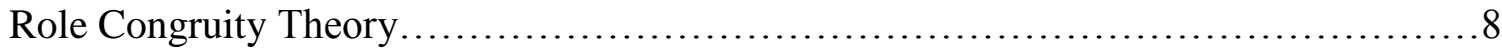

Impact of Role Congruity Considerations....................................

Role Congruity and the Effects on Mate, Dating and Attractiveness.............14

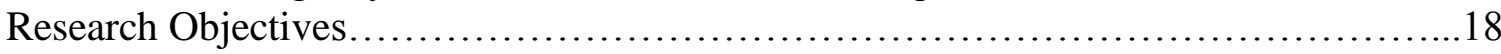

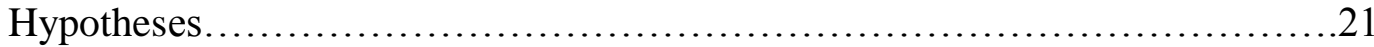

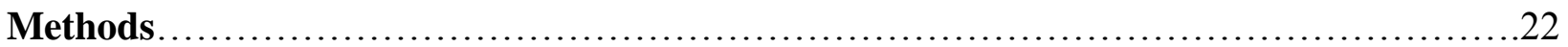

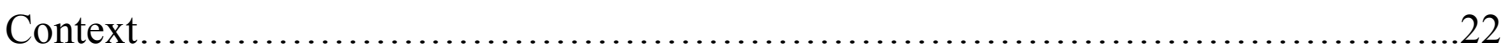

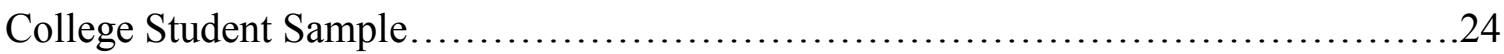

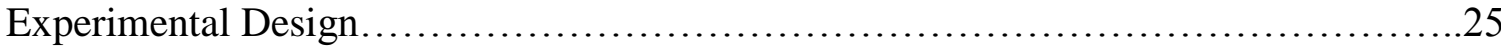

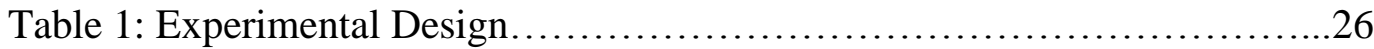

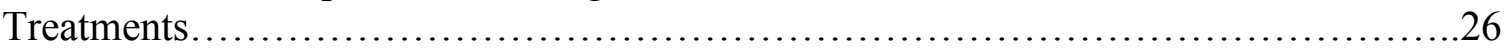

Table 2: Manipulated College Major, Hobbies and Personality Traits...........28

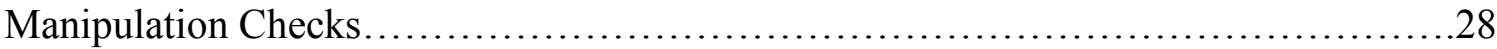

Figure 1: Slider Bar about the Potential Romantic Partner.......................29

Dependent Variables: Romantic Scales.............................................30

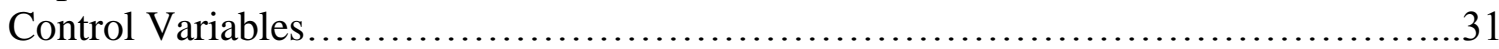

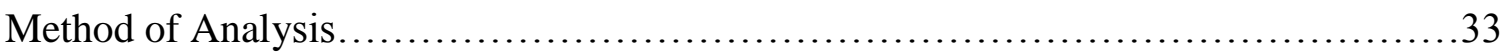

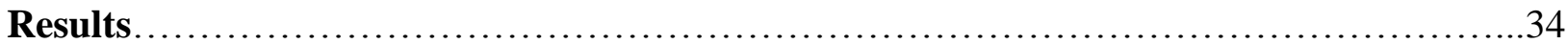

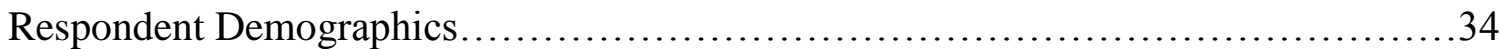

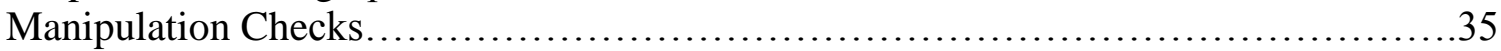

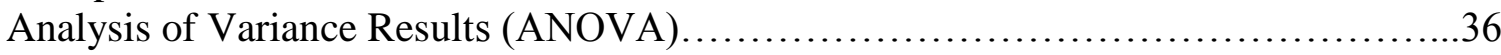

Male Respondents.........................................................

Campbell Romantic Attraction Scale.................................36

Reysen Likability Scale.......................................... 37

Thomae Desire for a Relationship Scale................................37

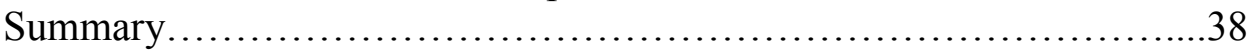

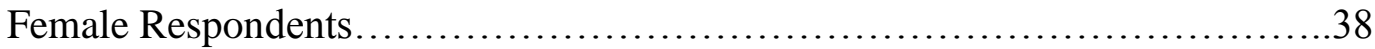

Campbell Romantic Attraction Scale....................................39

Figure 2: Mean Ratings by Women of Potential Romantic

Partner on the Campbell Romantic Attraction Scale.......41

Reysen Likability Scale...........................................43

Figure 3: Mean Ratings by Women of Potential Romantic

Partners on the Reysen Likability Scale....................43

Thomae Desire for a Relationship Scale .............................43

Combined Scale............................................43

Short Term Relationship Subscale..............................44

Long Term Relationship Subscale..............................45

Figure 4: Mean Ratings by Women of Potential 
Romantic Partners on the Thomae Desire

for a Relationship Scales .47

Regression Results .48

Table 3: Description of Vignette Numbers Including Which Major,

Personality and Vignette they are Associated With......................48

Campbell Romantic Attraction Scale......................................49

Male Respondents................................................49

Table 4: Statistically Significant Differences Between

Mean Scores for Male Respondents...................50

Female Respondents............................................50

Table 5: Statistically Significant Differences Between

Mean Scores for Female Respondents....................52

Figure 5: Female Campbell Ratings of Male Potential

Romantic Partners by Vignette........................53

Summary.......................................................53

Reysen Likability Scale............................................... 54

Male Respondents...............................................55

Table 6: Regression of Perspective Romantic Partner's

Personality, College Major and Reysen Score.............55

Female Respondent..............................................55

Table 7: Statistically Significant Differences Between

Mean Scores for Female Respondents..................59

Figure 6: Female Reysen Ratings of Male Potential

Romantic Partners by Vignette.......................60

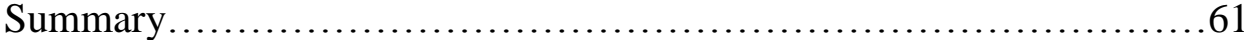

Thomae Desire for a Relationship Scale...................................61

Male Respondents.............................................61

Table 8: Statistically Significant Differences Between

Mean Scores for Male Respondents..................62

Female Respondents..........................................63

Table 9: Statistically Significant Differences Between

Mean Scores for Female Respondents.................66

Figure 7: Female Thomae Ratings of Male Potential

Romantic Partners by Vignette.......................67

Short Term Relationship Subscale.......................................67

Male Respondents..............................................67

Table 10: Regression of Perspective Romantic Partner's

Personality, College Major and Thomae

Short-Term Score....................................68

Female Respondents...........................................68

Table 11: Statistically Significant Differences Between

Mean Scores for Female Respondents...................71

Figure 8: Female Thomae Short Term Ratings of Male

Potential Romantic Partners by Vignette..................72

Long Term Relationship Subscale....................................... 72 
Male Respondents.............................................. 72

Table 12: Statistically Significant Differences Between Mean Scores for Male Respondents.......................74

Figure 9: Male Thomae Long-Term Ratings of Female

Romantic Partners by Vignette............................75

Female Respondents............................................. 75

Table 13: Statistically Significant Differences Between Mean Scores for Female Respondents......................78

Figure 10: Female Thomae Long Term Ratings of Male Potential Romantic Partners by Vignette...................79

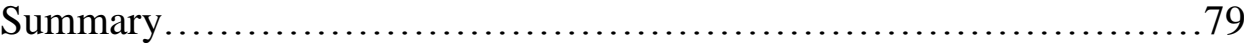

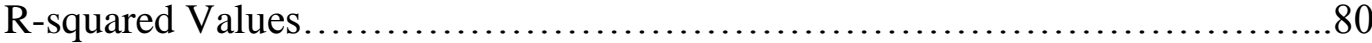

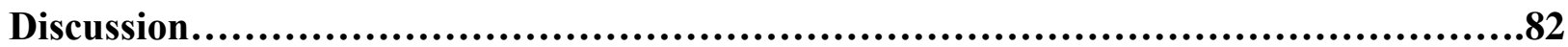

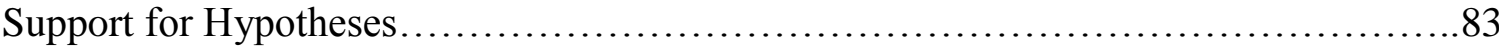

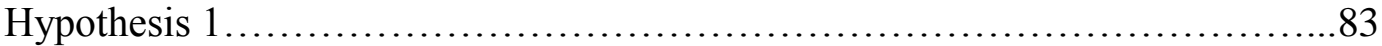

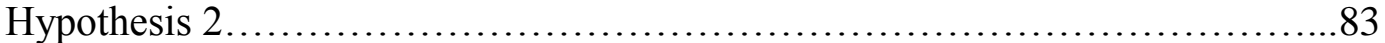

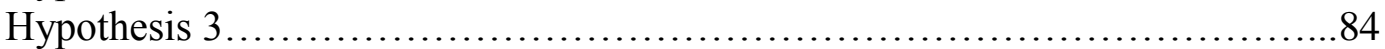

Table 14: Mean Score for Entirely Role Congruent, Entirely Role Incongruent and Combinations of Congruent and Incongruent for Each of the Five Scales..........................85

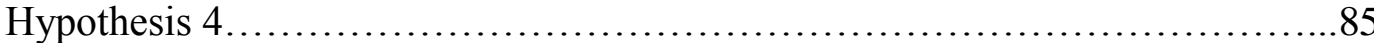

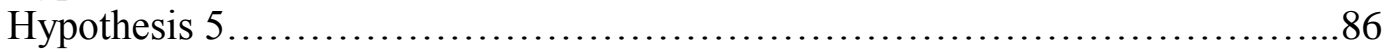

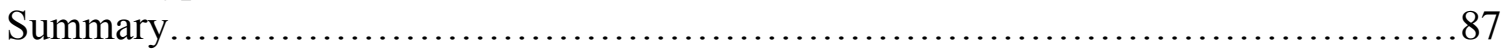

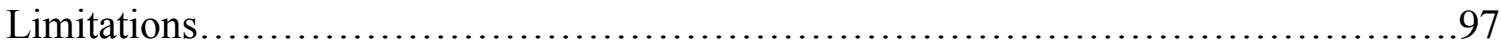

Directions for Future Research...............................................92

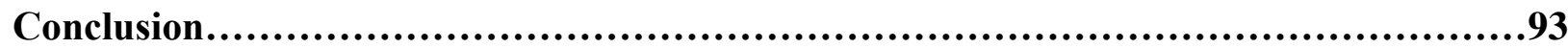

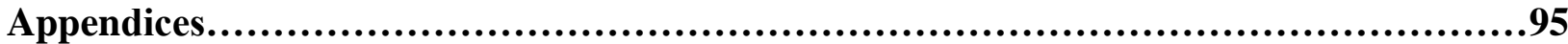

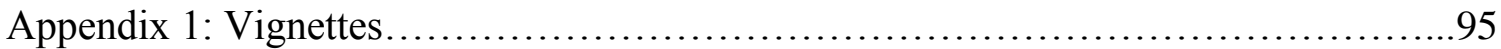

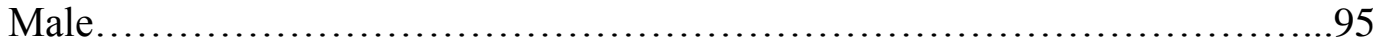

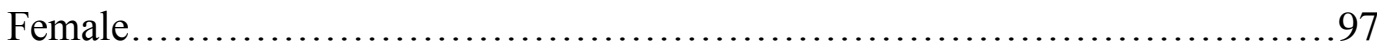

Appendix 2: Dependent Variable Scale..........................................99

Reysen's Likability Scale..................................................99

Thomae's Desire for a Relationship Scale...................................100

Campbell's Romantic Attraction Scale.....................................101

References..................................................................................104 


\section{INTRODUCTION}

Pink and blue: humans are socialized into gender norms and roles beginning at birth and these norms continue to be reinforced throughout the life course. There are societal expectations of what it means to be a female and what it means to be a male. Gender norms and roles are so rigid that they create gendered stereotypes that are often so pervasive that even without details about a person, when described in a given context or situation a gendered image of the individual is created.

Illustrations of this situation can be seen in every day media about men and women in occupations that are contrary to their gender role. A Kurdish military prodigy of just nineteen years old was killed while in combat. This soldier fought valiantly for their country and inspired their people. However, when they died, media coverage focused on the fact that this person was physically attractive and spent more time comparing them to a famous movie star than they did on their amazing military successes. Asia Ramazan Antar happens to be a female and her success as a solider was dwarfed by the fact that she was an attractive female (Gol, 2016).

An elementary school teacher was just starting their first year of teaching the first grade. They were excited by the opportunity to transform the children entering their classroom in September from babies to independent thinkers by May. Twenty five and armed with a college degree in elementary education, they set off to begin their first year of teaching. Shortly into the school year, parents of the students in their class began to call the office, questioning the teacher's career choice. Many parents even went so far as to spend a day sitting in on the classroom to monitor the teacher and make certain that they wanted their children to be in the class. Philip Wiederspan happens to be a male and the negative perceptions of male teachers, 
especially at the elementary school level, overshadowed the fact that he was a well-educated, dedicated and prepared teacher (James, 2013).

Perceptions of femininity, the quality of being female, and masculinity, qualities traditionally associated with men, cause individuals such as the two above to be treated unfairly by having their gender roles eclipse their occupational choices. Researchers have shown again and again that both women and men with traits incongruent to their gender roles are viewed as less competent and are less acceptable than those whose traits conform to their gender roles (Eagly and Karau, 2002; Shaffer and Johnson, 1980; and Diekman and Eagly, 2008). For example, female physicians are thought to be less capable than their male peers, thus indicating that gender role incongruity causes negative perceptions of female capability in the male dominated field of physicians and male nurses were perceived as highly feminine or even homosexual due to their gender role incongruent occupational choice thus undermining their capability and masculinity (Lupton, 2000).

The present study connects theories in a new and needed way in order to look at the effect of role congruity between gender, occupational status and personality traits and the effect that this has on the evaluation of potential romantic partner attractiveness. Research has shown that attraction can be affected by whether a potential romantic partner is gender role congruent or incongruent with some contradicting results (Chappetta and Barth, 2016; Thomae and Houston, 2015, Zillman et al., 1986). Previous research focuses either on a person's occupational status or on their personality traits in order to examine the effect of gender incongruent attributes on people's assessment of their attractiveness which leads some to conclude that gender role incongruence makes a person less attractive (Thomae and Houston, 2015; Schaffer and Johnson, 1980; Travaglia et al, 2009) and others to conclude that it makes a person more attractive 
(Chappetta and Barth, 2016). Little research has looked at the effect of both status characteristics such as occupation or college major and personal traits such as personality, likes-dislikes or hobbies. By using both categories of traits, clearer conclusions can be drawn about which characteristics have a bigger impact on evaluations of attractiveness and more accurate statements about the effects of gender role incongruence on evaluations of attraction.

There are also conflicting results as to whether or not gender role congruence makes a person more or less attractive than gender role incongruence in previous studies based on whether the researchers are looking at gender role congruity in respect to short or long term relationships (Thomae and Houston, 2015; Chappetta and Barth, 2016). In order to address this issue, levels of attraction towards gender role congruent and incongruent individuals in the context of both short and long term relationships will be examined. Attraction will also be examined in different contexts: romantic and friendship. This comparison is to determine if role (in)congruence has a difference effect on romantic relationships than on friendships thus examining a wider spectrum of possible peer relationships.

This study specifically helps to better understand how collegians choose dating and ultimately marital partners as well as the effect of gender role congruity and peer evaluations in a more broad sense. In initial conversations between college students there is a key question that is always asked of one another: "What is your major?" Knowing someone's major is a crucial barometer of who the person is at a college or university (Porter and Umbach, 2006). When gender and college major are incongruent, there is likely to be negative reactions in peers, regardless of the relative positivity of the person or the college major in question. If individuals who pursue gender atypical college majors and gender atypical careers are negatively affected by the mismatch of their gender and the societally perceived expectations put on them, this can lead 
to both psychological distress on the individual and also to social stresses from the lack of a support network. Peer perceptions of the congruity of gender roles and both occupational status and personality traits are also crucial to understand because they can have profound impacts on the perceived attractiveness of potential mates. The effect of gender role congruence on perceptions of attraction is an especially important issue to look at in a collegiate setting because according to Arnett (2000), finding a stable romantic relationship is a highly salient goal for college students.

In order to test whether or not role congruity has an impact on attractiveness, a vignette experiment is conducted. College students are asked to read a paragraph about a hypothetical peer. They then answer survey questions to assess whether or not they find the person to be an attractive candidate for a romantic relationship. This study measures the effect of role congruence or incongruence in both occupational status (as proxied by college major and career goals) and personality traits has on evaluations of attraction.

I hypothesize that individuals who exhibit gender incongruent college major and personality traits will be rated as the least desirable partners. Individuals who exhibit gender congruent major and personality traits will be rated as the most desirable partners. When a person has one set of characteristics that is congruent and the other is incongruent, the congruent characteristics will outweigh the effects of the incongruent ones, thus making them more attractive than those who completely deviate from gender norms. In other words, individuals who are entirely incongruent with their gender roles will be rated the most harshly, those who have congruent and incongruent characteristics will be rated moderately and those who are entirely congruent will be rated the best of the three. 


\section{LITERATURE REVIEW}

\section{Social Role Theory}

Role Theory is a social psychological perspective that asserts that people act in accordance with the roles that they occupy (Delamater and Myers, 2014). Roles are any positions that have expectations attached to them that tell the person who occupies the role what someone in that position (role) should do, how they should behave, what beliefs they hold and what their attitudes about things should be (Delamater and Myers, 2014). Roles occur at different levels such as the group (e.g., the goalie on a hockey team) or organizational level (e.g., a nurse at a hospital) or on the societal level (e.g., gender). Role expectations can be explicit such as with the case of many jobs, especially those that are in the service sector. The people who occupy the roles in these jobs generally are taught how to occupy the role by learning the information that is literally "in the handbook" such as what uniform to wear, how to treat customers, et cetera. Role expectations can also be implicit, such as the role of neighbor, a role that has no written rules of conduct but there are attached social expectations that a person in the role does things like lending a hand in a crisis, saying hello if you see them, to name a couple. Roles on the societal level are products of the social structure and do not have explicit handbooks for how to occupy the role but rather the expectations of social roles are taught and internalized through socialization, the process by which individuals learn skills, knowledge, values, motives and roles that apply to them so that they can then recreate and reinforce them (Delamater and Myers, 2014).

According to Social Role Theory, the norms attached to social roles are culturally shared expectations that take precedence over more specific roles (Eagly and Karau, 2002). Social role theory focusses on the importance of the expectations of roles within the social structure and 
how the occupation of one role has an effect on the behavioral tendencies of the people who occupy that role (Eagly, 1987). Social Role Theory further emphasizes the cultural aspect of roles and role expectations. The core of the theory is that roles are created by societies which give them their meaning and importance. The societies that create them strategically teach their members to conform to these roles as they have been constructed. For example, there are social expectations of those who occupy the role of "parent" such as caring for the health and wellbeing of your child, teaching them how to act when in public and ensuring they receive at least the required amount of education. When a child acts out in public it is seen as a failure of the parent properly performing their role and social sanctions will take place in the forms of stern looks, hushed comments or even formal removal from the situation. It is not the child that is often the recipient of these social sanctions but rather the parent for their failure to perform their social role.

A major category of social roles studied by social psychologists is gender roles. Through gender socialization, little boys and little girls are taught to embrace and exemplify roles and traits that are in line with their gender. Social Role Theory of Gender asserts that the male or masculine role focuses on possession of agentic qualities and goals that center on self-promotion and mastering the environment whereas the female or feminine role encompasses communal goals that center on helping others and maintaining interpersonal relationships (Diekman and Eagly, 2008; Diekman and Schneider, 2010). ${ }^{1}$ These personal traits are then linked to the occupation of other social roles. This means that women gravitate towards roles that are more communal, such as being the primary caregiver for children and men tend towards roles that are

\footnotetext{
${ }^{1}$ Social role theory of gender is also commonly referred to as "gender role theory" (Delamater and Myers, 2014; O'Neil et al, 1986). These terms can be used interchangeably. This paper will use social role theory of gender.
} 
more agentic, such as being the breadwinner of a family, since because those are the qualities that are prescribed for each gender (Diekman and Eagly, 2008).

The general social role of gender also affects how people operate within other roles in their life because it takes precedence over more specific roles and creates a division between genders, especially in areas such as occupation (Eagly et al., 2000). For example, the societal expectations of what it means to belong to the social category of man or woman has an effect on leadership and politics, with a big area of impact on occupation stratification (Eagly and Karau, 2002; Garcia-Retamero and Lopez-Zafra, 2006; Fox and Oxley, 2003; Diekman and Schneider, 2010; Simpson, 2004; Lupton 2000). Occupations tend to be either more agentic, masculine, or more communal, feminine. The role of an elementary school teacher is at its core a communal occupation in which the goal is to help children and benefit the community through quality education. While on the other hand, a career in finance has much more agentic goals focused on earnings and self-preservation in the industry, even if it is at the cost of others.

Gender roles are enforced by two mechanisms: external pressures and expectations as well as internalized norms and traits. The more a person has been socialized to ascribe to the goals and expectations associated with a person of their gender the more likely they are to then internalize these gender roles and come to embrace them in themselves and expect them in others (Diekman and Schneider, 2010). Social Role Theory of Gender suggests that men and women both face both internal and social pressures to conform to societally created and reinforced gender norms (O’Niel et al., 1986). This theory suggests that diverging from gender norms can be quite costly to an individual's wellbeing, particularly within social relations.

When the expectations associated with a role disagree with the expectations associated with one or more other roles, it is known as role conflict (O'Neil et al., 1986). Typically, people 
try to avoid the negative internal consequences that are associated with role conflict by maintaining roles that all align with one another (Diekman and Eagly, 2008). Social Role Theory of Gender asserts that individuals feel happier, more content, and less internal pressures when they occupy a role that is gender conforming than when they occupy a role that is incongruent with their gender. When individuals occupy roles that are seen as incongruent with their gender role, the individual typically experiences negative consequences such as internal conflict, low self-efficacy and depression due to isolation and other psychological stresses. The negative consequences to a person are caused by trying to simultaneously occupy two or more roles that do not agree with one another. Internal conflict has been shown to be even greater for men who are in gender atypical fields than for women who are in gender atypical fields (Jackson and Sullivan, 1990; Lupton, 2000).

\section{Role Congruity Theory}

Role Congruity Theory (hereafter RCT) extends Social Role Theory of Gender in order to consider the external consequences of inconsistencies between gender roles and other roles such as occupation (Heilman, 2012). External acceptance and perceptions have been shown to be negative to those who deviate from gender norms and are thus incongruent with gender role expectations (Diekman and Eagly, 2008). Those who occupy roles that are congruent with their gender have a greater ease in those roles due to the fact that they are expected to occupy them (Diekman and Schneider, 2010). In contrast, those who are in gender incongruent roles experience greater societal hardships such as stigmatization, stereotyping and isolation due to the fact that it is not widely accepted that they have this role. When women enter into more masculine, agentic roles and men enter into more feminine, communal roles, the possibility of social sanctions for the gender role deviation increases tremendously. 
Role congruity comparisons happen unconsciously during interactions. Even upon first meeting a person, our brains are programmed from birth and continually reinforced through society that this person must conform to one gender category or another (Fiske et al., 1991). When individuals do not conform to gendered norms or meet our gendered expectations, uncomfortability ensues and social sanctions or rationales are used in order to force the person into a more role congruent place, even if it is only symbolically (Simpson, 2004). Any role incongruence is uncomfortable, like a square peg trying to go in a round hole, things just do not seem to fit or make sense. But the pervasiveness and ubiquity of gender roles makes any incongruence with them all the more interesting and crucial.

\section{Impact of Role Congruity Considerations}

Many researchers have used RCT to look at the negative effects of gender role incongruence in relation to leadership, politics and occupation (Garcia-Retamero and LopezZafra, 2006; Diekman and Schneider, 2010; Fox and Oxley, 2003; Simpson, 2004; Lupton 2000). Other researchers have shown the positive impact of occupying roles that are incongruent to a person's gender role in crime situations (McGrimmon and Dilks, 2016) ${ }^{2}$. While gender role incongruent roles can have these positive impacts on individuals in terms of crime, the evidence strongly suggests that in non-deviant cases where there are clear masculine and feminine roles, those who deviate from their gender roles are negatively impacted. Their gender role incongruent

\footnotetext{
${ }^{2}$ While most research indicates that gender role congruity is preferable for individuals in terms of leadership, politics and occupation, research on role congruity and crime indicates that being gender role incongruent is actually more beneficial to the individual than being gender role congruent (McGrimmon and Dilks, 2016). Gender role incongruity is beneficial to a person especially when the victim is of the opposite sex. The positive consequences of gender role incongruity is due to the fact that gender roles make it seem very unlikely that a male will be victimized by a female whereas they make it seem very likely that a female will be victimized by a male. The gendered expectations of perpetrator and victim mean that females who are the most gender role incongruent in that they committed a crime against a male benefit the most from gender role incongruity whereas males who victimize females are arrested at faster rates for their gender role congruity (McGrimmon and Dilks, 2016).
} 
behaviors cause others to more harshly critique, judge and view them than their gender role congruent peers.

Many researchers have found that being gender role incongruent can be quite costly to individuals. Eagly and Karau test their RCT by using data from the Gallup Poll and General Social Survey as well as by looking at empirical tests others have completed (2002). The data from the Gallup Poll shows that as recently as 2000, a majority of people of both genders prefer male bosses to female bosses with $48 \%$ of respondents saying they preferred a male boss compared to $22 \%$ saying female and $28 \%$ saying that they did not care either way (Eagly and Karau, 2002, 580). Even when women are seen as being competent and therefore capable of leadership, they are not as likely as their male peers to be awarded a leadership position beause women are not seen as having the types of agentic traits such as confidence, assertiveness, competitiveness, that are associated with leaders and males (Eagly and Karau, 2002). In this way, women who attempt to enter into leadership roles are seen as being gender role incongruent and therefore are not afforded the same opportunities as their male peers.

In the studies of emergent leaders that Eagly and Karau examined, a majority of the time and especially when group tasks were typically masculine in nature (e.g. repairing a machine) men emerged as the group leader (2002). However, when tasks were more feminine (e.g. sewing a button) or social in nature (e.g. brainstorming) women were more able and more likely to take charge as the group leader (Eagly and Karau, 2002). These studies give groups of subjects a task and ask them to complete the task. Researchers observe and record the behaviors of the group members and are able to draw conclusions about leadership styles and patterns such as the gendered patterns previously mentioned. These gendered patterns of emergent leadership show that it is easier for individuals to take on the role of leader when the task is role congruent to their 
gender and it is harder to individuals to take on this role when the task it gender role incongruent (Eagly and Karau, 2002). Leadership is seen as a masculine role so men are always seen as being an acceptable leader, but when the task becomes too gender role incongruent for men, it is much easier and more likely that a woman will emerge as the group leader (Eagly and Karau, 2002).

Garcia-Retamero and Lopez-Zafra (2006) used Eagly and Karau's (2002) RCT to test if individuals in roles that seem incongruent to their gender were thought of differently than those whose roles were congruent with their gender. Through the use of a vignette experiment they found that men were favored overall in leadership positions but more significant to this study, they also found that women faced the most prejudices in what were deemed masculine fields (Garcia-Retamero and Lopez-Zafra, 2006). Women in leadership positions in feminine fields were looked at more highly than males in those positions, but these men were still not as severely prejudiced against as the females in masculine or even gender neutral industries were (GarciaRetamero and Lopez-Zafra, 2006). The difference in the treatment of men in leadership positions was attributed to the idea that "characteristics typical of leaders are usually defined in agentic terms, which are ascribed more strongly to men" (Garcia-Retamero and Lopez-Zafra, 2006, 51). Therefore men are assumed to be capable of leadership, regardless of the type of industry that they are in. So no matter how unfit their gender role may be for the field, the fact that the men presented in this experiment were in a position of authority puts them into a role more congruous with their gender whereas when women occupy leadership positions in masculine roles they are viewed much more negatively than their peers.

Research on political elections in the United States indicates that role congruency affects whether or not women run for an elected office as well as which elected offices they choose to run for (Fox and Oxley, 2003). The researchers conducted a longitudinal analysis of candidates 
for state executive offices from 1978 to 1998. They found that as time progressed, women who were equally as qualified as their male counterparts were just as likely to be elected into the office, but that gender stereotypes of feminine roles heavily influenced when and to what positions women were nominated as candidates for office (Fox and Oxley, 2003). Women were much more likely to be nominated to run in elections for offices that are seen as congruent with traditional female gender roles such as superintendent of education or a public lands commissioner. They were much less likely to even be nominated to elected offices that are seen as traditionally masculine such as governor, attorney general or treasurer (Fox and Oxley, 2003). In this way gender role congruency affects potential candidates before they are even up for elected office, thus indicating the influence of gender roles in the political sector.

Heilman's (2012) lack of fit model applies RCT to occupations, proposing that the more a workplace role is incongruent with typical attributes ascribed to that person's gender, she or he would suffer from a greater perceived lack of fit to their workplace role. Perceived lack of fit can then lead to a decrease in performance levels and decrease in confidence in their ability to perform their job thus leading to lower overall self-efficacy and lower evaluations from others (Heilman, 2012). Being successful in a gender incongruent role can have actualized negative career effects for a person as is the case of Ann Hopkins, a woman that was passed over for partnership at a prestigious accounting firm even though she had brought in $\$ 25$ million dollars and had more billable hours than the other, male candidates (Heilman, 2012). She was a perfectly competent candidate but she was seen as being too "macho", meaning she was being perceived as being too gender role incongruent and was therefore not seen as "a successful lady partner candidate" to the accounting firm (Heilman, 2012, 127). Perceptions of an individual's ability to 
succeed within an occupational setting are heavily influenced by their perceived role congruence or incongruence as was the case with Hopkins.

Jackson and Sullivan (1990) used vignette experiments to look at third party perceptions of women and men in various roles in their life across three categories: marital status, work status and parental status. They chose to look at these role statuses rather than at individual trait descriptors because it has been shown that gender categories are more strongly defined in terms of roles rather than traits (Jackson and Sullivan, 1990). The strong impact of role status means that whether or not someone is married, employed, and/or is a parent has been shown to have a significant effect on other's perceptions, with these effects varying for men and women (Jackson and Sullivan, 1990). The authors found that the role of "homemaker" has a much more negative impact on men than it does on women but overall unemployment has the worst effect on both genders. They found that these men were thought to be highly feminine and minimally masculine thus highlighting the price that men pay for putting themselves into a traditionally feminine role (Jackson and Sullivan, 1990).

Lupton (2000) found that these third party perceptions become actualized fears for men who work in traditionally feminine fields. These men fear being stigmatized by friends, family and people that they meet for their feminine career choice. They also have a fear of being made to be "less of a man" and seeming more feminine, thus as having diverged from their gender role so far as to no longer being fully accepted as such (Lupton, 2000). For women who enter into gender atypical fields, they still have to compromise their femininity, but they gain status by taking on the more masculine role whereas men who enter into feminine roles are seen as lessening their status in society (Simpson, 2004). 
Simpson (2004) used a qualitative approach to look at the experiences of men in gender atypical occupations. She found that men in four traditionally female fields- nursing, primary education, librarians and cabin crew members- negotiated a tension between enjoying their occupations and the female relationships they had because of them and the fear and anxiety associated with disclosing their job to new acquaintances. Their fear and anxiety was particularly high when the person they were just meeting was another male (Simpson, 2004). Due to their anxiety, many of these men performed "gender work" meaning they took the feminine nature of their job and reframed it so that it was became more in line with their masculine identities (Simpson, 2004). In this way, being gender role incongruent had a direct impact on the men in the study, who all worked full time but in occupations that are traditionally feminine.

The aforementioned research shows that role congruity has an actualized impact on individuals who enter into gender incongruent roles in a variety of contexts, especially occupational and work settings. This research shows the power of gender role norms. Social norms of gender cause individuals who deviate from these norms to feel pressured into reestablishing their masculinity or femininity as much as their role may allow them to. These researchers showed the impact of role congruency on the individuals who deviate from traditional gender roles, but they did not show the extent to which their family, friends and peers actually judged them for their gender role incongruence.

Role Congruity and the Effect on Mates, Dating and Attractiveness

Due to the pervasiveness of gender roles, they can have a huge impact on how attractive people find those who deviate from gender norms. Zillmann et al. (1986) analyzed the perceived attractiveness of individuals who conform to gender roles verses those who deviate from them. Subjects watched a horror film with a study confederate who was either instructed to have 
gender congruent reactions, in which males watched the film with mastery and enjoyment and females exhibited distress and anxiety in watching the film, while others watched with gender incongruent confederates (Zillmann et al., 1986). Mastery and enjoyment of viewing horror films was indicated by the confederates saying things like "That's the idea...use the knife" or "All right...you got him good this time!” while sitting reclined in the chair (Zillmann et al., 1986). Distress and anxiety while watching horror films was indicated by the confederate saying things like "Oh my God!" or "Yech...oh, how gross!" and by sitting very rigidly while fidgeting throughout the movie (Zillmann et al., 1986). Upon the completion of the film, they had subjects complete a 21-question Person Perception Inventory to determine levels of attraction that they felt towards the confederate. The researchers found that heterosexual men and women were most attracted to those of the opposite gender who expressed gender congruent attitudes towards horror films (Zillmann et al., 1986). These results indicate that those who express gender congruent attitudes and roles are more attractive in the eyes of potential heterosexual partners than those who are gender role incongruent.

Research from Shaffer and Johnson (1980) also supports the finding that those who are gender role congruent are more attractive than those who are gender role incongruent. They found that both male and female respondents believed hypothetical peers were more socially attractive when they exhibited gender role congruent occupational status (Shaffer and Johnson, 1980). This study does not look at romantic partner attractiveness, but rather the overall social attractiveness of the hypothetical peer. While this study is not an explicit test of gender role congruency or incongruency on romantic partner preferences, it does indicate an overall societal preference that is in align with RCT. Those who are role congruent are perceived as more 
socially attractive by their peers, thus indicating that they will be evaluated as more attractive by potential romantic partners seeing as they typically occupy the same peer groups.

More recent studies have shown that individuals are placing less emphasis on traditional gendered qualities and they are more concerned about gender neutral qualities such as mutual attraction, emotional maturity, a pleasing disposition and a dependable character when evaluating attractiveness (Henry et al., 2013). In a study of 270 undergraduates, Henry, Helm and Cruz (2013) found that respondents of both genders ranked these characteristics are most important in assessing attraction than other more traditionally gendered characteristics. In this study respondents were asked to rate eighteen personal characteristics that they desire in a romantic partner (Henry et al., 2013). They did find some evidence of traditional gender norms still having an effect on attraction when they looked at ranking differences between men and women. Men were more likely to rate "good health", "good cook/housekeeper" and "good looks" as more important than women while women were more likely to rate "ambitious/industrious" and "good financial prospect" as more important than men (Henry et al., 2013). The gendered differences in rankings reflect traditional gender norms in which a woman is the primary caretaker of the home and family and the man is the primary earner outside of the home. While college students are placing greater importance on some more gender neutral characteristics, when determining the attractiveness of an individual as a romantic partner, traditional gender roles still have an impact.

Hitsch, Hortaçsu and Ariely (2010) found in their analysis of online dating patterns that both men and women are more likely to contact and subsequently date a partner that has a similar education level of their own and earns a higher income. A concern for partner income, regardless of gender, could be due to the cultural shift towards dual earner households in which 
both partners are working and therefore regardless of gender, a potential romantic partner's income has a significant effect on ratings of attraction. However, they also found that in heterosexual situations, a potential romantic partner's occupation has a significant effect on women's willingness to contact a potential romantic partner while it does not have a significant effect on men's willingness (Hitsch et al., 2010). They found that women were more likely to contact a potential romantic partner who are lawyers, fire fighters, law enforcement or in the heath profession than a potential romantic partner who is a student (Hitsch et al., 2010). This pattern indicates that women continue to prefer men in traditionally masculine careers. Given that a majority of women in this study were older than a traditional college student, with only $12.9 \%$ of female responses between the ages of 18 and 25 , it could be the case that there is simply a preference for a male partner who has moved beyond a student and into a career. However, females were not more likely to contact a man who was in a traditionally feminine occupation (e.g. teaching, secretary) as compared to a man who is a student (Hitsch et al., 2010). This result indicates that it is not simply a preference for a man who is currently working as compared to one who is a student, but that it is a specific preference for a man in a traditionally masculine occupation, thus indicating that women prefer men in gender role congruent occupations when looking for a potential romantic partner. Men, on the other hand, according to this study do not have the same preference for occupational gender role congruence when looking for a female romantic partner.

A more recent study of college students found that the students actually preferred gender role incongruent potential romantic partners rather than gender role congruent ones (Chappetta and Barth, 2016). In this study, mock online dating profiles were constructed that included pictures of potential dates, descriptions of their hobbies, interests, what they were looking for in 
a romantic partner and other personality traits. These vignettes were then sent to survey participants who ranked the profiles based on two different scales of attraction and likability. The researchers found that the profiles that exhibited gender role incongruent hobbies and personality characteristics were rated as more attractive and were believed to be a more likable romantic partner than the profiles that were gender role congruent (Chappetta and Barth, 2016). This effect was greater for female respondents than male respondents, but overall there was a positive association with attraction and gender role incongruence, an effect that needs to be explored more seeing as it goes against what RCT would predict the outcome of the study to be.

\section{Research Objectives}

The present study uses RCT to explain its effect on attraction to potential romantic partners amongst college students. While this has been looked at by others (Chappetta and Barth, 2016; Thomae and Houston, 2015), this research looks at RCT in a new and unique way. Specifically, previous research is limited in three ways: 1) previous studies either put an emphasis on occupational status or personality traits as the source of gender roles; 2) these studies do not always specify the duration of the hypothetical relationship; and 3) previous studies do not fully explore the effect of neutral characteristics on attraction.

This research also seeks to find out just how important gender roles currently are in peer ratings of attraction. Previous studies provide conflicting evidence as to the importance of gender role congruence on ratings of attraction. As society continues to move towards gender inclusiveness, reexamining the effects of gender role congruence and incongruence becomes all the more important because there are more and more people diverging from traditional ideas of masculinity and femininity and instead embracing and endorsing gender role incongruent or neutral occupations, hobbies and personality characteristics. 
The study by Chappetta and Barth (2016) focuses heavily on personality traits such as hobbies and personal adjectives as the main indicator of role incongruence and therefore having the main effect on whether or not respondents find the person to be attractive. Thomae and Houston (2015), on the other hand, focus heavily on the effects of occupational status such as future occupation and familial goals as having the main effect on attraction depending on role congruence or incongruence. While both of these studies manipulate core aspects of a person to look at attraction levels, neither study fully takes both aspects of personhood into consideration in their vignettes and their results are therefore conflicting. Chappetta and Barth (2016) find that their respondents preferred individuals who were more gender role incongruent than congruent, however they focused on the effect of personality traits. Thomae and Houston (2015) found that when focusing more on occupational status, the more gender role congruent a person was the more attractive the respondent thought they were. By incorporating both occupational status in the form of college major and descriptions of life goals and personality traits in the form of hobbies, interests and personality traits, this study will be able to indicate if role congruence or incongruence in one category of a characteristic has a greater impact on levels of attraction than the other. This study will also indicate whether or not having one set of characteristics that is role congruent and one that is incongruent is a mitigating factor on attraction levels, a statement that previous research has been unable to make to the knowledge of this author.

The study from Chappetta and Barth (2016) as well as studies by others (Travaglia et al., 2009; Zillmann et al., 1986) do not explicitly make it clear as to whether or not they are measuring attraction in short-term, long-term or simply the initial meetings of the potential romantic partners. The study from Thomae and Houston (2015) uses a measure that specifically looks at the effect of role congruence on long-term relationships. The distinction that they make 
is crucial because the duration of the hypothetical relationship can have a huge impact on attraction ratings. When a subject is prompted to think about the attractiveness of a role congruent or incongruent person in a long-term relationship, questions about earning potential, household duties and other long-term issues become much more salient in the respondent's mind (Eagly et al., 2009, Eagly and Wood, 1999). However, if not indicated a respondent may only be thinking in terms of a short-term relationship in which the impacts of occupation and familial goals may not have as big of an impact thus meaning role incongruence in these areas may not have as big of an effect on attraction levels. In this study, respondents will be asked questions about their attraction to the hypothetical romantic partner in terms of both a short-term relationship as well as a long-term relationship. Including both short and long term measures will help to further parse out any differences role congruence or incongruence in occupational status or personality traits have on attraction as well as simply determining if duration of the relationship has any bearing on attraction levels.

Previous studies also do not look at the effects of neutral characteristics on attraction, and in the case of this study, if being gender neutral in either occupational status or personality traits but role congruent or incongruent in the other has a bearing on attraction. By including a gender neutral control for both types of characteristics, once again it will be easier to determine which type of characteristics has a greater impact on attraction levels of respondents. Gender-neutral college majors, personality traits and hobbies are very common and so including them not only adds an extra element of realism to the study design but it also aides in the analysis of the various levels of impact role congruence has on attraction levels. 


\section{Hypotheses}

H1: Respondents will be most attracted to completely gender role congruent partners.

H2: Respondents will be least attracted to completely gender role incongruent partners. These hypotheses are supported by previous research on RCT and Social Role Theory (Shaffer and Johnson, 1980; D’Agosotino and Day, 1991; Eagly and Karau, 2002).

H3: When potential partners exhibit both gender role congruent and gender role incongruent or gender neutral characteristics, respondents will find this potential partner more attractive than the partners that were completely gender role incongruent, but not as attractive as those that were completely gender role congruent.

This hypothesis is supported by Social Role Theory which emphasizes the importance of gender as a social role that individuals occupy and by RCT which states that there is a strong motivation for individuals to align their behaviors with those that are in line with the roles that they occupy (Eagly and Karau, 2002; Diekman and Eagly, 2008; Hielman, 2012; Diekman and Schneider, 2010).

H4: Gender role congruence or incongruence will have a larger effect on attraction in long-term relationships than in short-term relationships. This hypothesis is supported by the idea that the costs and benefits of being in a romantic relationship with a person are affected by the potential duration of the relationship (Thomae and Houston, 2015). This is due to the fact that economic considerations of gender role congruence or incongruence in occupations are more consequential in long term verses short term relationships (Eastwick et al., 2006, Henry et al., 2013, Hitsch et al., 2010). 
H5: Male respondents will find potential female romantic partners who are gender role incongruent to be more attractive than female respondents will find potential male romantic partners who are gender role incongruent to be.

This hypothesis is supported by the idea that it is more costly for men to deviate from masculinity than it is for women to deviate from femininity (Hitsch et al., 2010, Henry et al., 2013, Jackson and Sullivan, 1990; Lupton, 2000). Due to this, the men who are more role incongruent (feminine) will be perceived as less attractive by the female respondents than the females who are more role incongruent (masculine) will be perceived to be by the male respondents.

\section{METHODS}

The current study hopes to fill in the current holes in the literature by looking at the effect of gender role congruence of personality traits and college major ${ }^{3}$ on college student's attraction to potential romantic partners.

\section{Context}

As previously mentioned, the office politics of the undergraduate (and even graduate) population of any university context come to a head with the question of "what's your major?" College major is a highly salient piece of a collegian's identity and can have huge impacts on an individual's social interactions and social status. No matter how positive a college major may be on its own (e.g. nursing or engineering) if an individual in an objectively positive college major

\footnotetext{
${ }^{3}$ In this experiment, college major is being used as a proxy for occupational status. While not all collegians go on to pursue a career that directly corresponds to their college major, it is a strong indicator of occupational status at the collegiate level.
} 
(i.e. leads to economic prosperity, leads to helping people, et cetera) is seen as being gender role incongruent by occupying that role, there is likely to be negative social consequences.

College is also a prime time to look for and find life-long romantic partners. College settings provide both physical proximity and social networking opportunities for peers to interact and form romantic bonds that eventually lead to marriage (Arum et al, 2008). The environment of colleges and universities provides both formal structures (e.g. clubs, campus events, classes, et cetera) and informal interactions caused by proximity and circumstance (e.g. having one cafeteria, common lobbies in dormitories, working in the library, et cetera) that allow individuals who are seeking a mate a plethora of opportunities to meet someone (Arum et al, 2008).

In the past, marriage has been shown to be a highly salient goal amongst individuals in a collegiate setting and the environment of college aids in promoting and maintaining that salience (Arnett, 2000, 2004). However marital patterns have changed over the past several decades. Younger generations are getting married later in life and less frequently than their parents' generation (Elliott et al, 2012). An examination of marital trends based upon Census data from 1890-2010 by Elliott et al. (2012) shows that the average age at first marriage amongst men has increased from not quite 24 years old in 1960 to almost 29 years old in 2010 . The same trend can be seen amongst women, who in 1960 got married for the first time at an average age of 21 compared to the average age at first marriage of almost 27 in 2010 (Elliott et al, 2012).

Not only has the average age at first marriage increased among adults in the United States, but the percentage of adults who are married has also decreased. According to the Pew Research Center's analysis of 2010 census data, only $51 \%$ of United States adults (age eighteen or older) were married in 2010 (Cohn et al, 2011). This is compared to the $72 \%$ of all U.S. adults 
(age eighteen or older) that were married in 1960 according to Census data from that year (Cohn et al, 2011).

This does not necessarily mean that these unmarried adults will never marry, especially when the increase in average age at marriage is considered. In fact, by age thirty only $25 \%$ of adults in the United States are unmarried meaning that $75 \%$ of adults are married (Arnett, 2004). However, even if these collegiate adults do not ever decide to marry, that does not mean that they will not enter into lifelong partnerships, cohabiting relationships or common law marriages. These trends mean that while college students may not have immediate plans to marry, live together or commit to someone for life upon graduating college, college students are still in the process of planning for their futures in both their careers and personal lives (Arnett, 2004).

According to Arnett (2004), by age twenty five $70 \%$ of adults have obtained at least some form of a college degree. This means that a majority of young adults in the United States spend a good portion of their time at either a college, university or community college where they are surrounded by their peers and have the ability to form personal and potentially lifelong friendships and romantic relationships. Even if marriage or lifelong romantic partnerships are not at the front of collegians minds, the circumstances of a collegiate setting, the high rates of young adults that attend college and the goal of marriage or lifelong partnership in at least the back of their minds makes studying partner preferences at the collegiate level crucial.

\section{College Student Sample}

Students at a large land-grant institution in the Appalachian region of the United States were electronically sent an invitation to participate in the voluntary study along with a link to the vignette experiment described below. The email address of all undergraduates at the university were obtained from the registrar. There were approximately 20,000 email addresses in the initial 
list. In order to select a sample to send the request to complete the study to, the 20,000 emails were divided into ten subsamples of about 2,000. The 20,000 emails were divided by assigning the numbers $1-10$ in numerical order to all 20,000 . The list was then sorted by number thus giving ten random samples of around 2,000 email addresses. A request to complete the study was sent to the first group of approximately 2,000 students. They were sent a reminder email two days later. The number of responses was at around 500 after the first group was emailed twice. A second sample of students were then emailed with a request to complete the study. They were also sent a reminder email two days later. Students were incentivized to participate in the study for a chance to win one of ten $\$ 20$ gift cards. Of the 3,962 total emails sent, there were 1,125 total responses, a response rate of $28.39 \%$. Nine hundred ninety-five of the 1,125 responses provided enough data to be used in the analysis (25.11\% response rate of the total emails sent).

\section{Experimental Design}

In order to look at the impact of role congruence in college major and personality traits on attraction, a vignette experiment was disseminated and collected via Qualtrics. After consenting to participate and verifying that they were over the age of eighteen, respondents were prompted to answer three questions. They were asked their current relationship status (e.g. single and looking, single and not-looking, in a long-term relationship, etc.), their gender identify (male, female or not listed) and who they prefer to date (men, women or no preference). Respondents' answers to the questions about their gender identification and dating preference were used to determine the gender of the potential romantic partner in the vignette they received. Randomly assigning the vignettes sex based on respondents' dating preference was to ensure that respondents received vignettes corresponding to the sex that they are most likely to date. If a person responded that they were likely to date both sexes, they were given a random vignette of 
either sex. This matching process ensured that every respondent received a vignette that represented a person they would realistically consider as a potential romantic partner.

A vignette experiment using mock online dating profiles was used to look at these effects. The experiment employed a 3x3 design with college major and personality traits on either axis. The three conditions for each characteristics were gender role congruent, gender role incongruent and gender role neutral. The following table illustrates the experimental design.

Table 1: Experiment Design

\begin{tabular}{|c|c|c|c|c|}
\hline \multirow{2}{*}{ : } & \multicolumn{4}{|c|}{ College Major } \\
\hline & & Role Congruent & $\begin{array}{c}\text { Role } \\
\text { Incongruent }\end{array}$ & Neutral \\
\hline$\Xi$ & Role Congruent & RC X RC & RI X RC & N X RC \\
\hline$\Xi$ & Role Incongruent & RC X RI & RIX RI & N X RI \\
\hline 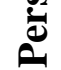 & Neutral & RC X N & RI X N & N X N \\
\hline
\end{tabular}

\section{Treatments}

Each vignette presented a description of a potential romantic partner. These descriptions were written to mimic a paragraph on a dating website or app, an increasingly popular way for collegiate individuals to meet romantic partners. In fact, according to a 2016 article from the Pew Research Center, 27\% of 18-24 year olds have tried online dating, an increase of $16 \%$ from 2013 (Smith and Anderson, 2016). These profiles did not include photographs so as to not take the focus of attraction away from the college major and personality traits that are at the center of this study. The vignettes were modeled on those used in several studies in order to incorporate both college major and personality traits as well as incorporating research from others on the gendering of college majors, hobbies and characteristics (Chappetta and Barth, 2016, Thomae and Houston, 2015, Siebler et al., 2008; Lippa, 2005). The vignettes used in this experiment can be found in Appendix 1. 
Information on the gender distribution of students in college majors was cross-checked using multiple sources as well as current and recent enrollment patterns at the university studied as obtained from the Office of Institutional Research. Based on this research, mechanical engineering was selected as the masculine college major, sociology as the gender neutral and elementary education as the feminine college major ${ }^{4}$. While each of these is not necessarily the major most dominated by a gender or perfectly equally distributed, based on the data they are highly dominated by one gender over the other or they are fairly neutral while also having an immediate gendered connotation or lack thereof in the case of the gender neutral major. Each vignette contained a mention of the potential partner's college major as well as a statement about their future career and familial plans. This statement was used to reinforce the gendered or gender neutral implications of their college major since it was the only occupational status variable used in the profiles.

The potential partner's personality traits were manipulated by two factors: personality traits and hobbies. Both of these were used to manipulate the role congruence, incongruence or neutrality of the potential romantic partner in order to ensure that the gendering of the person's personality traits were made to be as obvious as possible without compromising the integrity of the experiment. Gendered personality traits were pulled from the Bem Sex Role Inventory (hereafter referred to as BSRI). The BSRI is a sixty point inventory that has individuals rank how

\footnotetext{
${ }^{4}$ According to data from the Office of Institutional Research at West Virginia University, for the years 2014 and 2015 (numbers recorded in the fall of each year), the average male enrollment in the mechanical engineering major was $89.79 \%$ with an average of $10.21 \%$ of mechanical engineering majors being female. Female had an average enrollment of $96.64 \%$ in elementary education compared to the male average enrollment of 3.36\%. Sociology had an average male enrollment of $44.14 \%$ and a female enrollment average of $55.86 \%$. While there were a few majors that had a slightly more equitable split for the gender neutral college major and some that had a more gendered average for the masculine and feminine college majors, these three were selected due to their gendered or neutral connotation and because they represent numerically popular majors at West Virginia University. This data is supported by the National Center for Education Statistics data on the number of degrees awarded by subject for males and females for 2013-2014 (http://nces.ed.gov/programs/digest/2014menus_tables.asp )
} 
strongly adjectives reflect their personality in order to determine how masculine, feminine or gender neutral they are (Bem, 1974). The items on this inventory have been validated thoroughly as to their ability to measure a persons' masculinity, femininity or gender neutrality (Bem, 1974; Garcia-Retamero and Lopez-Zafra, 2006; Jackson and Sullivan, 1990; Lindsey and Zakahi, 1996). The personality traits selected as masculine were competitive and ambitious. The gender neutral personality traits were unpredictable and genuine (a synonym of the BSRI term "sincere"). Finally, the feminine personality traits selected were shy and cheerful.

The hobbies selected for the vignettes have been used by others in their research of gender roles and perceptions (Chappetta and Barth, 2016). They were also verified by crossreferencing psychological research from Lippa on the gendering of hobbies (Lippa, 2005). The masculine hobbies selected were playing sports and playing video games, the gender neutral hobbies chosen were listening to music and watching movies and the feminine hobbies chosen were shopping and baking.

Table 2: Manipulated College Major, Hobbies and Personality Traits

\begin{tabular}{|r|c|c|c|}
\hline Masculine & College Major & Hobbies & Personality Traits \\
\hline Feminine & Elementary Education & $\begin{array}{c}\text { Playing Sports } \\
\text { Playing Video Games }\end{array}$ & $\begin{array}{c}\text { Baking } \\
\text { Ambitious }\end{array}$ \\
\hline Gender Neutral & Sociology & $\begin{array}{c}\text { Listening to Music } \\
\text { Watching Movies }\end{array}$ & $\begin{array}{c}\text { Shy } \\
\text { Cheerful }\end{array}$ \\
& \multicolumn{2}{|c|}{$\begin{array}{c}\text { Unpredictable } \\
\text { Genuine }\end{array}$} \\
\hline
\end{tabular}

\section{Manipulation Checks}

After reading their vignette, respondents were asked to rank how traditionally masculine or traditionally feminine they found their potential romantic partner to be. This ranking was done on a sliding bar scale with the label "masculine" on the far left and the label "feminine" on the far right. The sliding scale was presented to the respondents with the marker beginning directly 
in between the two labels. Qualtrics was set-up so that respondents had to move the marker even slightly before it would allow the respondents to move on to the rest of the survey. This requirement was to ensure that the respondents took the time to actually reflect on the person they had just read about.

\section{Figure 1: Slider Bar about the Potential Romantic Partner}

Now that you have gotten to know your peer you will be asked some questions about them. Please use the information you have learned to answer the questions to the best of your ability. There is no right or wrong answer, we are simply interested in what you think.

Please slide the bar in order to indicate how masculine or feminine you believe your peer to be with -10 being the most masculine a person can be and 10 being the most feminine a person can be.

Masculine

$-10 \quad-8$

$-6$

$-4$

$-2$

0

2

4

6

$8 \begin{array}{rr}\text { Feminine } \\ 10\end{array}$

Click to write Choice 1

This assessment was the first thing respondents completed upon reading about their potential romantic partner and it served three purposes. It was put in place to help to get the respondent to really think about their potential romantic partner thus allowing them to better form an opinion of them and better answer questions about them. It also served as a check for the completely gender role congruent, gender role incongruent and gender neutral profiles to make certain that the vignettes are accurately representing each category. It also served as the first 
level of measurement of how college major and personality traits balance one another in relation to peer perceptions. By having the respondents rate the potential romantic partner using the slider bar, the profiles that have a combination of gender role congruent, gender role incongruent and gender neutral characteristics were rated as either feminine, masculine or neutral, thus indicting which category of characteristics is more influential on peer perceptions. The slider bar was used as a proxy for the BSRI in order to keep the length of the survey shorter while still measuring the respondent's opinion of whether their potential romantic partner was traditionally masculine, traditionally feminine or more gender neutral.

\section{Dependent Variables: Romantic Scales}

After reading the dating profile and completing the slider bar question about their potential romantic partner, respondents were then asked to answer a series of questions about their potential romantic partner. The survey included a combination of scales from previous studies to measure the respondent's level of attraction towards the potential romantic partner in both the short and long term (Jackson and Sullivan, 1990; Thomae and Houston 2015; Reysen, 2005; Campbell, 1999). A full listing of questions for each scale can be found in Appendix 2.

Reysen's Likability Scale and Campbell's Romantic Attraction Scale (Reysen, 2005; Campbell, 1999) have been used together in previous studies to measure respondents' interest in potential partners (e.g. Chappetta and Barth, 2016; Moss, 2010). They consist of eleven and five items that measure peer perceptions of interpersonal qualities and attraction, respectively. To score each scale, the responses are totaled with higher totals indicating greater likability and greater attraction to the potential romantic partner.

An additional measure of attraction was added to further help in determining how attractive respondents found their potential romantic partner and the duration of relationship that 
they would be interested in with them. This measure is based off of Thomae's Desire for a Relationship Scale and consists of items such as "I would be interested in dating a person like X" and "I could imagine marrying a person like X" (Thomae and Houston, 2015). A statement to measure respondents' willingness to hook-up with the potential romantic partner was added in order to reflect the growing popularity of hook-up culture among collegiate students (Heldman and Wade, 2010). This scale was tested as a whole as it has been done previously by totaling respondents' responses to the questions and creating a total Thomae score. It was also divided into two separate scores: the items that ask about the respondents' desire for a short term relationship and the items that ask about the respondent's desire for a long term relationship. Each was totaled as the entire scale was totaled in order to create a short term desire score and a long term desire score with higher scores indicating greater desire for a relationship.

\section{Control Variables}

Respondents finished the survey by answering additional demographic questions about themselves including but not limited to their school status (e.g. first year undergraduate, graduate student, et cetera), race and their college major. In addition, they were asked to complete the same slider bar question as previously described (Figure 1) but this time in regard to themselves. Again, the slider bar is serving as a proxy for the BSRI in order to keep the survey length shorter and decrease levels of survey fatigue among respondents. Respondents were asked to complete this in order to determine how strongly they subscribe to gender role congruent qualities in their own lives, thus indicating the level of importance they may place on others having similar congruence, incongruence or gender neutrality. It also served as a check to see if a respondent's own gender role congruence, incongruence or neutrality had an impact on whether or not they find a person who is gender role congruent, incongruent or neutral attractive. 
Research from Thomae and Houston (2015) indicates that respondent's views on traditional gender ideology has a significant impact on their attraction to gender role incongruent individuals. In their experiment they found similar results to those later found by Chappetta and Barth (2016). Vignette descriptions of traditional and non-traditional potential romantic partners were given to respondents who then answered surveys to analyze their rates of benevolent sexism, hostile sexism and level of attraction to the hypothetical romantic partner. Female respondents indicated higher levels of attraction towards males with gender role incongruent occupation characteristics, family desires and other diffuse characteristics (Thomae and Houston, 2015). However, the higher a female scored on the measure of benevolent sexism, the less likely they were to be attracted to gender role incongruent men (Thomae and Houston, 2015). The results of male subjects reflect a similar pattern, indicating that the more strongly an individual believes in traditional gender roles the more likely they are to prefer gender role traditional romantic partners and the less attracted they are to those who are gender role incongruent.

This result is unsurprising; the more a respondent has internalized and normalized gender roles the more likely they are to be attracted to gender role congruent qualities in a potential partner. In contrast, if a respondent deviates from gender roles they are more likely to accept and be attracted to those who also deviate from gender roles. In fact the more strongly a person accepts a gender-types role, whether congruent or incongruent with their gender, the more likely they are to find a person with a complimentary personality attractive (D'Agostino and Day, 1991). A second study that used respondents' levels of benevolent and hostile sexism as indicators of their traditional gender beliefs found results that are consistent with these as well (Travaglia et al., 2009). In this study, they found that women who more strongly identified with traditional gender roles preferred hypothetical romantic partners who had higher amounts of 
status or resources, characteristics that are traditionally masculine. They also found that men who more strongly identified with traditional gender roles put greater emphasis on the physical attractiveness and reproductive vitality when evaluating potential romantic partners, characteristics that are traditionally considered more important in female potential mates (Travaglia et al., 2009). In this study, much like the previous one, the results indicate that the effect of gender role congruence of the potential partner on respondents' attraction to them is highly dependent upon respondent's previous beliefs about gender roles and their acceptance or denial of them in their own lives (D’Agostino and Day, 1991; Travaglia et al., 2009). The more a person subscribes to traditional gender roles, the greater the impact of a potential partner's gender roles have on their level of attraction to them.

\section{Method of Analysis}

A combination of ANOVA and regression testing was used to analyze the data. The nine experimental conditions were tested using ANOVA testing. ANOVA testing uses a ratio or continuous level dependent variable and a categorical independent variable that has more than two categories (e.g. gender with the options being male, female and transgender). I used ANOVA to examine the effect of gender role congruence, incongruence or neutrality of college major or personality characteristics (independent variables) on attraction with the attraction scales being the dependent variables in separate ANOVA tests. I also conducted two-way ANOVA tests to see if there was an interaction effect between the potential romantic partner's college major and their personality on the respondent's rating of attraction.

For all scales and both sexes, scale scores were regressed on vignette conditions with the respondent's masculinity/femininity score, race, and relationship status as control variables. Using the vignette variable is equivalent to testing for an interaction between personality and 
college major because the vignette variable is coded so that each represents only one combination of personality and college major. After each regression, a pairwise comparison of the vignette conditions was estimated in order to see if there were any statistically significant differences between scale score means between vignettes beyond the comparisons to the reference vignette that was produced through the regression. If none of the vignette pairs from the initial regression and pairwise comparison were significant, scale scores were regressed on separate variables for college major and personality characteristics to determine main effects. After this regression a pairwise comparison was again estimated in order to see if there were any statistically significant differences between the mean scores of the three college majors to each other and of the three personality types to each other. The results of all of these regressions are in the results section. They are organized by sex and scale.

\section{RESULTS}

\section{Respondent Demographics}

The 903 responses that were analyzed consisted of 335 male respondents (37.1\%) and 568 female responses (62.9\%). There were between 57 and 70 responses per male vignette (female respondents) and between 32 and 40 responses per female vignette (male respondents). The respondents had a mean age of 20.13 and $89.3 \%$ of them were Caucasian.

Although there were 92 gay and lesbian respondents, with eighteen vignettes 92 responses is not enough to analyze these individuals' preferences with any statistical or practical power. They were dropped from the analysis with the hopes of conducting future research on gender roles in the LGBTQ population. 


\section{Manipulation Checks}

According to a one-way ANOVA test, there is evidence that the respondents' ratings of the potential romantic partner's masculinity/femininity/neutrality is in line with the potential romantic partner's college major $\left(\mathrm{F}_{2,902}=5.01, \mathrm{p}=0.0068\right)$. These results are regardless of the potential romantic partner's sex indicating that all vignettes with potential romantic partners with a feminine major were tested against all vignettes with a masculine college major and all vignettes with a neutral college major. The slider-bar question used to assess the respondents' views of the potential romantic partner's gender identity had a range of -10 to 10 with negative ten being the most masculine, zero representing gender neutral, and positive ten being the most feminine. The potential romantic partners with the masculine college major were assessed to be the most masculine $(-0.85)$, the potential romantic partners with the neutral college major were assessed to be the closest to zero $(-0.16)$ and the potential romantic partner with the feminine college major were assessed to be the most feminine (0.54). There was a statistically significant difference between the masculinity/femininity scores for the masculine and feminine college majors with the mean feminine college major masculinity/femininity score being 1.39 points higher than the masculine college major score $(\mathrm{p}=0.005)$. There were not statistically significant differences between the feminine and neutral majors $(\mathrm{p}=0.350)$ or the masculine and neutral majors $(\mathrm{p}=0.357)$, however the mean scores indicate that they do follow the expected pattern indicating that the manipulation of college major worked as expected.

This result was the same for personality characteristics. According to a one-way ANOVA test, there is evidence that the respondents' ratings of the potential romantic partner's masculinity/femininity/neutrality is in line with the potential romantic partner's personality characteristics $\left(\mathrm{F}_{2,902}=4.42, \mathrm{p}=0.0124\right)$. These results are regardless of the potential romantic 
partner's sex indicating that all vignettes with potential romantic partners with a feminine personality were tested against all vignettes with a masculine personality and all vignettes with a neutral personality. The potential romantic partners with the masculine personality were assessed to be the most masculine $(-1.71)$, the potential romantic partners with the neutral personality were assessed to be the closest to zero $(-0.74)$ and the potential romantic partner with the feminine personality were assessed to be the most feminine (2.07). There was a statistically significant difference between the masculinity/femininity scores for the masculine and feminine personalities with the mean feminine personality masculinity/femininity score being 1.32 points higher than the masculine personality score $(\mathrm{p}=0.009)$. There were not statistically significant differences between the feminine and neutral personalities $(\mathrm{p}=0.520)$ or the masculine and neutral personalities $(\mathrm{p}=0.349)$, however the mean scores indicate that they do follow the expected pattern indicating that the manipulation of personality worked as expected.

\section{Analysis of Variance Results (ANOVA)}

All of the results that follow and are broken down by gender and romantic scale with the Thomae Scale being further broken down into two scales: Thomae Desire for a Short Term Relationship and Thomae Desire for a Long Term Relationship.

\section{Male Respondents}

\section{Campbell Romantic Attraction Scale}

According to a two-way ANOVA test there is no statistically significant evidence that there is an interaction effect between the potential romantic partner's college major and their personality on male's levels of romantic attraction as measured by the Campbell scale $\left(\mathrm{F}_{4}\right.$, ${ }_{334}=0.84, \mathrm{p}=0.5021$ ). In addition, according to one-way ANOVA tests, for males there is no statistically significant evidence that the potential romantic partner's college major $\left(\mathrm{F}_{2,334}=0.62\right.$, 
$\mathrm{p}=0.5406)$ or personality $\left(\mathrm{F}_{2,334}=1.87, \mathrm{p}=0.1558\right)$ has a main effect on respondents' levels of attraction as measured by the Campbell Romantic Attraction Scale. This suggests that there is no statistically significant relationship between heterosexual male's levels of romantic attraction to a woman and her college major or personality traits. This finding means that there is no statistically significant evidence that heterosexual men's attraction to women is affected by her level of role congruence, incongruence or neutrality.

\section{Reysen Likability Scale}

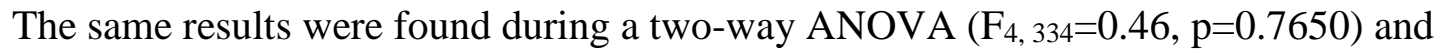
one-way ANOVA tests when looking at the effect the potential romantic partner's college major $\left(\mathrm{F}_{2,334}=0.63, \mathrm{p}=0.5343\right)$ and personality $\left(\mathrm{F}_{2,334}=0.35, \mathrm{p}=0.7074\right)$ had on respondents' levels of attraction as measured by the Reysen Likability Scale. This suggests that there is no statistically significant relationship between heterosexual male's perceptions of a woman's likability outside of the context of a relationship and her college major or personality traits. This again means that there is no statistically significant evidence that heterosexual men's attraction to women is affected by her level of role congruence, incongruence or neutrality.

\section{Thomae Desire for a Relationship Scale}

These results hold true even when looking at the effect the potential romantic partner's college major and personality had on respondents' levels of attraction for a short term relationship and for a long term relationship as measured by the Thomae Desire for a Relationship Scale. For heterosexual men, according to a two-way ANOVA test there is no statistically significant evidence that there is an interaction effect between the potential romantic partner's college major and their personality on male's levels of desire for a relationship as measured by the combined Thomae scale $\left(\mathrm{F}_{4,334}=0.79, \mathrm{p}=0.3344\right)$, the short term scale $\left(\mathrm{F}_{4}\right.$, 
$\left.{ }_{334}=0.79, \mathrm{p}=0.5320\right)$ or the long term scale $\left(\mathrm{F}_{4,334}=0.78, \mathrm{p}=0.5396\right)$. For all three Thomae scales, a one-way ANOVA test showed that there is no statistically significant evidence that a potential romantic partner's college major (combined: $F_{2,334}=1.10, p=0.3344$, short: $F_{2,334}=1.10$, $\mathrm{p}=0.3344$, long: $\mathrm{F}_{2,334}=1.71, \mathrm{p}=0.1821$ ) or personality (combined: $\mathrm{F}_{2,334}=1.26, \mathrm{p}=0.2850$, short: $\mathrm{F}_{2,334}=1.26, \mathrm{p}=0.2850$, long: $\mathrm{F}_{2,334}=1.62, \mathrm{p}=0.2000$ ) has a main effect on their desire for $\mathrm{a}$ relationship, regardless of duration. This finding suggests that there is no statistically significant relationship between heterosexual male's perceptions of a woman's desirability as a dating partner and her college major or personality traits. This, once again, means that there is no statistically significant evidence that heterosexual men's attraction to women is affected by her level of role congruence, incongruence or neutrality.

\section{Summary}

According to ANOVA testing, heterosexual male respondents' levels of attraction to a woman in a romantic context, a non-romantic context and in a short term or long term relationship are not affected by the woman's college major or personality traits in a statistically significant way. Female levels of role congruence, incongruence or neutrality do not have a statistically significant effect on male potential romantic partner's romantic attraction, nonromantic attraction or desire for a short or long term relationship. Heterosexual male college students are not effected by gender role (in)congruity in a statistically significant way based on ANOVA analysis.

\section{Female Respondents}

For female respondents and all of the scales, a two-way ANOVA test was performed in order to see if there was an interaction effect between the potential romantic partner's college major and their personality characteristics. For all five scale, there was no statistically significant 
evidence that there was an interaction effect between the potential romantic partner's college

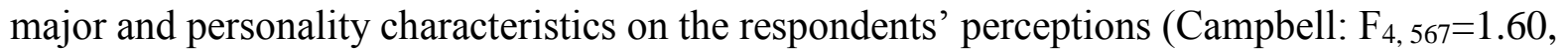
$\mathrm{p}=0.1739$, Reysen: $\mathrm{F}_{4,567}=1.22, \mathrm{p}=0.2997$, Thomae combined: $\mathrm{F}_{4,567}=0.62, \mathrm{p}=0.6471$, Thomae short: $\mathrm{F}_{4,567}=0.40, \mathrm{p}=0.8105$, Thomae long: $\left.\mathrm{F}_{4,567}=0.40, \mathrm{p}=0.8105\right)$. This result indicates that for female respondents the effect of the potential romantic partner's college major or personality did not depend on the effect of the other. According to one-way ANOVA testing, there are several statistically significant main effects for heterosexual females' perceptions of the male potential

romantic partners. The results of these one-way ANOVA tests are broken up by each scale tested and discussed below.

\section{Campbell Romantic Attraction Scale}

According to a two-way ANOVA, there is statistically significant evidence of a main effect of respondents' mean levels of attraction as measured by the Campbell Romantic Attraction Scale and the potential romantic partners' college major $\left(\mathrm{F}_{2,567}=4.04, \mathrm{p}=0.0181\right)$. According to a one-way ANOVA test, there is statistically significant evidence that there is a difference in respondents' mean levels of attraction as measured by the Campbell Romantic Attraction Scale between at least two of the potential romantic partners' college majors $\left(\mathrm{F}_{2}\right.$, 565 $=4.88, \mathrm{p}=0.0079)$. The Bonferroni post-hoc test reveals that there is a statistically significant difference between respondents' mean levels of romantic attraction to potential male romantic partners who are in the feminine college major and those who are in the gender neutral college major. Female respondents' mean Campbell Romantic Attraction Scale score for a man in a feminine college major was 1.85 points. $(\mathrm{p}=0.007)$ greater than the mean score for a man in a gender neutral college major. This means that heterosexual women were significantly more likely to find a male potential romantic partner more attractive within the context of a romantic 
relationship when he was in a feminine college major — gender role incongruent — than when he was in a gender neutral college major-gender role neutral. There were not any statistically significant differences between feminine major (incongruent) and masculine major (congruent) $(\mathrm{p}=1.000)$ or masculine major (congruent) and neutral major $(\mathrm{p}=0.095)$.

According to a two-way ANOVA, there is not statistically significant evidence that there is a main effect of respondents' mean levels of attraction as measured by the Campbell Romantic Attraction Scale and the potential romantic partners' personality characteristics $\left(F_{2,567}=0.92\right.$, $\mathrm{p}=0.4353$ ). This result means that the potential romantic partners' personality did not have a statistically significant effect on respondents' ratings on the Campbell Romantic Attraction Scale.

Figure 2: The Campbell Romantic Attraction Scale had a range of 5-35 with higher scores corresponding with greater likability. Statistically significant difference between feminine and neutral (1.85 points, $p=0.0007)$.

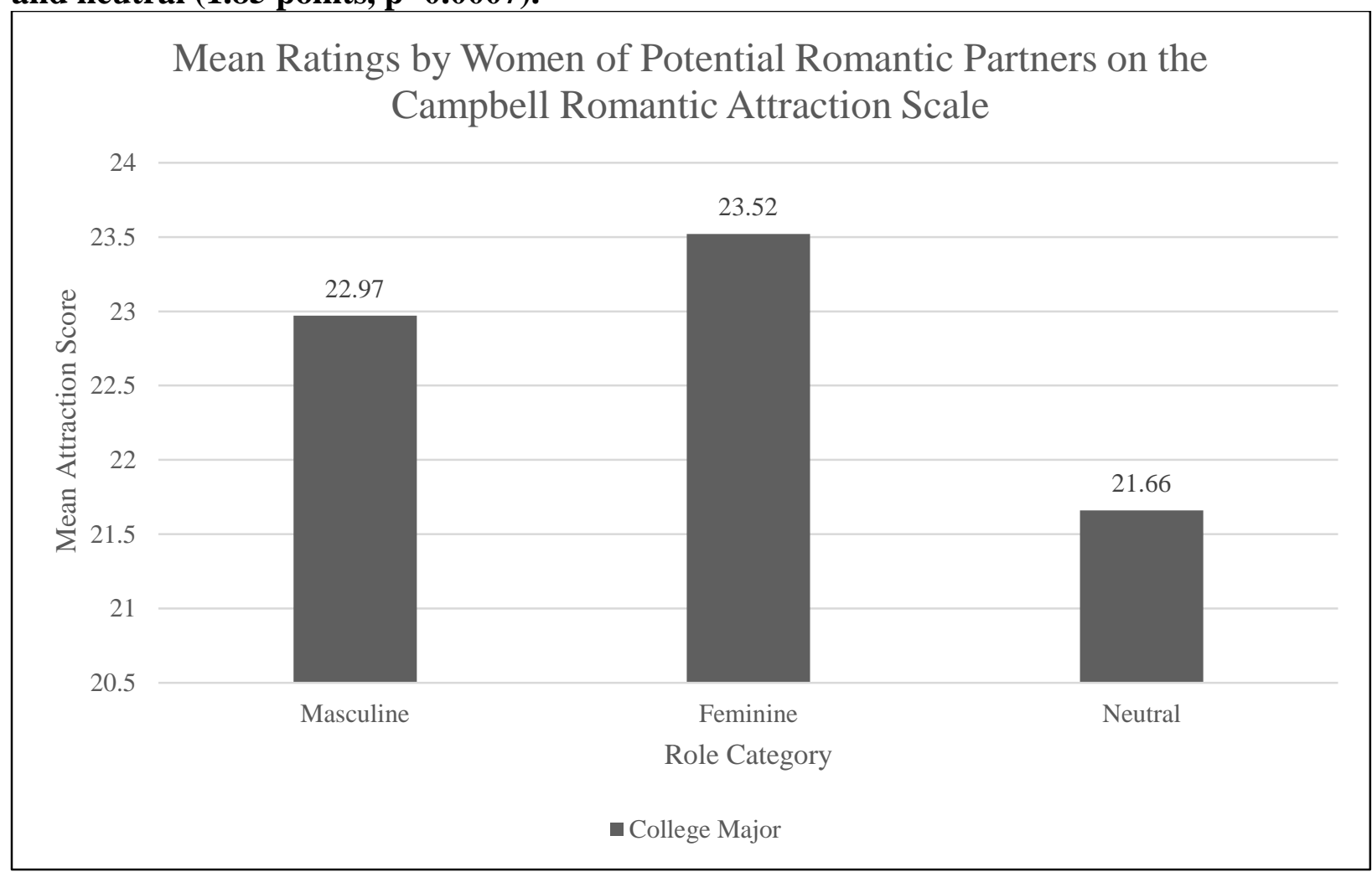




\section{Reysen Likability Scale}

According to a two-way ANOVA, there is statistically significant evidence that there is a main effect of respondents' mean levels of attraction as measured by the Reysen Likability Scale and the potential romantic partners' college major $\left(\mathrm{F}_{2,567}=15.90, \mathrm{p}<0.001\right)$ and their personality $\left(\mathrm{F}_{2,567}=15.54, \mathrm{p}<0.001\right)$.

According to a one-way ANOVA test, there is statistically significant evidence that there is a difference in respondents' mean levels of attraction as measured by the Reysen Likability Scale between at least two of the potential romantic partners' college majors $\left(F_{2,565}=16.82\right.$, $\mathrm{p}<0.01)$. The Bonferroni post-hoc test reveals that there is a statistically significant difference between respondents' mean levels of romantic attraction to potential male romantic partners who are in the feminine college major and those who are in the gender neutral college major and those who are in the masculine college major. Female respondents' mean Reysen Likability Scale score for a man in a feminine college major (gender role incongruent) was 4.58 points $(\mathrm{p}<0.01)$ greater than the mean score for a man in a gender neutral college (gender role neutral) major and 5.29 points $(\mathrm{p}<0.01)$ greater than the mean score for a man in a masculine college major (gender role congruent). This means that heterosexual women were statistically significantly more likely to find a male potential romantic partner more likable in a nonromantic context when he was in a feminine college major - gender role incongruent — than when he was in a gender neutral — gender role neutral—or when he was in a masculine college major — gender role congruent. There is not statistically significant evidence of a difference between masculine college major (congruent) and the gender neutral college major $(\mathrm{p}=1.000)$.

There were similar results for personality. According to a one-way ANOVA test, there is statistically significant evidence that there is a difference in respondents' mean levels of 
attraction as measured by the Reysen Likability Scale between at least two of the potential romantic partners' personality characteristics $\left(\mathrm{F}_{2,565}=16.47, \mathrm{p}<0.01\right)$. The Bonferroni post-hoc test reveals that there is a statistically significant difference between respondents' mean levels of romantic attraction to potential male romantic partners who have feminine personality characteristics (gender role incongruent) and those who have gender neutral personality characteristics (gender role neutral) and those who have masculine personality characteristics (gender role congruent). Female respondents' mean Reysen Likability Scale score for a man with feminine personality characteristics (gender role incongruent) was 4.33 points $(\mathrm{p}<0.01)$ greater than the mean score for a man with gender neutral personality characteristics (gender role neutral) and 5.38 points $(\mathrm{p}<0.01)$ greater than the mean score for a man with masculine personality characteristics (gender role congruent). This means that heterosexual women were statistically significantly more likely to find a male potential romantic partner more attractive outside of the context of a romantic relationship when he had feminine personality characteristics — gender role incongruent — than when he had gender neutral—gender role neutral — or masculine personality characteristics — gender role congruent. There is no statistically significant difference between masculine (congruent) and gender neutral personalities $(\mathrm{p}=1.000)$. 
Figure 3: The Reysen Likability Scale had a range of 11-77 with higher scores corresponding with greater likability. Statistically significant difference between feminine and neutral and feminine and masculine college majors $(p<0.01, p<0.01)$ and personalities $(\mathbf{p}<0.01, \mathbf{p}<0.01)$.

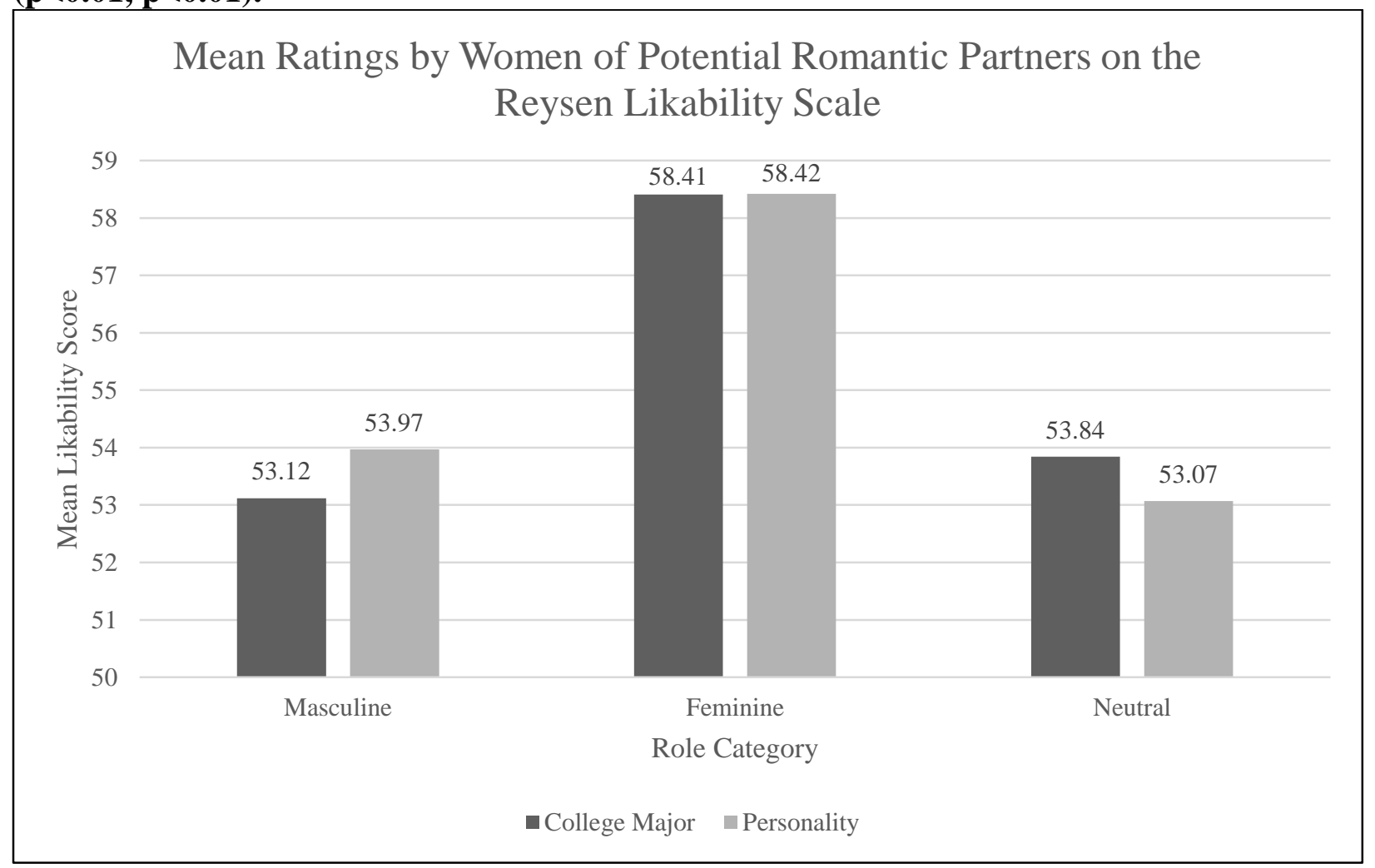

Thomae Desire for a Relationship Scale

Combined Scale. According to a two-way ANOVA, there is statistically significant evidence of a main effect of respondents' mean levels of attraction as measured by the Thomae Desire for a Relationship Scale and the potential romantic partners' college major $\left(F_{2,567}=10.11\right.$, $\mathrm{p}<0.01)$. According to a one-way ANOVA test, there is statistically significant evidence that there is a difference in respondents' mean levels of attraction as measured by the Thomae Desire for a Relationship Scale between at least two of the potential romantic partners' college majors $\left(\mathrm{F}_{2,565}=10.52, \mathrm{p}<0.01\right)$. The Bonferroni post-hoc test reveals that there is a statistically significant difference between respondents' mean levels of desire for a relationship with potential male romantic partners who are in the feminine college major (gender role incongruent) 
and those who are in the gender neutral college major (gender role neutral). Female respondents' mean Thomae Desire for a Relationship Scale score for a man in a feminine college major (gender role incongruent) was 7.56 points $(\mathrm{p}<0.01)$ greater than the mean score for a man in a gender neutral college major (gender role neutral). This finding means that heterosexual women were statistically significantly more likely to find a male potential romantic partner a more desirable romantic partner when he was in a feminine college major-gender role incongruentthan when he was in a gender neutral college major-gender role neutral. There was not a statistically significant difference between the feminine (incongruent) and masculine (congruent) major ( $\mathrm{p}=0.07)$ or the masculine (congruent) and neutral college major $(\mathrm{p}=0.057)$. According to a two-way ANOVA, there is not statistically significant evidence that there is a main effect of respondents' mean levels of attraction as measured by the Thomae Desire for a Relationship Scale and the potential romantic partners' personality characteristics $\left(\mathrm{F}_{2,567}=0.47\right.$, $\mathrm{p}=0.6278$ ). This result means that the potential romantic partners' personality did not have a statistically significant effect on respondents' ratings on the Thomae Desire for a Relationship Scale.

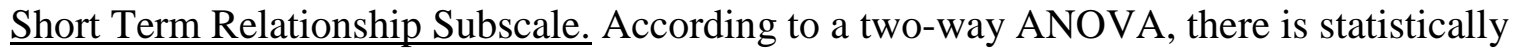
significant evidence that there is a main effect of respondents' mean levels of attraction as measured by the Thomae Desire for a Short-Term Relationship Scale and the potential romantic partners' college major $\left(\mathrm{F}_{2,567}=8.27, \mathrm{p}=0.0003\right)$. According to a one-way ANOVA test, there is statistically significant evidence that there is a difference in respondents' mean level of attraction as measured by the Thomae Desire for a Short-Term Relationship Scale between at least two of the potential romantic partners' college majors $\left(\mathrm{F}_{2,565}=8.64, \mathrm{p}=0.0002\right)$. The Bonferroni post-hoc test reveals that there is a statistically significant difference between respondents' mean levels of 
desire for a relationship with potential male romantic partners who are in the feminine college major (gender role incongruent) and those who are in the gender neutral college major (gender role neutral) and those who are in a masculine (gender role congruent) college major. Female respondents' mean Thomae Desire for a Short-Term Relationship Scale score for a man in a feminine college major (gender role incongruent) was 2.69 points $(\mathrm{p}<0.01)$ greater than the mean score for a man in a gender neutral college major (gender role neutral) and 1.77 points $(\mathrm{p}=0.021)$ greater than the mean score for a man in a masculine (gender role congruent) college major. This finding indicates that heterosexual women were statistically significantly more likely to find a male potential romantic partner a more desirable short-term romantic partner when he was in a feminine college major - gender role incongruent — than when he was in a gender neutral— gender role neutral—or when he was in a masculine college major-gender role congruent. There was not a statistically significant difference between the masculine (congruent) and neutral major $(\mathrm{p}=0.480)$.

According to a two-way ANOVA, there is not statistically significant evidence that there is a main effect of respondents' mean levels of attraction as measured by the Thomae Desire for a Short-Term Relationship Scale and the potential romantic partners' personality characteristics $\left(\mathrm{F}_{2,567}=1.13, \mathrm{p}=0.3231\right)$. This result means that the potential romantic partners' personality did not have a statistically significant effect on respondents' ratings on the Thomae Desire for a Short-Term Relationship Scale.

Long Term Relationship Subscale. According to a two-way ANOVA, there is statistically significant evidence that there is a main effect of respondents' mean levels of attraction as measured by the Thomae Desire for a Long-Term Relationship Scale and the potential romantic partners' college major $\left(\mathrm{F}_{2,567}=8.75, \mathrm{p}=0.0002\right)$. According to a one-way ANOVA test, there is 
statistically significant evidence that there is a difference in respondents' mean levels of attraction as measured by the Thomae Desire for a Long-Term Relationship Scale between at least two of the potential romantic partners' college majors $\left(F_{2,565}=9.94, p=0.0001\right)$. The Bonferroni post-hoc test reveals that there is a statistically significant difference between respondents' mean levels of desire for a relationship with potential male romantic partners who are in the gender neutral college major (gender role neutral) and those who are in the masculine (gender role congruent) and the feminine (gender role incongruent) college majors. Female respondents' mean Thomae Desire for a Long-Term Relationship Scale score for a man in a gender neutral college major (gender role neutral) was 2.93 points $(\mathrm{p}=0.023)$ less than the mean score for a man in a masculine (gender role congruent) college major and 4.87 points $(\mathrm{p}<0.01)$ less than the mean score for a man in a feminine (gender role incongruent) college major. This finding means that heterosexual women were statistically significantly less likely to find a male potential romantic partner a more desirable long-term romantic partner when he was in a gender neutral college major-gender role neutral — than when he was in a gender role congruent (masculine) or incongruent (feminine) college major. There was not a statistically significant difference between the feminine (incongruent) and masculine (congruent) major $(\mathrm{p}=0.227)$. According to a two-way ANOVA, there is not statistically significant evidence that there is a main effect of respondents' mean levels of attraction as measured by the Thomae Desire for a Long-Term Relationship Scale and the potential romantic partners' personality characteristics $\left(\mathrm{F}_{2,567}=0.15, \mathrm{p}=0.8523\right)$. This result means that the potential romantic partners' personality did not have a statistically significant effect on respondents' ratings on the Thomae Desire for a Long-Term Relationship Scale. 
Figure 4: The Thomae Desire for a Relationship Scale had a range of 13-91 with higher scores corresponding with greater desire for a relationship. The Thomae Short-Term Scale has a score range of 6-42 and the Thomae Long-Term Scale has a score range of 7-49.

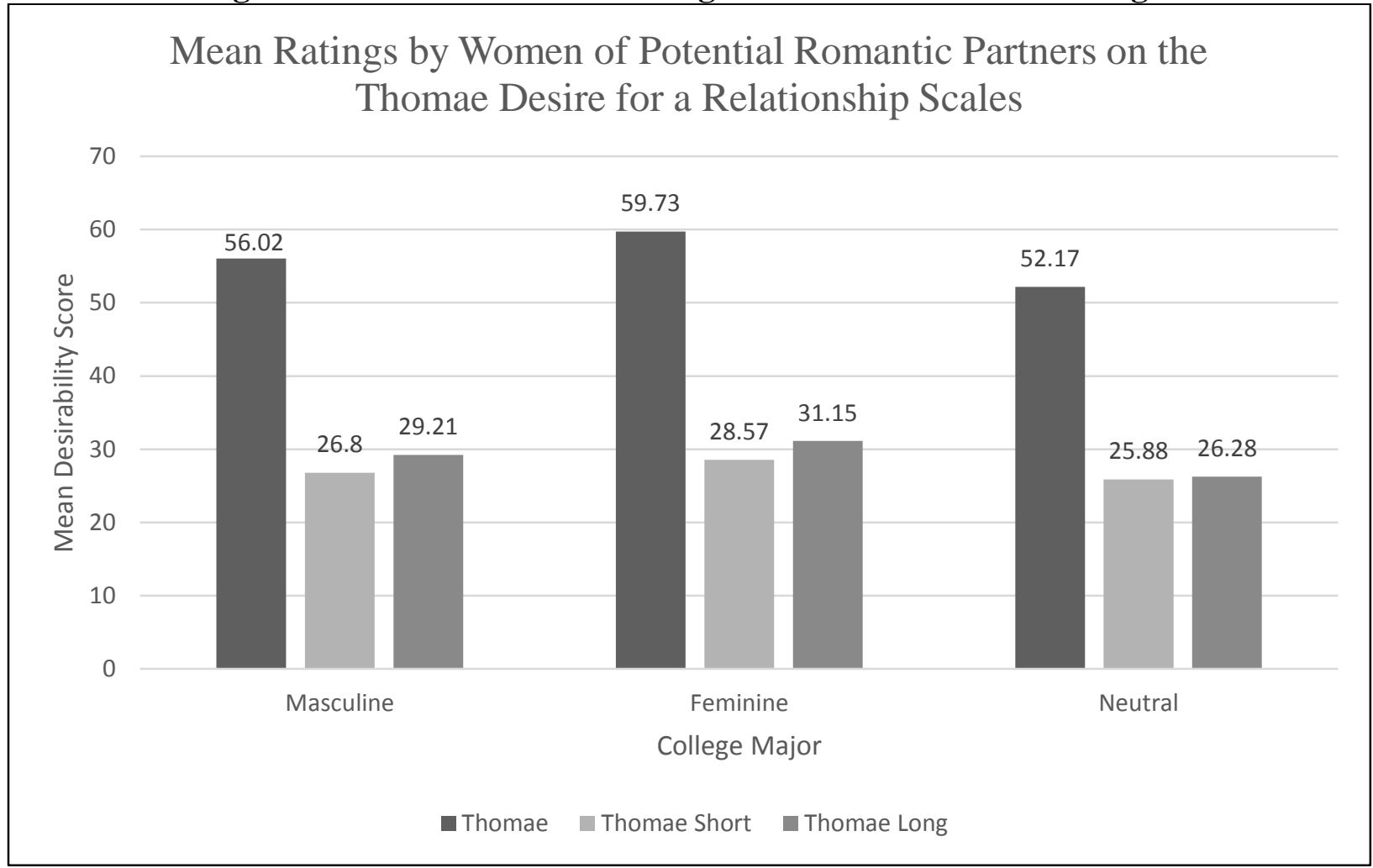

\section{Regression Results}

After completing ANOVA testing, ordinary least squares (OLS) regression tests were completed to further examine the relationship between role (in)congruity and assessments of attraction. In each of the regressions presented below there are three control variables: respondents' own masculinity/femininity, respondents' minority status and respondents' relationship status at the time of the experiment. All three of the control variables were based on self-report responses on the survey. The presentation of the results in this section is by scale and then gender of the respondent so that the differences between male and female responses for each scale could be looked at simultaneously in order to show the similarities and differences between the genders. 
In order to aid in the understanding of the significant difference between vignettes, I use the key presented in the following chart. This key is to help prevent the results from becoming too cluttered with words and so that it is easy for the reader to understand how the vignettes that had statistically significant differences in scale ratings are different in terms of college major and personality characteristic role congruence, incongruence and neutrality.

Table 3: Description of vignette number including which major, personality and vignette code they are associated with.

\begin{tabular}{|c|c|c|c|c|}
\hline & $\begin{array}{l}\text { Vignette } \\
\text { Number }\end{array}$ & Vignette Code & Major & Personality \\
\hline \multirow{9}{*}{ 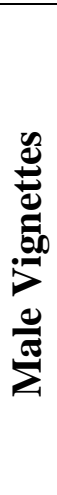 } & 1 & MRC/PRC & Masculine (RC) & Masculine (RC) \\
\hline & 2 & MRC/PRI & Masculine (RC) & Feminine (RI) \\
\hline & 3 & MRC/PN & Masculine (RC) & Neutral \\
\hline & 4 & MRI/PRC & Feminine (RI) & Masculine (RC) \\
\hline & 5 & MRI/PRI & Feminine (RI) & Feminine (RI) \\
\hline & 6 & MRI/PN & Feminine (RI) & Neutral \\
\hline & 7 & MN/PRC & Neutral & Masculine (RC) \\
\hline & 8 & MN/PRI & Neutral & Feminine (RI) \\
\hline & 9 & MN/PN & Neutral & Neutral \\
\hline \multirow{9}{*}{ 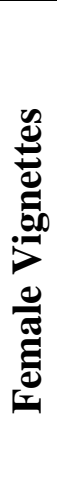 } & 10 & MRC/PRC & Feminine (RC) & Feminine (RC) \\
\hline & 11 & $\mathrm{MRC} / \mathrm{PRI}$ & Feminine (RC) & Masculine (RI) \\
\hline & 12 & $\mathrm{MRC} / \mathrm{PN}$ & Feminine (RC) & Neutral \\
\hline & 13 & MRI/PRC & Masculine (RI) & Feminine (RC) \\
\hline & 14 & MRI/PRI & Masculine (RI) & Masculine (RI) \\
\hline & 15 & $\mathrm{MRI} / \mathrm{PN}$ & Masculine (RI) & Neutral \\
\hline & 16 & $\mathrm{MN} / \mathrm{PRC}$ & Neutral & Feminine (RC) \\
\hline & 17 & MN/PRI & Neutral & Masculine (RI) \\
\hline & 18 & $\mathrm{MN} / \mathrm{PN}$ & Neutral & Neutral \\
\hline
\end{tabular}




\section{Campbell Romantic Attraction Scale}

\section{Male Respondents}

For male respondents on the Campbell Romantic Attraction Scale there was only one pair of vignettes that were statistically significantly different from one another. According to the regression, there is statistically significant evidence that for male respondents the mean Campbell Scale score for vignette 14 was higher than the mean score for vignette $12\left(b_{1}=2.76\right.$, $\mathrm{p}=0.032)$. There is statistically significant evidence that the men who received vignette 14 (masculine major, masculine personality) rated the potential romantic partner 2.76 points higher than the men who received vignette 12 (feminine major, neutral personality). This finding indicates that men are more attracted to women who are entirely (major and personality) role incongruent than a woman in a role congruent major with a neutral personality. Men preferred a potential romantic partner who had both a masculine major and a masculine personality characteristics rather than a potential romantic partner who had a feminine career and gender neutral personality characteristics.

The control variable for relationship status was also statistically significant with ratings from single people 1.28 points higher than those who were in a relationship $(\mathrm{p}=0.032)$. This result indicates that when a male is in a relationship he is less likely to rate a potential romantic partner as an attractive romantic partner than his single counterparts. No other control variables were statistically significant meaning that minority status and the respondent's own masculinity/femininity did not have a statistically significant effect on male ratings of the potential romantic partners on the Campbell Romantic Attraction Scale. 
Table 4: Statistically Significant Differences Between Mean Scores for Male Respondents Dependent Variable: Campbell Score

\begin{tabular}{|c|c|c|c|}
\hline Vignette Relationship & $\begin{array}{l}\text { First Vig. } \\
\text { Mean }\end{array}$ & $\begin{array}{l}\text { Second } \\
\text { Vig. Mean }\end{array}$ & Difference \\
\hline $\begin{array}{r}14 \text { vs. } 12 \\
\text { MRI/PRI vs. MRC/PN } \\
\end{array}$ & 25.44 & 22.68 & $\begin{array}{l}2.76^{*} \\
(1.28) \\
\end{array}$ \\
\hline \multicolumn{4}{|l|}{ Control Variables } \\
\hline $\begin{array}{l}\text { Respondent Masculinity or } \\
\text { Femininity Score }\end{array}$ & $\begin{array}{l}0.04 \\
(0.10)\end{array}$ & & \\
\hline Minority Status & $\begin{array}{l}1.74 \\
(0.93)\end{array}$ & & \\
\hline $\begin{array}{l}\text { Relationship Status (not } \\
\text { single) }\end{array}$ & $\begin{array}{l}1.28^{*} \\
(0.59)\end{array}$ & & \\
\hline$y$-intercept & $\begin{array}{l}20.90 \\
(0.59)\end{array}$ & & \\
\hline R-squared & 0.0467 & & \\
\hline
\end{tabular}

Note: The individual coefficient is statistically significant at ${ }^{+} \mathrm{p}=0.05,{ }^{*} \mathrm{p}<0.05$, ${ }^{*} \mathrm{*} p<0.01$ or $* * * \mathrm{p}<0.001$. Difference between mean scores or coefficient with robust standard errors in parenthesis.

\section{Female Respondents}

For female respondents, according to the Campbell Romantic Attraction Scale male potential romantic partners who were in a gender neutral college major were rated statistically significantly lower than potential romantic partners who were in masculine or feminine college majors. This result supports the results of the ANOVA analysis.

According to the regression, there is statistically significant evidence that for female respondents the mean Campbell Scale score for vignette 9 was lower than the mean scores for vignettes $6\left(b_{1}=-3.77, p<0.001\right), 4\left(b_{1}=-3.32, p=0.001\right), 1\left(b_{1}=-3.00, p=0.002\right)$, and $2\left(b_{1}=-2.38\right.$, $\mathrm{p}=0.027)$. There is statistically significant evidence that the females who received vignette 9 (neutral major, neutral personality) rated the potential romantic partner 3.77 points lower than vignette 6 (feminine major, neutral personality), 3.32 points lower than vignette 4 (feminine major, masculine personality), 3 points lower than vignette 1 (masculine major, masculine personality), and 2.38 points lower than vignette 2 (masculine major, feminine personality). 
There is also statistically significant evidence that for female respondents the mean Campbell Scale score for vignette 7 was lower than the mean score for vignette $6\left(b_{1}=-2.44, p=0.022\right)$. There is statistically significant evidence that the females who received vignette 7 (neutral major, masculine personality) rated the potential romantic partner 2.44 points lower than those who received vignette 6 (feminine major, neutral personality).

Based on the patterns of statistically significant differences between vignette means, women are less likely to like a man with a neutral college major (vig. 9 and 7) than a man with a role congruent — masculine — or feminine — role incongruent — college major regardless of the man's personality (vig. 6, 4, 1 and 2).

None of the control variables were statistically significant meaning that a respondent's relationship status, minority status or own level of masculinity/femininity did not have an impact on their ratings of their potential romantic partner on the Campbell Romantic Attraction Scale. 
Table 5: Statistically Significant Differences Between Mean Scores for Female Respondents Dependent Variable: Campbell Score

\begin{tabular}{|c|c|c|c|}
\hline Vignette Relationship & $\begin{array}{l}\text { First Vig. } \\
\text { Mean }\end{array}$ & $\begin{array}{l}\text { Second } \\
\text { Vig. Mean }\end{array}$ & Difference \\
\hline $\begin{array}{r}9 \text { vs. } 6 \\
\text { MN/PN vs. MRI/PN }\end{array}$ & 20.67 & 24.44 & $\begin{array}{l}-3.77 * * * \\
(1.01)\end{array}$ \\
\hline $\begin{array}{r}9 \text { vs. } 4 \\
\text { MN/PN vs. MRI/PRC }\end{array}$ & 20.67 & 23.99 & $\begin{array}{l}-3.32 * * \\
(1.01)\end{array}$ \\
\hline $\begin{array}{r}9 \text { vs. 1 } \\
\text { MN/PN vs. MRC/PRC }\end{array}$ & 20.67 & 23.67 & $\begin{array}{l}-3.00^{* *} \\
(0.96)\end{array}$ \\
\hline $\begin{array}{r}7 \text { vs. } 6 \\
\text { MN/PRC vs. MRI/PN }\end{array}$ & 22.00 & 24.44 & $\begin{array}{l}-2.44^{*} \\
(1.07)\end{array}$ \\
\hline $\begin{array}{r}9 \text { vs. } 2 \\
\text { MN/PN vs. MRC/PRI } \\
\end{array}$ & 20.67 & 23.05 & $\begin{array}{l}-2.38^{*} \\
(1.07) \\
\end{array}$ \\
\hline \multicolumn{4}{|l|}{ Control Variables } \\
\hline $\begin{array}{l}\text { Respondent Masculinity } \\
\text { or Femininity Score }\end{array}$ & $\begin{array}{l}-0.08 \\
(0.09)\end{array}$ & & \\
\hline Minority Status & $\begin{array}{l}-1.54 \\
(0.83)\end{array}$ & & \\
\hline $\begin{array}{l}\text { Relationship Status (not } \\
\text { single) }\end{array}$ & $\begin{array}{l}-0.46 \\
(0.53)\end{array}$ & & \\
\hline$y$-intercept & $\begin{array}{l}26.54 \\
(1.53)\end{array}$ & & \\
\hline R-squared & 0.0415 & & \\
\hline
\end{tabular}

Note: The individual coefficient is statistically significant at ${ }^{+} \mathrm{p}=0.05,{ }^{*} \mathrm{p}<0.05, * * \mathrm{p}<0.01$ or $* * * \mathrm{p}<0.001$. Difference between mean scores or coefficient with robust standard errors in parenthesis. 
Figure 5: Regression of female respondents' ratings of male potential romantic partners by vignette on the Campbell Romantic Attraction Scale.

Female Campbell Ratings of Male Potential Romantic Partners by Vignette

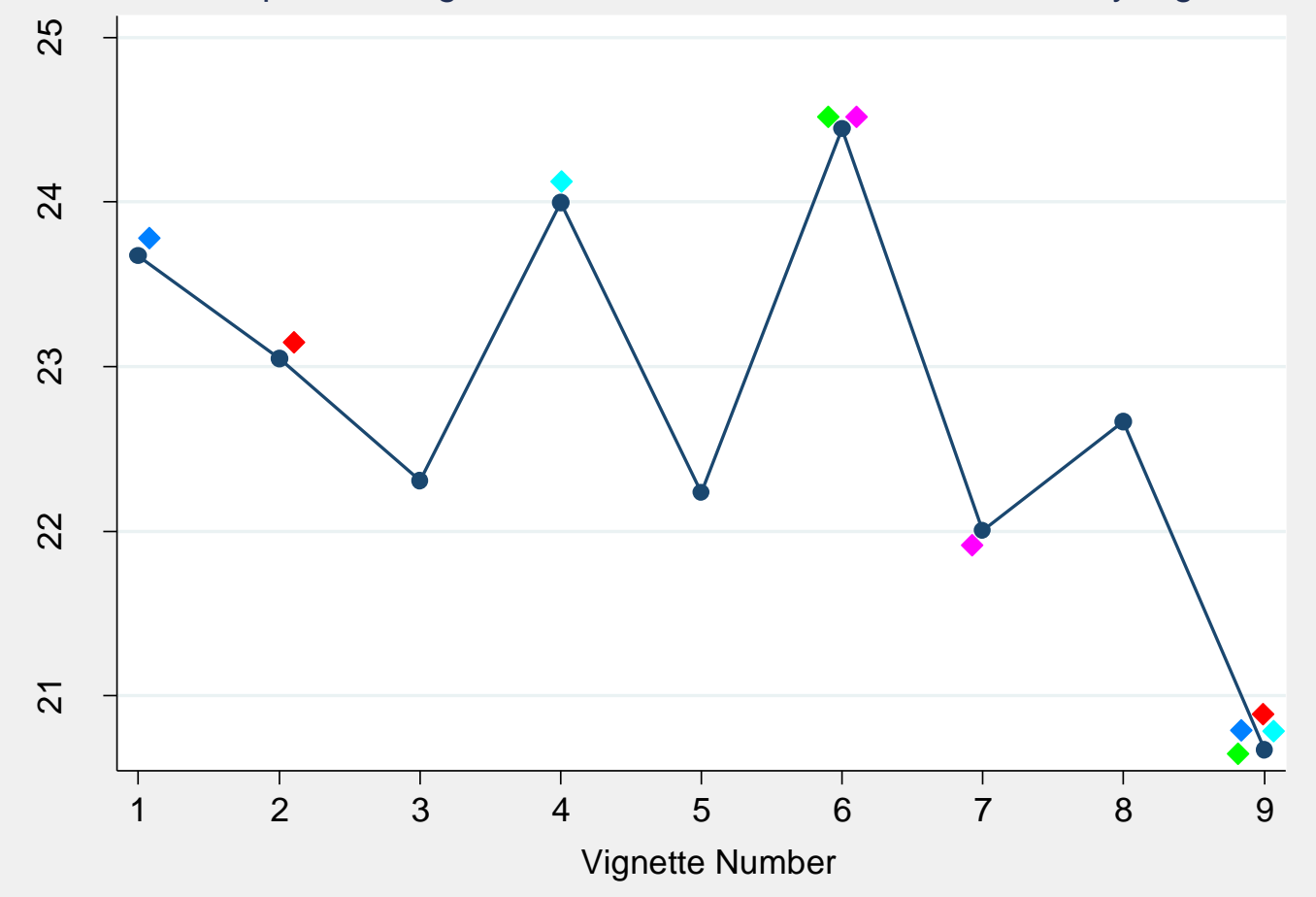

Note: The pairs of colored diamonds represent statistically significant differences in the mean scores of the two vignettes that the shapes are closest to.

\section{Summary}

There were statistically significant differences between the ratings of at least one pair of vignettes for both male and female respondents on the Campbell's Romantic Attraction Scale. However, there were five statistically significantly different pairs of vignettes for female respondents and only one statistically significant pair for male respondents. This finding indicates that on the Campbell Romantic Attraction Scale, the roles of the male potential romantic partner had a larger impact on the assessment of their attractiveness than the roles of the female potential romantic partners had on the assessment of their attractiveness. For male respondents though, being in a relationship had a statistically significant effect on their ratings of the potential romantic partners whereas it did not have a statistically significant effect on the 
ratings of female respondents. Male respondents who reported that they were in a relationship rated the potential romantic partners to be 1.28 points less attractive than their single counterparts. This indicates that being in a relationship has a larger impact on male's willingness to rate a potential romantic partner who is not their partner as attractive than being in a relationship has on female's willingness to rate a potential romantic partner as attractive.

\section{Reysen Likability Scale}

\section{Male Respondents}

There is no statistically significant evidence that for male respondents there is a difference between the mean Reysen scores of any two vignettes. There is also no statistically significant evidence that for male respondents there is a difference between the mean Reysen scores of any of the college majors or personality characteristics.

There is statistically significant evidence that the control variable race had an effect with Caucasian respondents rating the potential romantic partners 3.18 points more likable than minority respondents $(\mathrm{p}=0.030)$. This result means that when a male indicated minority status he was less likely to rate the potential romantic partner as likable on the Reysen Likability Scale than his Caucasian counterparts.

There is also statistically significant evidence that the control variable for relationship status had an effect with single individuals rating the potential romantic partner 2.23 points more likable than those who were in a relationship $(\mathrm{p}=0.036)$. This result again indicates that when a male is in a relationship he is less likely to rate a potential romantic partner as a likable potential romantic partner than his single counterparts.

The control variable for the respondents' own masculinity/femininity was not statistically significant meaning the respondent's own masculinity/femininity did not have a statistically 
significant effect on male ratings of the potential romantic partners on the Reysen Likability Scale.

Table 6: Regression of Perspective Romantic Partner's Personality, College Major and Reysen Score Dependent Variable: Reysen Score

\begin{tabular}{|l|l|}
\hline Independent Variable & \\
\hline Major 2 (feminine) & -0.47 \\
& $(1.17)$ \\
\hline Major 3 (neutral) & -1.58 \\
& $(1.28)$ \\
\hline Personality 2 (feminine) & 1.05 \\
& $(1.22)$ \\
\hline Personality 3 (neutral) & -0.25 \\
& $(1.21)$ \\
\hline Respondent Masculinity or & -0.37 \\
Femininity Score & $(0.23)$ \\
\hline Minority Status & $3.18^{*}$ \\
& $(1.46)$ \\
\hline Relationship Status (not & $2.23^{*}$ \\
single) & $(1.06)$ \\
\hline y-intercept & $46.39^{* * *}$ \\
& $(3.12)$ \\
\hline R-squared & 0.0463 \\
\hline
\end{tabular}

Note: The individual coefficient is statistically significant at ${ }^{+} \mathrm{p}=0.05,{ }^{*} \mathrm{p}<0.05,{ }^{*} \mathrm{p}<0.01$ or $* * * p<0.001$. Difference between mean scores or coefficient with robust standard errors in parenthesis. Reference groups: major-masculine, personality-masculine.

\section{Female Respondents}

The most statistically significant differences between mean vignette scores were seen for female respondents on the Reysen Likability Scale. As supported by the ANOVA results, vignettes that had feminine qualities were rated statistically significantly higher than the vignettes that did not have feminine characteristics.

According to the regression, there is statistically significant evidence that for female respondents the mean Reysen Scale score for vignette 9 was lower than the mean scores for vignettes $5\left(b_{1}=-8.56, p<0.001\right), 8\left(b_{1}=-6.78, p<0.001\right), 4\left(b_{1}=-6.15, p=0.001\right), 2\left(b_{1}=-5.99\right.$, $\mathrm{p}<0.001)$, and $6\left(\mathrm{~b}_{1}=-5.74, \mathrm{p}<0.001\right)$. There is statistically significant evidence that the females 
who received vignette 9 (neutral major, neutral personality) rated the potential romantic partner 8.56 points lower than vignette 5 (feminine major, feminine personality), 6.78 points lower than vignette 8 (neutral major, feminine personality), 6.15 points lower than vignette 4 (feminine major, masculine personality), 5.99 points lower than vignette 2 (masculine major, feminine personality), and 5.74 points lower than vignette 6 (feminine major, neutral personality).

There is also statistically significant evidence that for female respondents the mean Reysen Scale score for vignette 7 was lower than the mean scores for vignettes $5\left(b_{1}=-7.18\right.$, $\mathrm{p}<0.001), 4\left(\mathrm{~b}_{1}=-4.76, \mathrm{p}=0.011\right), 2\left(\mathrm{~b}_{1}=-4.61, \mathrm{p}=0.008\right), 6\left(\mathrm{~b}_{1}=4.36, \mathrm{p}=0.010\right)$, and $8\left(\mathrm{~b}_{1}=5.39\right.$, $\mathrm{p}=0.001)$. There is statistically significant evidence that the females who received vignette 7 (neutral major, masculine personality) rated the potential romantic partner 7.18 points lower than vignette 5 (feminine major, feminine personality), 4.76 points lower than vignette 4 (feminine major, masculine personality), 4.61 points lower than vignette 2 (masculine major, feminine personality), 4.36 points lower than vignette 6 (feminine major, neutral personality) and 5.39 points lower than vignette 8 (neutral major, feminine personality).

There is also statistically significant evidence that for female respondents the mean Reysen Scale score for vignette 3 was lower than the mean scores for vignettes $2\left(b_{1}=-6.49\right.$, $p=0.001), 6\left(b_{1}=6.24, p=0.001\right), 4\left(b_{1}=6.64, p=0.001\right), 8\left(b_{1}=7.27, p<0.001\right)$, and $5\left(b_{1}=9.05\right.$, $\mathrm{p}<0.001)$. There is statistically significant evidence that the females who received vignette 3 (masculine major, neutral personality) rated the potential romantic partner 6.49 points lower than vignette 2 (masculine major, feminine personality), 6.24 points lower than vignette 6 (feminine major, neutral personality), 6.64 points lower than vignette 4 (feminine major, masculine personality), 7.27 points lower than vignette 8 (neutral major, feminine personality) and 9.05 points lower than vignette 5 (feminine major, feminine personality). 
There is also statistically significant evidence that for female respondents the mean Reysen Scale score for vignette 6 was lower than the mean score for vignette $5\left(b_{1}=-2.82\right.$, $\mathrm{p}=0.053)$. There is statistically significant evidence that the females who received vignette 6 (feminine major, neutral personality) rated the potential romantic partner 2.82 points lower than those who received vignette 5 (feminine major, feminine personality).

There is also statistically significant evidence that for female respondents the mean Reysen Scale score for vignette 1 was lower than the mean scores for vignettes $6\left(b_{1}=5.51\right.$, $\mathrm{p}=0.001), 2\left(\mathrm{~b}_{1}=7.76, \mathrm{p}=0.001\right), 4\left(\mathrm{~b}_{1}=5.91, \mathrm{p}=0.002\right), 8\left(\mathrm{~b}_{1}=6.54, \mathrm{p}<0.001\right)$, and $5\left(\mathrm{~b}_{1}=8.33\right.$, $\mathrm{p}<0.001)$. There is statistically significant evidence that the females who received vignette 1 (masculine major, masculine personality) rated the potential romantic partner 5.51 points lower than vignette 6 (feminine major, neutral personality), 7.76 points lower than vignette 2 (masculine major, feminine personality), 5.91 points lower than vignette 4 (feminine major, masculine personality), 6.54 points lower than vignette 8 (neutral major, feminine personality) and 8.33 points lower than vignette 5 (feminine major, feminine personality).

Based on the patterns of statistically significant differences between vignette mean scores for the Reysen Likability Scale, the more feminine the vignette (major or personality or both) the more likely a woman was to give the potential romantic partner a higher rating. The vignettes that were statistically significantly lower than others were the vignettes that were entirely neutral (9), neutral major and masculine personality (7), masculine major and neutral personality (3) or entirely masculine (1). The only time a vignette with a feminine characteristic was rated statistically significantly lower than another vignette was when the other vignette also had a feminine characteristic. In the case of vignette 6 verses 5, the feminine major and neutral 
personality (6) was rated statistically significantly lower than the vignette with a feminine major and feminine personality (5).

All of the vignettes that were rated statistically significantly higher than others had at least one feminine characteristic. They were the vignettes that were entirely feminine (5), neutral major and feminine personality (8), masculine major and feminine personality (2), feminine major and masculine personality (4), and feminine major and neutral personality (6). This finding indicates that women perceived the male potential romantic partners to be more likable outside of the context of a romantic relationship when he exhibited at least one role incongruent (feminine) characteristic.

This is an interesting result considering the literature would suggest that role congruent statuses would get the most positive responses (Shaffer and Johnson, 1980; D’Agostino and Day, 1991; Eagly and Karau, 2002). However, according to the regression results female respondents on the Reysen Likability Scale, the potential romantic partners that were rated the most likable were those that were gender role incongruent in at least one aspect. Further hypothesizing as to why females rated the potential romantic partners with at least one feminine characteristic to be the most likable will be noted in the discussion section.

None of the control variables were statistically significant meaning that a respondent's relationship status, minority status or own level of masculinity/femininity did not have an impact on their ratings of their potential romantic partner on the Reysen Likability Scale. 
Table 7: Statistically Significant Differences Between Mean Scores for Female Respondents Dependent Variable: Reysen Score

\begin{tabular}{|c|c|c|c|}
\hline Vignette Relationship & $\begin{array}{l}\text { First Vig. } \\
\text { Mean }\end{array}$ & $\begin{array}{l}\text { Second Vig. } \\
\text { Mean }\end{array}$ & Difference \\
\hline $\begin{array}{r}9 \text { vs. } 5 \\
\text { MN/PN vs. MRI/PRI }\end{array}$ & 51.49 & 60.05 & $\begin{array}{l}-8.56 * * * \\
(1.53)\end{array}$ \\
\hline $\begin{array}{r}7 \text { vs. } 5 \\
\text { MN/PRC vs. MRI/PRI }\end{array}$ & 52.88 & 60.05 & $\begin{array}{l}-7.18 * * * \\
(1.59)\end{array}$ \\
\hline $\begin{array}{r}9 \text { vs. } 8 \\
\text { MN/PN vs. MN/PRI }\end{array}$ & 51.49 & 58.27 & $\begin{array}{l}-6.78 * * * \\
(1.59)\end{array}$ \\
\hline $\begin{array}{r}3 \text { vs. } 2 \\
\text { MRC/PN vs. MRC/PRI }\end{array}$ & 51.00 & 57.49 & $\begin{array}{l}-6.49 * * \\
(1.90)\end{array}$ \\
\hline $\begin{array}{r}9 \text { vs. } 4 \\
\text { MN/PN vs. MRI/PRC }\end{array}$ & 51.49 & 57.64 & $\begin{array}{l}-6.15^{* *} \\
(1.79)\end{array}$ \\
\hline $\begin{array}{r}9 \text { vs. } 2 \\
\text { MN/PN vs. MRC/PRI }\end{array}$ & 51.49 & 57.49 & $\begin{array}{l}-5.99 * * * \\
(1.68)\end{array}$ \\
\hline $\begin{array}{r}9 \text { vs. } 6 \\
\text { MN/PN vs. MRI/PN }\end{array}$ & 51.49 & 57.24 & $\begin{array}{l}-5.74 * * * \\
(1.61)\end{array}$ \\
\hline $\begin{array}{r}7 \text { vs. } 4 \\
\text { MN/PRC vs. MRI/PRC }\end{array}$ & 52.88 & 57.64 & $\begin{array}{l}-4.76^{*} \\
(1.87)\end{array}$ \\
\hline $\begin{array}{r}7 \text { vs. } 2 \\
\text { MN/PRC vs. MRC/PRI }\end{array}$ & 52.88 & 57.49 & $\begin{array}{l}-4.61 * * \\
(1.72)\end{array}$ \\
\hline $\begin{array}{r}7 \text { vs. } 6 \\
\text { MN/PRC vs. MRI/PN }\end{array}$ & 52.88 & 57.24 & $\begin{array}{l}-4.36 * * \\
(1.68)\end{array}$ \\
\hline $\begin{array}{r}6 \text { vs. } 5 \\
\text { MRI/PN vs. MRI/PRI }\end{array}$ & 57.24 & 60.05 & $\begin{array}{l}-2.82^{+} \\
(1.45)\end{array}$ \\
\hline $\begin{array}{r}8 \mathrm{vs.} 7 \\
\text { MN/PRI vs. MN/PRC }\end{array}$ & 58.27 & 52.88 & $\begin{array}{l}5.39 * * \\
(1.67)\end{array}$ \\
\hline $\begin{array}{r}6 \text { vs. } 1 \\
\text { MRI/PN vs. MRC/PRC }\end{array}$ & 57.24 & 51.73 & $\begin{array}{l}5.51 * * \\
(1.68)\end{array}$ \\
\hline $\begin{array}{r}2 \text { vs. } 1 \\
\text { MRC/PRI vs. MRC/PRC }\end{array}$ & 57.49 & 51.73 & $\begin{array}{l}7.76^{* *} \\
(1.74)\end{array}$ \\
\hline $\begin{array}{r}4 \text { vs. } 1 \\
\text { MRI/PRC vs. MRC/PRC }\end{array}$ & 57.64 & 51.73 & $\begin{array}{l}5.91 * * \\
(1.87)\end{array}$ \\
\hline $\begin{array}{r}6 \text { vs. } 3 \\
\text { MRI/PN vs. MRC/PN }\end{array}$ & 57.24 & 51.00 & $\begin{array}{l}6.24 * * \\
(1.90)\end{array}$ \\
\hline $\begin{array}{r}8 \text { vs. } 1 \\
\text { MN/PRI vs. MRC/PRC }\end{array}$ & 58.27 & 51.73 & $\begin{array}{l}6.54 * * \\
(1.67)\end{array}$ \\
\hline $\begin{array}{r}4 \text { vs. } 3 \\
\text { MRI/PRC vs. MRC/PN }\end{array}$ & 57.64 & 51.00 & $\begin{array}{l}6.64 * * * \\
(2.05)\end{array}$ \\
\hline $\begin{array}{r}8 \mathrm{vs.} 3 \\
\text { MN/PRI vs. MRC/PN }\end{array}$ & 58.27 & 51.00 & $\begin{array}{l}7.27 * * * \\
(1.88)\end{array}$ \\
\hline $\begin{array}{r}5 \text { vS. } 1 \\
\text { MRI/PRI vs. MRC/PRC }\end{array}$ & 60.05 & 51.73 & $\begin{array}{l}8.33 * * * \\
(1.60)\end{array}$ \\
\hline $\begin{array}{r}5 \text { vs. } 3 \\
\text { MRI/PRI vs. MRC/PN } \\
\end{array}$ & 60.05 & 51.00 & $\begin{array}{l}9.05 * * * \\
(1.78)\end{array}$ \\
\hline
\end{tabular}




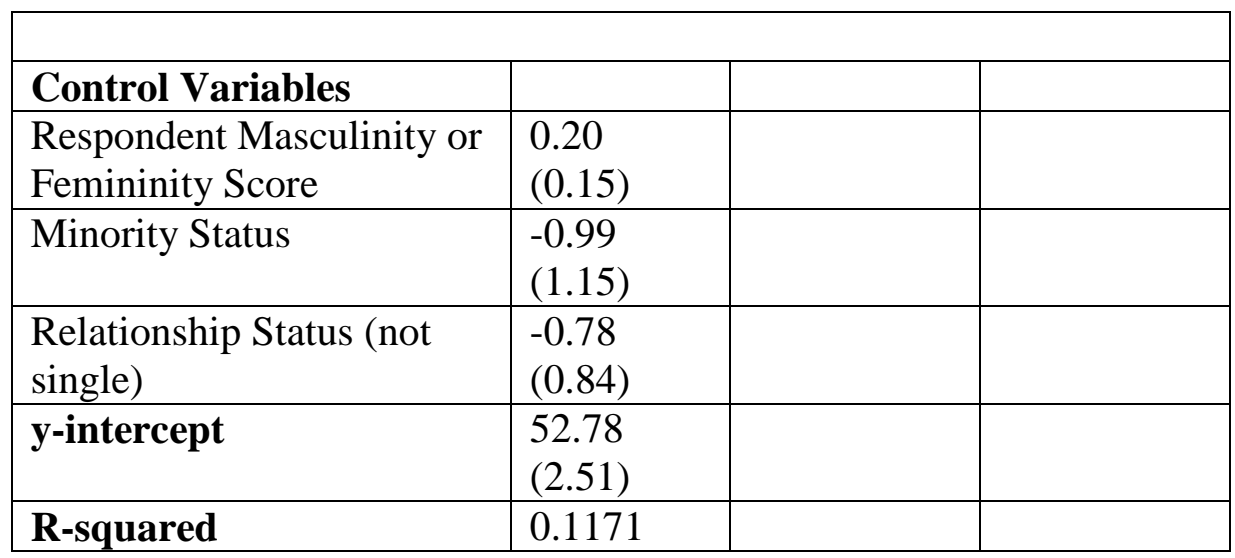

Note: The individual coefficient is statistically significant at ${ }^{+} \mathrm{p}=0.05,{ }^{*} \mathrm{p}<0.05,{ }^{*} \mathrm{p}<0.01$ or $* * * p<0.001$. Difference between mean scores or coefficient with robust standard errors in parenthesis.

Figure 6: Regression of female respondents' ratings of male potential romantic partners by vignette on the Reysen Likability Scale.

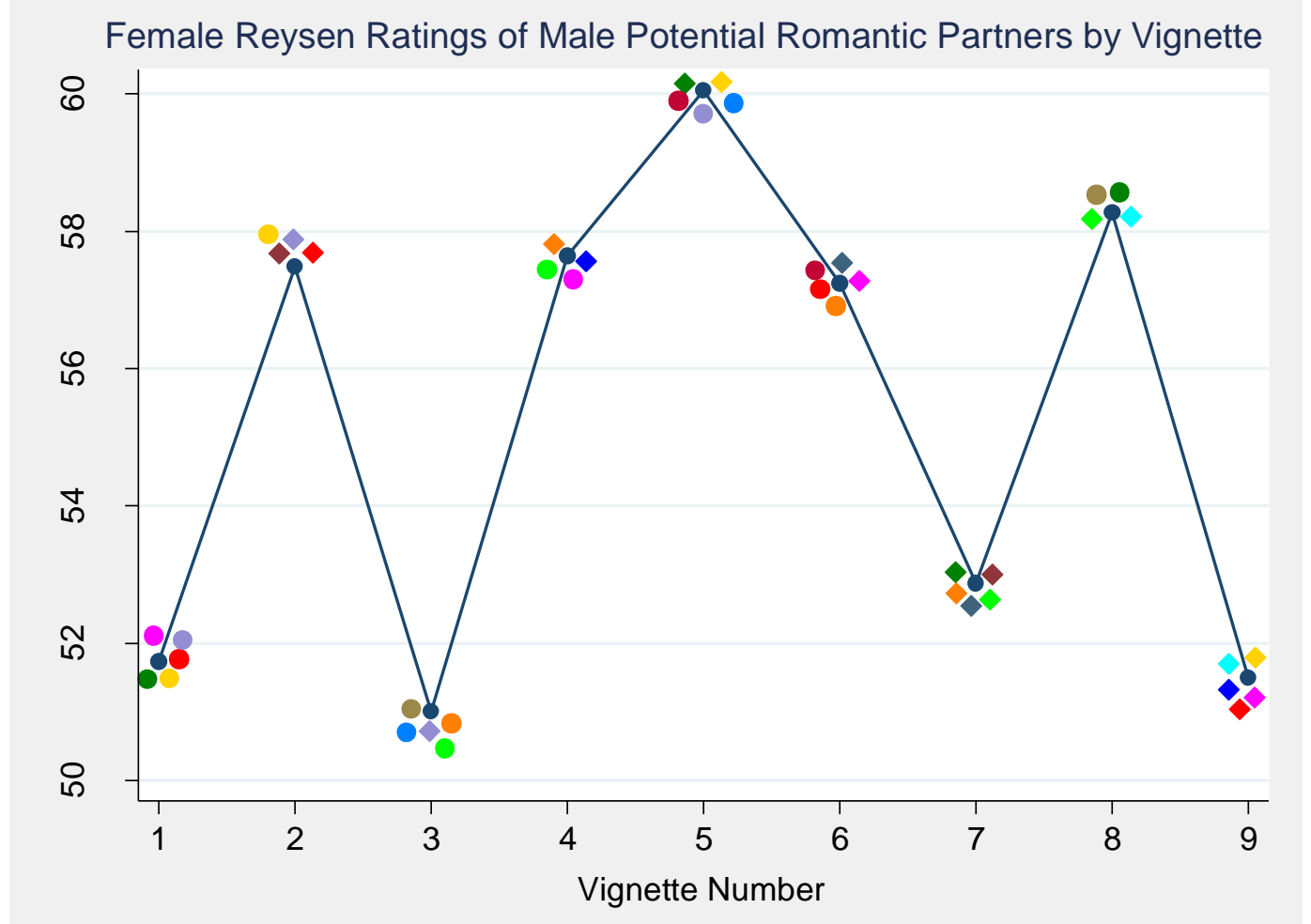

Note: The pairs of colored diamonds or circles represent statistically significant differences in the mean scores of the two vignettes that the shapes are closest to. 


\section{Summary}

There were striking differences between male and female responses on the Reysen Likability Scale. Male respondents had no statistically significantly differences between any vignettes whereas female respondents had twenty-one statistically significantly difference pairs of vignettes. This result shows that there is definitely a gendered difference in what is thought to be likable in a non-romantic context. Two of the control variables for male respondents were statistically significant whereas none of the control variables were statistically significant for females. This result indicates that minority status and relationship status of the respondents have a greater impact on their ratings of potential romantic partners as likable for males than the impact that minority status and relationship status have on female respondents' rating of potential romantic partners' non-romantic likability. While these two control variables had an effect on male assessments of likability and not on female assessments, based upon the huge disparity in statistically significant differences between mean Reysen scores, female ratings of men were much more heavily influenced by the roles of the potential romantic partner than male ratings of female potential romantic partners were.

\section{Thomae Desire for a Relationship Scale}

\section{Male Respondents}

For male respondents on the Thomae Desire for a Relationship Scale there was only one pair of vignettes that were statistically significantly different from one another. According to the regression, there is statistically significant evidence that for male respondents the mean Thomae Scale score for vignette 17 was lower than the mean score for vignette $11\left(b_{1}=-6.28\right.$, $\mathrm{p}=0.012$ ). There is statistically significant evidence that the men who received vignette 17 (neutral major, masculine personality) rated the potential romantic partner 6.28 points lower than 
the men who received vignette 11 (feminine major, masculine personality). This finding indicates that men are more likely to desire a relationship with a woman with a role incongruent personality (masculine) when she is in a role congruent college (feminine) college major than when she is in a gender neutral college major.

Relationship status was once again a statistically significant control variable with single respondents rating the potential romantic partner 3.89 points higher than those who were in a relationship $(\mathrm{p}=0.012)$. This result again indicates that when a male is in a relationship he is less likely to rate a potential romantic partner as a desirable romantic partner than his single counterparts. No other control variables were statistically significant meaning that minority status and the respondent's own masculinity/femininity did not have a statistically significant effect on male ratings of the potential romantic partners on the Thomae Desire for a Relationship Scale.

Table 8: Statistically Significant Differences Between Mean Scores for Male Respondents Dependent Variable: Thomae Score

\begin{tabular}{|c|c|c|c|}
\hline Vignette Relationship & $\begin{array}{l}\text { First Vig. } \\
\text { Mean }\end{array}$ & $\begin{array}{l}\text { Second } \\
\text { Vig. Mean }\end{array}$ & Difference \\
\hline $\begin{array}{r}17 \text { vs. } 11 \\
\text { MN/PRI vs. MRC/PRI } \\
\end{array}$ & 58.15 & 64.43 & $\begin{array}{l}-6.28^{*} \\
(2.50)\end{array}$ \\
\hline \multicolumn{4}{|l|}{ Control Variables } \\
\hline $\begin{array}{l}\text { Respondent Masculinity } \\
\text { or Femininity Score }\end{array}$ & $\begin{array}{l}0.05 \\
(0.25)\end{array}$ & & \\
\hline Minority Status & $\begin{array}{l}1.97 \\
(2.30)\end{array}$ & & \\
\hline $\begin{array}{l}\text { Relationship Status (not } \\
\text { single) }\end{array}$ & $\begin{array}{l}3.89 * \\
(1.55) \\
\end{array}$ & & \\
\hline$y$-intercept & $\begin{array}{l}53.68 \\
(4.37) \\
\end{array}$ & & \\
\hline R-squared & 0.0451 & & \\
\hline
\end{tabular}

Note: The individual coefficient is statistically significant at ${ }^{+} \mathrm{p}=0.05,{ }^{*} \mathrm{p}<0.05,{ }^{*} \mathrm{p}<0.01$ or $* * * p<0.001$. Difference between mean scores or coefficient with robust standard errors in parenthesis. 


\section{Female Respondents}

Staying consistent with the ANOVA results, the regression results for female respondents on the Thomae Desire for a Relationship Scale indicate that female respondents had the least desire for a relationship with the potential romantic partner who was in a gender neutral college major. This indicates a strong female preference against a potential romantic partner in a gender neutral college major.

According to the regression, there is statistically significant evidence that for female respondents the mean Thomae Scale score for vignette 9 was lower than the mean scores for vignettes $6\left(b_{1}=-10.28, p<0.001\right), 4\left(b_{1}=-9.01, p=0.003\right), 5\left(b_{1}=-8.85, p=0.002\right), 1\left(b_{1}=-7.18\right.$, $\mathrm{p}=0.008)$, and $2\left(\mathrm{~b}_{1}=-7.00, \mathrm{p}=0.021\right)$. There is statistically significant evidence that the females who received vignette 9 (neutral major, neutral personality) rated the potential romantic partner 10.28 points lower than vignette 6 (feminine major, neutral personality), 9.01 points lower than vignette 4 (feminine major, masculine personality), 8.85 points lower than vignette 5 (feminine major, feminine personality), 7.18 points lower than vignette 1 (masculine major, masculine personality), and 7 points lower than vignette 2 (masculine major, feminine personality).

There is also statistically significant evidence that for female respondents the mean Thomae Scale score for vignette 7 was lower than the mean scores for vignettes $6\left(b_{1}=-9.02\right.$, $\mathrm{p}=0.002), 4\left(\mathrm{~b}_{1}=-7.75, \mathrm{p}=0.016\right), 5\left(\mathrm{~b}_{1}=-7.59, \mathrm{p}=0.013\right)$, and $1\left(\mathrm{~b}_{1}=-5.92, \mathrm{p}=0.042\right)$. There is statistically significant evidence that the females who received vignette 7 (neutral major, masculine personality) rated the potential romantic partner 9.02 points lower than those who received vignette 6 (feminine major, neutral personality), 7.75 points lower than vignette 4 (feminine major, masculine personality), 7.59 points lower than vignette 5 (feminine major, 
feminine personality) and 5.92 points lower than vignette 1 (masculine major, masculine personality).

There is also statistically significant evidence that for female respondents the mean Thomae Scale score for vignette 6 was higher than the mean scores for vignettes $8\left(b_{1}=-5.74\right.$, $\mathrm{p}=0.049)$ and $3\left(\mathrm{~b}_{1}=6.13, \mathrm{p}=0.039\right)$. There is statistically significant evidence that the females who received vignette 6 (feminine major, neutral personality) rated the potential romantic partner 5.74 points higher than those who received vignette 8 (neutral major, feminine personality) and 6.13 points higher than those who received vignette 3 (masculine major, neutral personality). This indicates that women are more likely to desire a relationship with a man with a feminine major (vig. 6) rather than a man with a neutral major (vig. 8). Women are also less likely to desire a relationship a man with a neutral personality when he has a masculine major (vig. 3) than when he has a feminine major (vig. 6).

None of the control variables were statistically significant meaning that a respondent's relationship status, minority status or own level of masculinity/femininity did not have an impact on their ratings of their potential romantic partner on the Thomae Desire for a Relationship Scale.

For all of the statistically significant differences, save for vignette 6 verses 3 which was explained above, the patterns indicate that women are statistically significantly less likely to like a man in a gender neutral college major than a role congruent or incongruent major. Vignettes 9 and 7 (neutral major) were repeatedly rated lower than vignettes with a masculine or feminine major. Vignette 8 (neutral major) was also rated statistically significantly lower than vignette 6 (feminine major). This indicates female respondent's strong preference against the potential 
romantic partner in the gender neutral college major. These results support the results of the ANOVA analysis.

It is not surprising that the man in a gender role congruent (masculine) college major was rated statistically significantly higher (in some cases) than the gender role neutral college major (Eagly and KArau, 2002; Diekman and Eagly, 2008; Hielman, 2012; Diekman and Schneider, 2010). It was surprising though how frequently females rated the potential romantic partner in the gender role incongruent college major more highly than the potential romantic partner in the gender role neutral college major. According to the literature, those who are gender role incongruent should be judged more negatively but these results indicate that when compared to a potential romantic partner in a gender neutral college major, male potential romantic partners in feminine majors are rated as more desirable romantic partners. 
Table 9: Statistically Significant Differences Between Mean Scores for Female Respondents Dependent Variable: Thomae Score

\begin{tabular}{|c|c|c|c|}
\hline Vignette Relationship & $\begin{array}{l}\text { First Vig. } \\
\text { Mean }\end{array}$ & $\begin{array}{l}\text { Second } \\
\text { Vig. Mean }\end{array}$ & Difference \\
\hline $\begin{array}{r}9 \text { vs. } 6 \\
\text { MN/PN vs. MRI/PN }\end{array}$ & 50.23 & 60.50 & $\begin{array}{l}-10.28 * * * \\
(2.67)\end{array}$ \\
\hline $\begin{array}{r}7 \text { vs. } 6 \\
\text { MN/PRC vs. MRI/PN }\end{array}$ & 51.48 & 60.50 & $\begin{array}{l}-9.02 * * \\
(2.90)\end{array}$ \\
\hline $\begin{array}{r}9 \text { vs. } 4 \\
\text { MN/PN vs. MRI/PRC }\end{array}$ & 50.23 & 59.24 & $\begin{array}{l}-9.01 * * \\
(2.98)\end{array}$ \\
\hline $\begin{array}{r}9 \text { vs. } 5 \\
\text { MN/PN vs. MRI/PRI }\end{array}$ & 50.23 & 59.08 & $\begin{array}{l}-8.85 * * \\
(2.81)\end{array}$ \\
\hline $\begin{array}{r}7 \text { vs. } 4 \\
\text { MN/PRC vs. MRI/PRC }\end{array}$ & 51.48 & 59.24 & $\begin{array}{l}-7.75^{*} \\
(3.19)\end{array}$ \\
\hline $\begin{array}{r}7 \text { vs. } 5 \\
\text { MN/PRC vs. MRI/PRC }\end{array}$ & 51.48 & 59.08 & $\begin{array}{l}-7.59 * \\
(3.04)\end{array}$ \\
\hline $\begin{array}{r}9 \text { vs. } 1 \\
\text { MN/PN vs. MRC/PRC }\end{array}$ & 50.23 & 57.40 & $\begin{array}{l}-7.18 * * \\
(8.70)\end{array}$ \\
\hline $\begin{array}{r}9 \text { vs. } 2 \\
\text { MN/PN vs. MRC/PRI } \\
\end{array}$ & 50.23 & 57.23 & $\begin{array}{l}-7.00 * * \\
(3.03)\end{array}$ \\
\hline $\begin{array}{r}7 \text { vs. } 1 \\
\text { MN/PRC vs. MRC/PRC }\end{array}$ & 51.48 & 57.40 & $\begin{array}{l}-5.92 * * \\
(2.90)\end{array}$ \\
\hline $\begin{array}{r}8 \text { vs. } 6 \\
\text { MN/PRI vs. MRI/PN } \\
\end{array}$ & 55.12 & 60.50 & $\begin{array}{l}-5.74 * * \\
(2.72)\end{array}$ \\
\hline $\begin{array}{r}6 \text { vs. } 3 \\
\text { MRI/PN vs. MRC/PRI }\end{array}$ & 60.50 & 54.23 & $\begin{array}{l}6.13 * \\
(2.97) \\
\end{array}$ \\
\hline \multicolumn{4}{|l|}{ Control Variables } \\
\hline $\begin{array}{l}\text { Respondent Masculinity or } \\
\text { Femininity Score }\end{array}$ & $\begin{array}{l}-0.05 \\
(0.24)\end{array}$ & & \\
\hline Minority Status & $\begin{array}{l}-3.41 \\
(2.19)\end{array}$ & & \\
\hline $\begin{array}{l}\text { Relationship Status (not } \\
\text { single) }\end{array}$ & $\begin{array}{l}-0.51 \\
(1.42)\end{array}$ & & \\
\hline$y$-intercept & $\begin{array}{l}62.18 \\
(4.17)\end{array}$ & & \\
\hline R-squared & 0.0462 & & \\
\hline
\end{tabular}

Note: The individual coefficient is statistically significant at ${ }^{+} \mathrm{p}=0.05,{ }^{*} \mathrm{p}<0.05$, ${ }^{*} \mathrm{*} p<0.01$ or $* * * \mathrm{p}<0.001$. Difference between mean scores or coefficient with robust standard errors in parenthesis. 
Figure 7: Regression of female respondents' ratings of male potential romantic partners by vignette on the Thomae Desire for a Relationship Scale.

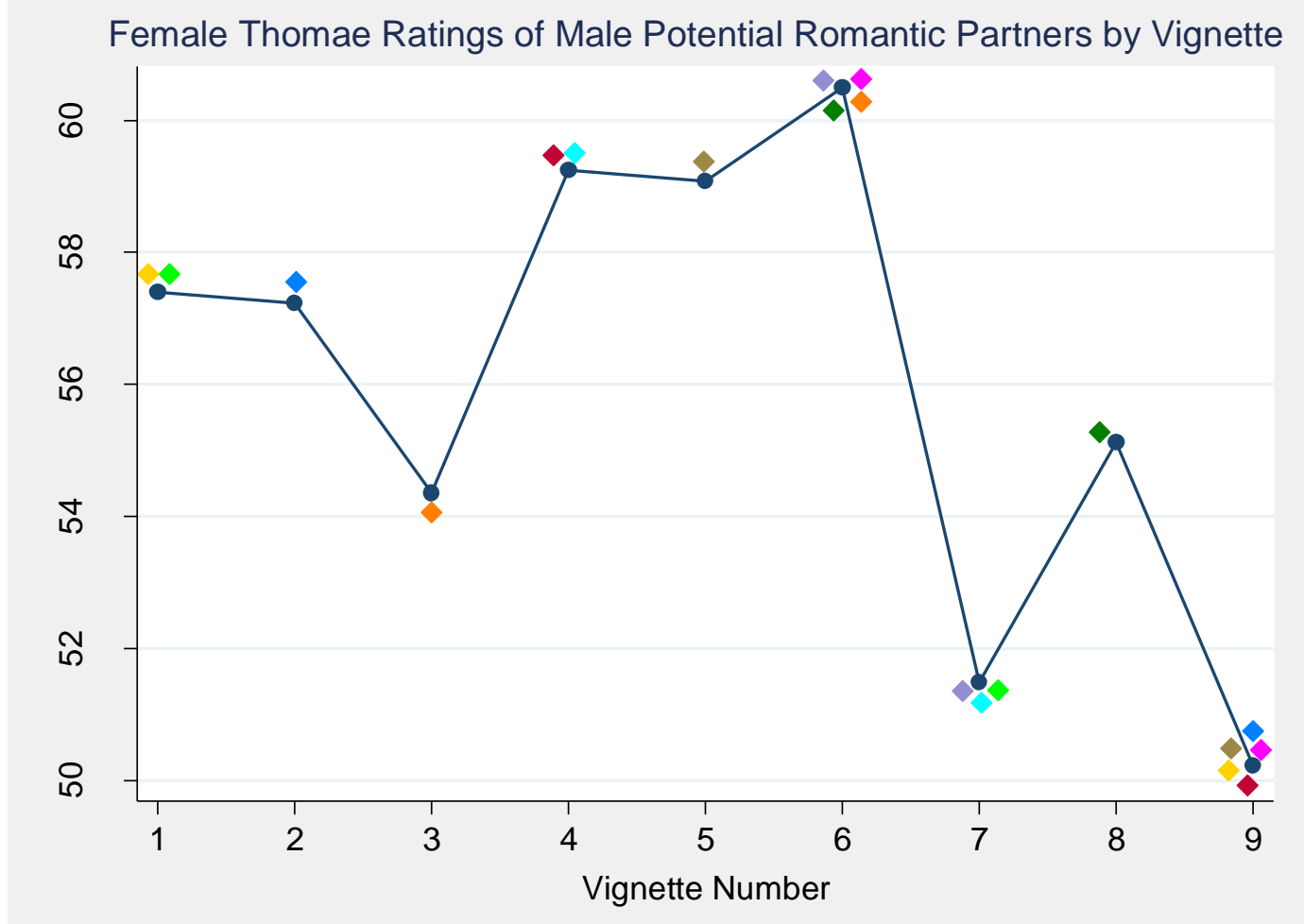

Note: The pairs of colored diamonds represent statistically significant differences in the mean scores of the two vignettes that the shapes are closest to.

\section{$\underline{\text { Short Term Relationship Subscale }}$}

\section{Male Respondents}

There is no statistically significant evidence that for male respondents there is a difference between the mean Thomae Short-Term scores of any two vignettes. There is also no statistically significant evidence that for male respondents there is a difference between the mean Thomae Short-Term scores of any of the college majors or personality characteristics.

However, the control variable for relationship status was statistically significant with single respondents rating the potential romantic partner 1.58 points higher than those who were in a relationship $(\mathrm{p}=0.022)$. This result again indicates that when a male is in a relationship he is less likely to rate a potential romantic partner as a desirable short-term romantic partner than his 
single counterparts. No other control variables were statistically significant meaning that minority status and the respondent's own masculinity/femininity did not have a statistically significant effect on male ratings of the potential romantic partners on the Thomae Desire for a Short-Term Relationship Scale.

Table 10: Regression of Perspective Romantic Partner's Personality, College Major and Thomae Short-Term Score Dependent Variable: Thomae Short-Term Score

\begin{tabular}{|l|l|}
\hline Independent Variable & \\
\hline Major 2 (feminine) & 0.38 \\
& $(0.81)$ \\
\hline Major 3 (neutral) & 0.09 \\
& $(0.76)$ \\
\hline Personality 2 (feminine) & -0.37 \\
& $(0.77)$ \\
\hline Personality 3 (neutral) & -1.25 \\
& $(0.74)$ \\
\hline Respondent Masculinity or & 0.02 \\
Femininity Score & $(0.11)$ \\
\hline Minority Status & 1.34 \\
& $(0.93)$ \\
\hline Relationship Status (not & $1.58^{*}$ \\
single) & $(0.68)$ \\
\hline y-intercept & $26.37 * * *$ \\
& $(1.87)$ \\
\hline R-squared & 0.0295 \\
\hline
\end{tabular}

Note: The individual coefficient is statistically significant at ${ }^{+} \mathrm{p}=0.05,{ }^{*} \mathrm{p}<0.05,{ }^{*} \mathrm{p}<0.01$ or $* * * \mathrm{p}<0.001$. Difference between mean scores or coefficient with robust standard errors in parenthesis.

\section{Female Respondents}

Many of the statistically significantly different pairs of vignettes for female respondents on the Thomae Desire for a Relationship Scale were also statistically significantly different when looking at the results of the Thomae Desire for a Short-Term Relationship Subscale. The results again indicate that females are less likely to desire a relationship with a potential romantic partner who is in a gender neutral college major as compared to a potential romantic partner in a gender role congruent or gender role incongruent college major. 
According to the regression, there is statistically significant evidence that for female respondents the mean Thomae Short-Term Scale score for vignette 9 was lower than the mean scores for vignettes $6\left(b_{1}=-3.20, p=0.005\right), 4\left(b_{1}=-3.14, p=0.011\right), 5\left(b_{1}=-2.98, p=0.005\right)$, and 2 $\left(b_{1}=-2.60, p=0.030\right)$.There is statistically significant evidence that the females who received vignette 9 (neutral major, neutral personality) rated the potential romantic partner 3.2 points lower than vignette 6 (feminine major, neutral personality), 3.14 points lower than vignette 4 (feminine major, masculine personality), 2.98 points lower than vignette 5 (feminine major, feminine personality), and 2.6 points lower than vignette 2 (masculine major, feminine personality).

There is also statistically significant evidence that for female respondents the mean Thomae Short-Term Scale score for vignette 7 was lower than the mean scores for vignettes 6 $\left(b_{1}=-2.90, p=0.016\right), 4\left(b_{1}=-2.83, p=0.029\right)$, and $5\left(b_{1}=-2.67, p=0.019\right)$. There is statistically significant evidence that the females who received vignette 7 (neutral major, masculine personality) rated the potential romantic partner 2.9 points lower than those who received vignette 6 (feminine major, neutral personality), 2.83 points lower than vignette 4 (feminine major, masculine personality) and 2.67 points lower than vignette 5 (feminine major, feminine personality).

Once again, the pattern of vignettes 9 and 7-both neutral majors-being rated statistically significantly lower than vignettes with a role congruent (masculine) or role incongruent (feminine) major occurred. This finding indicates that female respondents were less likely to desire a man for a short-term relationship if he is in a gender neutral major than a man in a role congruent or incongruent major. Once again, this is an interesting result because it is supported by the literature when the vignettes with a gender neutral college major are rated 
statistically significantly lower than the vignettes with a masculine college major but it is not supported when the vignettes with a gender neutral college major are rated statistically significantly lower than the vignettes with a feminine college major.

There is also statistically significant evidence that for female respondents the mean Thomae Short-Term Scale score for vignette 3 was lower than the mean scores for vignettes 5 $\left(b_{1}=2.45, p=0.034\right), 4\left(b_{1}=2.61, p=0.045\right)$, and $6\left(b_{1}=2.68, p=0.026\right)$. There is statistically significant evidence that the females who received vignette 3 (masculine major, neutral personality) rated the potential romantic partner 2.45 points lower than those who received vignette 5 (feminine major, feminine personality), 2.61 points lower than vignette 4 and 2.61 points lower than those who received vignette 6 (feminine major, neutral personality). This finding indicates a preference of female respondents for a man in a role incongruent major rather than a role congruent major in the context of a short-term relationship.

Once again, for female respondents none of the control variables were statistically significant meaning that a respondent's relationship status, minority status or own level of masculinity/femininity did not have an impact on their ratings of their potential romantic partner on the Thomae Desire for a Short-Term Relationship Scale. 
Table 11: Statistically Significant Differences Between Mean Scores for Female Respondents

Dependent Variable: Thomae Short-Term Score

\begin{tabular}{|c|c|c|c|}
\hline Vignette Relationship & $\begin{array}{l}\text { First Vig. } \\
\text { Mean }\end{array}$ & $\begin{array}{l}\text { Second } \\
\text { Vig. Mean }\end{array}$ & Difference \\
\hline $\begin{array}{r}9 \text { vs. } 6 \\
\text { MN/PN vs. MRI/PN }\end{array}$ & 25.37 & 28.57 & $\begin{array}{l}-3.20 * * \\
(1.13)\end{array}$ \\
\hline $\begin{array}{r}9 \text { vs. } 4 \\
\text { MN/PN vs. MRI/PRC } \\
\end{array}$ & 25.37 & 28.50 & $\begin{array}{l}-3.14 * \\
(1.23)\end{array}$ \\
\hline $\begin{array}{r}9 \text { vs. } 5 \\
\text { MN/PN vs. MRI/PRI }\end{array}$ & 25.37 & 28.34 & $\begin{array}{l}-2.98^{* *} \\
(1.06)\end{array}$ \\
\hline $\begin{array}{r}7 \text { vs. } 6 \\
\text { MN/PRC vs. MRI/PN }\end{array}$ & 25.68 & 28.57 & $\begin{array}{l}-2.90^{*} \\
(1.19)\end{array}$ \\
\hline $\begin{array}{r}7 \text { vs. } 4 \\
\text { MN/PRC vs. MRI/PRC }\end{array}$ & 25.68 & 28.50 & $\begin{array}{l}-2.83^{*} \\
(1.29)\end{array}$ \\
\hline $\begin{array}{r}7 \text { vs. } 5 \\
\text { MN/PRC vs. MRI/PRC }\end{array}$ & 25.68 & 28.34 & $\begin{array}{l}-2.67^{*} \\
(1.14)\end{array}$ \\
\hline $\begin{array}{r}9 \text { vs. } 2 \\
\text { MN/PN vs. MRC/PRI }\end{array}$ & 25.37 & 27.97 & $\begin{array}{l}-2.60^{*} \\
(1.20)\end{array}$ \\
\hline $\begin{array}{r}5 \text { vs. } 3 \\
\text { MRI/PRC vs. MRC/PRI }\end{array}$ & 28.34 & 25.89 & $\begin{array}{l}2.45^{*} \\
(1.15)\end{array}$ \\
\hline $\begin{array}{r}4 \text { vs. } 3 \\
\text { MRI/PRC vs. MRC/PRI } \\
\end{array}$ & 28.50 & 25.89 & $\begin{array}{l}2.61^{*} \\
(1.30)\end{array}$ \\
\hline $\begin{array}{r}6 \text { vs. } 3 \\
\text { MRI/PN vs. MRC/PRI } \\
\end{array}$ & 28.57 & 25.89 & $\begin{array}{l}2.68^{*} \\
(1.20) \\
\end{array}$ \\
\hline \multicolumn{4}{|l|}{ Control Variables } \\
\hline $\begin{array}{l}\text { Respondent Masculinity } \\
\text { or Femininity Score }\end{array}$ & $\begin{array}{l}-0.13 \\
(0.10)\end{array}$ & & \\
\hline Minority Status & $\begin{array}{l}-1.16 \\
(0.90)\end{array}$ & & \\
\hline $\begin{array}{l}\text { Relationship Status (not } \\
\text { single) }\end{array}$ & $\begin{array}{l}-0.46 \\
(0.56)\end{array}$ & & \\
\hline$y$-intercept & $\begin{array}{l}29.75 \\
(1.67) \\
\end{array}$ & & \\
\hline R-squared & 0.0424 & & \\
\hline
\end{tabular}

Note: The individual coefficient is statistically significant at ${ }^{+} \mathrm{p}=0.05,{ }^{*} \mathrm{p}<0.05, * * \mathrm{p}<0.01$ or $* * * p<0.001$. Difference between mean scores or coefficient with robust standard errors in parenthesis. 
Figure 8: Regression of female respondents' ratings of male potential romantic partners by vignette on the Thomae Desire for a Short-Term Relationship Scale.

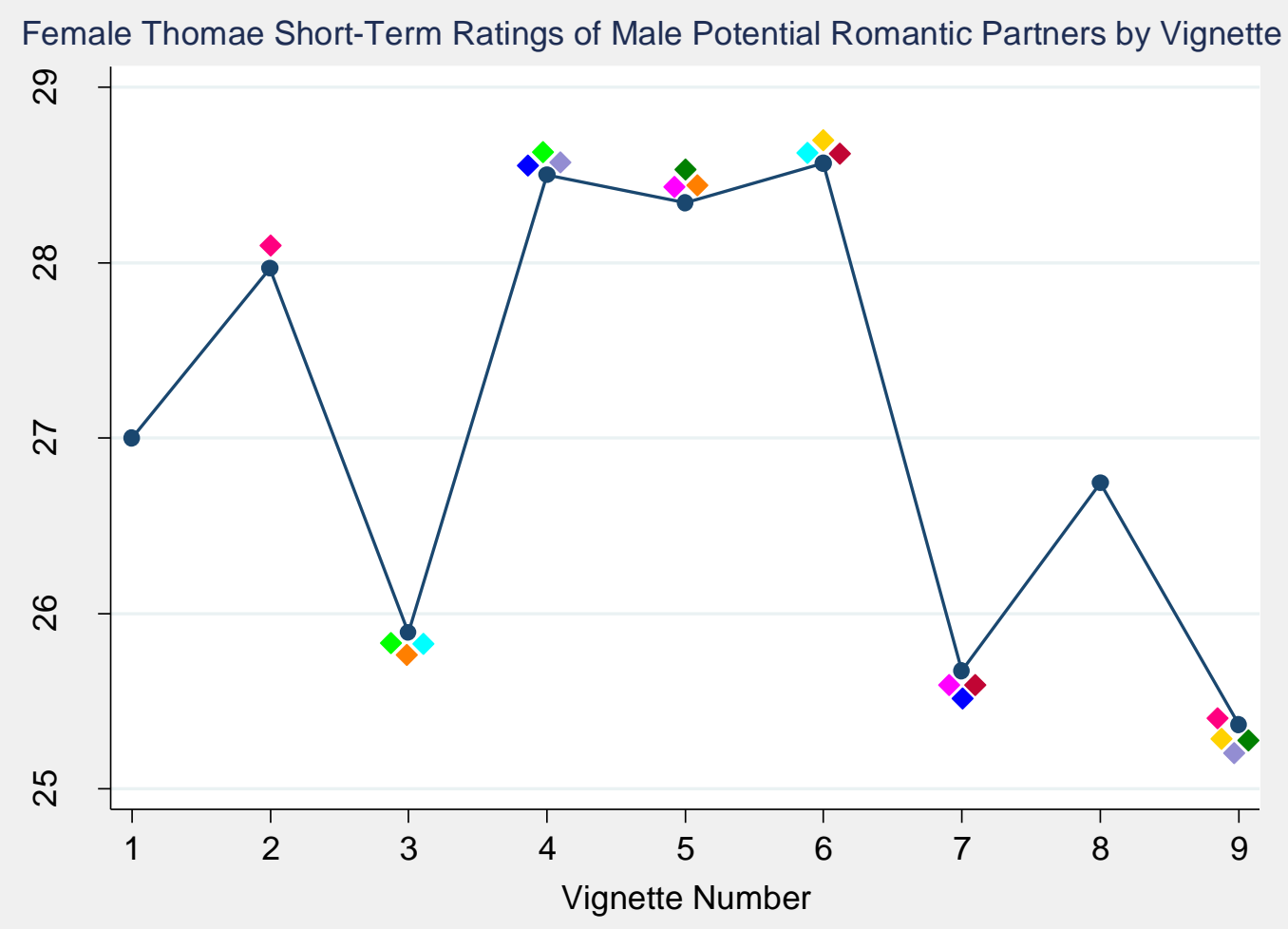

Note: The pairs of colored diamonds represent statistically significant differences in the mean scores of the two vignettes that the shapes are closest to.

\section{Long Term Relationship Subscale}

\section{Male Respondents}

According to the regression, there is statistically significant evidence that for male respondents the mean Thomae Long-Term Scale score for vignette 11 was higher than the mean scores for vignettes $17\left(b_{1}=-5.39, p=0.002\right), 13\left(b_{1}=-4.44, p=0.026\right)$, and $16\left(b_{1}=-4.05, p=0.051\right)$. There is statistically significant evidence that the men who received vignette 11 (feminine major, masculine personality) rated the potential romantic partner 5.39 points higher than vignette 17 (neutral major, masculine personality), 4.44 points higher than vignette 13 (masculine major, feminine personality) and 4.05 points higher than vignette 16 (neutral major, feminine personality). Based on these results, in regards to a long term relationship men prefer a woman 
with a role congruent college major (vig. 11) over a gender neutral major (vig. 17 and 16) and a woman with a role incongruent personality (vig. 11) over a role congruent personality (vig. 13 and 16).

Relationship status was once again significant with single individuals rating the potential romantic partner 2.35 points higher than those who are in a relationship $(\mathrm{p}=0.023)$. This result shows, as it has on all five scales, that when a male is in a relationship he is less likely to rate a potential romantic partner as a desirable romantic partner than his single counterparts. Based on the regression results of all five scales men who are in a relationship are statistically significantly less likely to find a potential romantic partner attractive in a romantic or non-romantic context or to find her to be a desirable short-term or long-term romantic partner than their single peers.

No other control variables were statistically significant meaning that minority status and the respondent's own masculinity/femininity did not have a statistically significant effect on male ratings of the potential romantic partners on the Thomae Desire for a Long-Term Relationship Scale. 
Table 12: Statistically Significant Differences Between Mean Scores for Male Respondents Dependent Variable: Thomae Long-Term Score

\begin{tabular}{|c|c|c|c|}
\hline Vignette Relationship & $\begin{array}{l}\text { First Vig. } \\
\text { Mean }\end{array}$ & $\begin{array}{l}\text { Second } \\
\text { Vig. Mean }\end{array}$ & Difference \\
\hline $\begin{array}{r}17 \text { vs. } 11 \\
\text { MN/PRI vs. MRC/PRI }\end{array}$ & 28.52 & 33.91 & $\begin{array}{l}-5.39 * * \\
(1.75)\end{array}$ \\
\hline $\begin{array}{r}13 \text { vs. } 11 \\
\text { MRI/PRC vs. MRC/PRI }\end{array}$ & 29.47 & 33.91 & $\begin{array}{l}-4.44 * \\
(1.98)\end{array}$ \\
\hline $\begin{array}{r}16 \text { vs. } 11 \\
\text { MN/PRC vs. MRC/PRI } \\
\end{array}$ & 29.86 & 33.91 & $\begin{array}{l}-4.05^{+} \\
(2.07)\end{array}$ \\
\hline \multicolumn{4}{|l|}{ Control Variables } \\
\hline $\begin{array}{l}\text { Respondent Masculinity } \\
\text { or Femininity Score }\end{array}$ & $\begin{array}{l}0.03 \\
(0.17)\end{array}$ & & \\
\hline Minority Status & $\begin{array}{l}0.69 \\
(1.70)\end{array}$ & & \\
\hline $\begin{array}{l}\text { Relationship Status (not } \\
\text { single) }\end{array}$ & $\begin{array}{l}2.35^{*} \\
(1.03)\end{array}$ & & \\
\hline$y$-intercept & $\begin{array}{l}26.47 \\
(2.95)\end{array}$ & & \\
\hline R-squared & 0.0487 & & \\
\hline
\end{tabular}

Note: The individual coefficient is statistically significant at ${ }^{+} \mathrm{p}=0.05,{ }^{*} \mathrm{p}<0.05,{ }^{*} \mathrm{p}<<0.01$ or $* * * \mathrm{p}<0.001$. Difference between mean scores or coefficient with robust standard errors in parenthesis. 
Figure 9: Regression of male respondents' ratings of female potential romantic partners by vignette on the Thomae Desire for a Long-Term Relationship Scale.

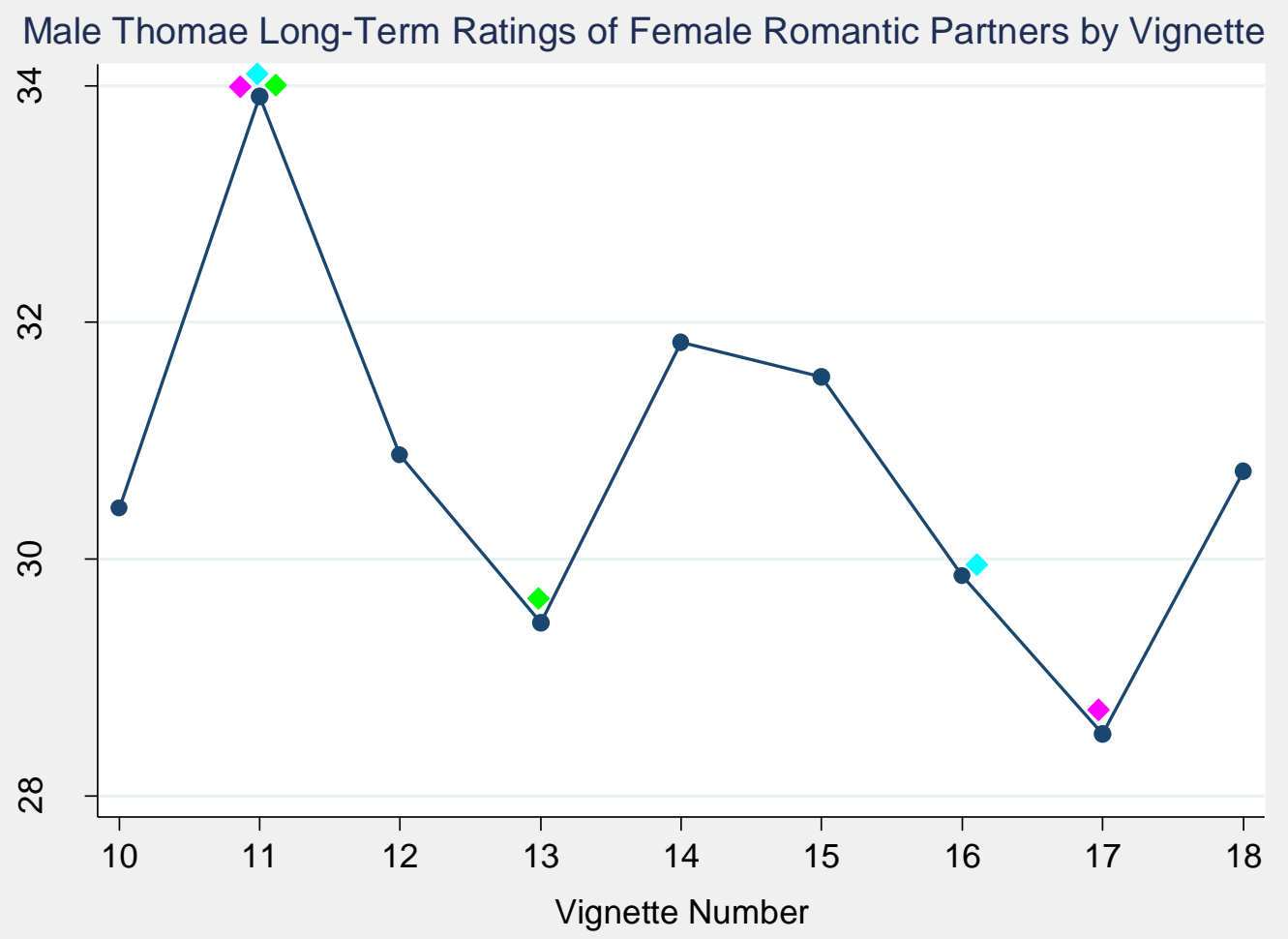

Note: The pairs of colored diamonds represent statistically significant differences in the mean scores of the two vignettes that the shapes are closest to.

Female Respondents

All of the statistically significant differences between mean vignette scores for female respondents on the Thomae Desire for a Short-Term Relationship Scale were also significant for female respondents on the Thomae Desire for a Relationship Scale and all but two were also significant on the Thomae Desire for a Short-Term Relationship Scale. This pattern indicates that what had a negative impact on female ratings of potential long-term romantic partners also had a negative impact on their desire for a short-term relationship and their overall desire for a relationship with the potential romantic partner. The results indicate once again that the potential romantic partner who was in a gender neutral college major was rated statistically significantly lower than the potential romantic partner who was in a feminine or masculine college major. 
According to the regression, there is statistically significant evidence that for female respondents the mean Thomae Long-Term Scale score for vignette 9 was lower than the mean scores for vignettes $6\left(b_{1}=-7.07, p<0.001\right), 4\left(b_{1}=-5.88, p=0.003\right), 5\left(b_{1}=-5.88, p=0.002\right), 1\left(b_{1}=-\right.$ 5.54, $\mathrm{p}=0.002)$, and $2\left(\mathrm{~b}_{1}=-4.40, \mathrm{p}=0.029\right)$. There is statistically significant evidence that the females who received vignette 9 (neutral major, neutral personality) rated the potential romantic partner 7.07 points lower than vignette 6 (feminine major, neutral personality), 5.88 points lower than vignette 4 (feminine major, masculine personality), 5.88 points lower than vignette 5 (feminine major, feminine personality), 5.54 points lower than vignette 1 (masculine major, masculine personality) and 4.40 points lower than vignette 2 (masculine major, feminine personality).

There is also statistically significant evidence that for female respondents the mean Thomae Long-Term Scale score for vignette 7 was lower than the mean scores for vignettes 6 $\left(b_{1}=-6.12, p=0.002\right), 4\left(b_{1}=-4.93, p=0.020\right), 5\left(b_{1}=-4.92, p=0.017\right)$, and $1\left(b_{1}=-4.59, p=0.016\right)$. There is statistically significant evidence that the females who received vignette 7 (neutral major, masculine personality) rated the potential romantic partner 6.12 points lower than those who received vignette 6 (feminine major, neutral personality), 4.93 points lower than vignette 4 (feminine major, masculine personality), 4.92 points lower than vignette 5 (feminine major, feminine personality), and 4.59 points lower than vignette 1 (masculine major, masculine personality).

As with all of the female respondent regression results, none of the control variables were statistically significant meaning that a respondent's relationship status, minority status or own level of masculinity/femininity did not have an impact on their ratings of their potential romantic partner on the Thomae Desire for a Long-Term Relationship Scale. 
The pattern of statistically significant differences between vignettes provides further evidence for female respondents' preferences for a potential romantic partner with a role congruent or role incongruent college major rather than a neutral college major. Women were statistically significantly less likely to rate that they desired a long-term relationship with a potential romantic partner when he was in a gender neutral college major than when he was in a masculine or feminine major. This again is somewhat supported by the literature with vignettes with a masculine major being rated more desirable than those with a gender neutral major but it is counter to the theory in that the vignettes with a feminine college major also tended to be rated more highly than those with a gender neutral college major. 
Table 13: Statistically Significant Differences Between Mean Scores for Female Respondents

Dependent Variable: Thomae Long-Term Score

\begin{tabular}{|c|c|c|c|}
\hline Vignette Relationship & $\begin{array}{l}\text { First Vig. } \\
\text { Mean }\end{array}$ & $\begin{array}{l}\text { Second } \\
\text { Vig. Mean }\end{array}$ & Difference \\
\hline $\begin{array}{r}9 \text { vs. } 6 \\
\text { MN/PN vs. MRI/PN }\end{array}$ & 24.86 & 31.93 & $\begin{array}{l}-7.07 * * * \\
(1.77)\end{array}$ \\
\hline $\begin{array}{r}7 \text { vs. } 6 \\
\text { MN/PRC vs. MRI/PN }\end{array}$ & 25.81 & 31.93 & $\begin{array}{l}-6.12 * * \\
(1.92)\end{array}$ \\
\hline $\begin{array}{r}9 \text { vs. } 4 \\
\text { MN/PN vs. MRI/PRC }\end{array}$ & 24.86 & 30.74 & $\begin{array}{l}-5.88^{* *} \\
(1.94)\end{array}$ \\
\hline $\begin{array}{r}9 \text { vs. } 5 \\
\text { MN/PN vs. MRI/PRI }\end{array}$ & 24.86 & 30.73 & $\begin{array}{l}-5.88^{* *} \\
(1.90)\end{array}$ \\
\hline $\begin{array}{r}9 \text { vs. } 1 \\
\text { MN/PN vs. MRC/PRC }\end{array}$ & 24.86 & 30.40 & $\begin{array}{l}-5.54 * * \\
(1.76)\end{array}$ \\
\hline $\begin{array}{r}7 \text { vs. } 4 \\
\text { MN/PRC vs. MRI/PRC }\end{array}$ & 25.81 & 30.74 & $\begin{array}{l}-4.93^{*} \\
(2.10)\end{array}$ \\
\hline $\begin{array}{r}7 \text { vs. } 5 \\
\text { MN/PRC vs. MRI/PRC }\end{array}$ & 25.81 & 30.73 & $\begin{array}{l}-4.92 * \\
(2.06)\end{array}$ \\
\hline $\begin{array}{r}7 \text { vs. } 1 \\
\text { MN/PRC vs. MRC/PRC }\end{array}$ & 25.81 & 30.40 & $\begin{array}{l}-4.59 * \\
(1.90)\end{array}$ \\
\hline $\begin{array}{r}9 \text { vs. } 2 \\
\text { MN/PN vs. MRC/PRI } \\
\end{array}$ & 24.86 & 29.26 & $\begin{array}{l}-4.40^{*} \\
(2.01) \\
\end{array}$ \\
\hline \multicolumn{4}{|l|}{ Control Variables } \\
\hline $\begin{array}{l}\text { Respondent Masculinity } \\
\text { or Femininity Score }\end{array}$ & $\begin{array}{l}0.09 \\
(0.16)\end{array}$ & & \\
\hline Minority Status & $\begin{array}{l}-2.25 \\
(1.47)\end{array}$ & & \\
\hline $\begin{array}{l}\text { Relationship Status (not } \\
\text { single) }\end{array}$ & $\begin{array}{l}-0.05 \\
(0.96)\end{array}$ & & \\
\hline$y$-intercept & $\begin{array}{l}32.44 \\
(2.82)\end{array}$ & & \\
\hline R-squared & 0.0462 & & \\
\hline
\end{tabular}

Note: The individual coefficient is statistically significant at ${ }^{+} \mathrm{p}=0.05,{ }^{*} \mathrm{p}<0.05, * * \mathrm{p}<0.01$ or $* * * \mathrm{p}<0.001$. Difference between mean scores or coefficient with robust standard errors in parenthesis. 
Figure 10: Regression of female respondents' ratings of male potential romantic partners by vignette on the Thomae Desire for a Long-Term Relationship Scale.

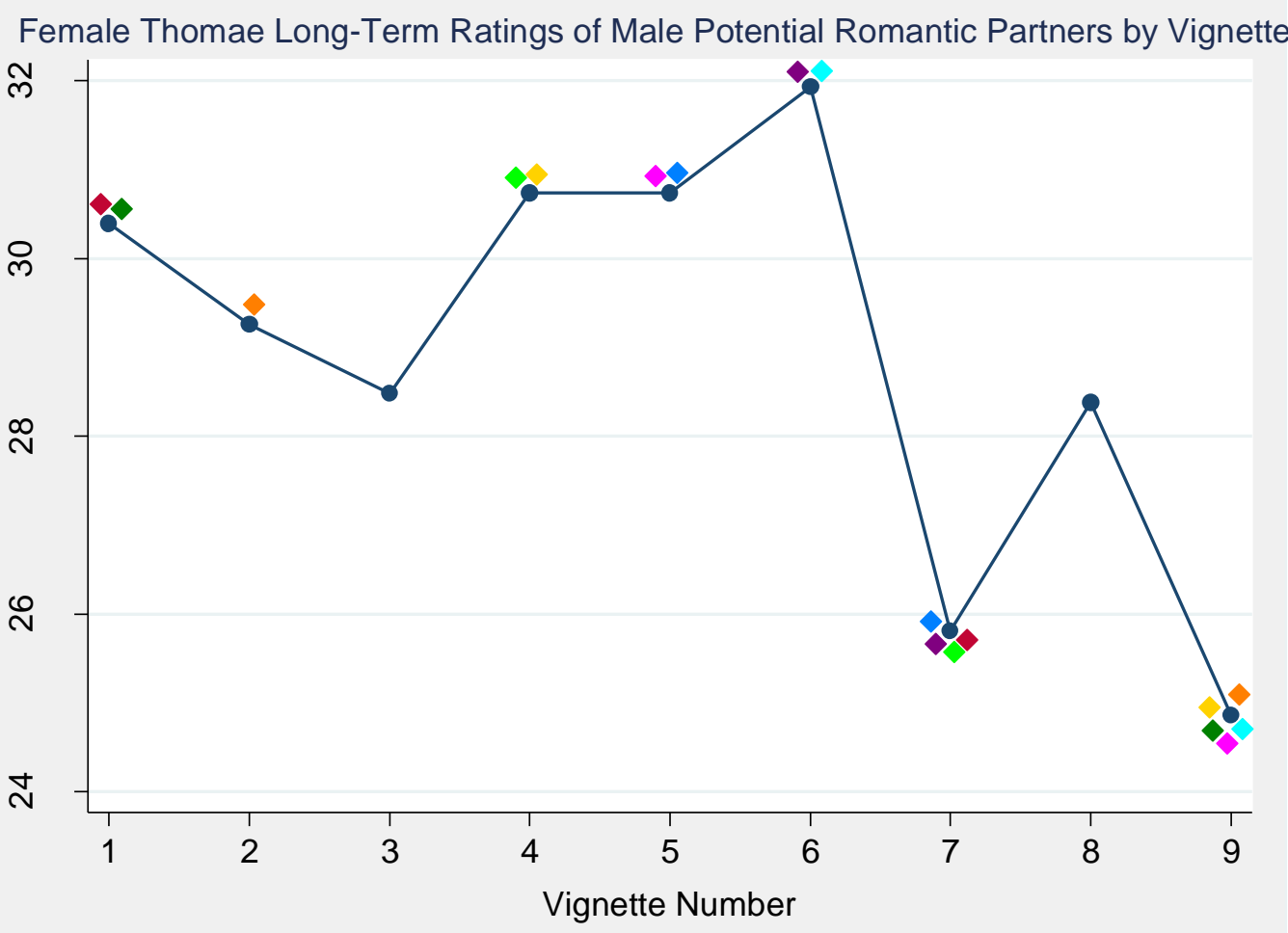

Note: The pairs of colored diamonds represent statistically significant differences in the mean scores of the two vignettes that the shapes are closest to.

\section{Summary}

Male respondents had the most statistically significant differences between pairs of vignettes on the Thomae Long-Term Desire for a Relationship Scale. They also had a statistically significantly difference on the Thomae Desire for a Relationship Scale but there were not any statistically significantly difference pairs on the Thomae Desire for a Short-Term Relationship Scale. Female respondents again had many more statistically significantly different pairs on all three scales than male respondents with eleven on the Thomae Scale, ten on the short-term scale and nine on the long-term scale. This shows once again that the roles of the potential romantic partner had a greater impact on female respondents than the impact the roles of the potential romantic partners had on male respondents. Female respondents had more 
statistically significant differences between pairs of vignettes on all five scales in this study than male respondents. This may indicate that role (in)congruity has a larger impact on female respondents' assessment of attractiveness of male potential romantic partners than role (in)congruity has on male assessment of attraction of female potential romantic partners.

Relationship status continued to have an effect on male ratings of the potential romantic partners with men who reported being in a relationship rating the potential romantic partner statistically significantly lower than their single counterparts. This was not the case with female respondents indicating that relationship status has a greater effect on male respondents' assessment of potential romantic partners than it does on female respondents. Minority status and respondents' level of masculinity/femininity did not have a statistically significant effect on either gender of respondent.

\section{R-squared Values}

For all of the regressions presented above, the adjusted R-squared was between 0.0295 (male Thomae short-term subscale) and 0.0487 (male Thomae long-term subscale). The adjusted R-squared values mean that for all scales for both male and female respondents the variables in the regression explained between $2.95 \%$ and $4.87 \%$ of the variance of scale scores. The only regression that had an adjusted R-squared outside of this range was the regression of female respondent's scores on the Reysen Likability Scale $\left(r^{2}=0.1171\right)$. This result means that the variables in the regression explained $11.71 \%$ of variability in the scores given to the nine vignettes. As shown above, female responses to the Reysen Likability Scale had the most statistical significance so it is not surprising that this also had the highest R-squared thus meaning the model explains response variability the best. 
Even with this being the highest adjusted R-squared of any of the regressions presented above, it is still not a very high value. The low value of all of the adjusted R-squared values in this study could be due to problems with the independent and dependent variables. Attraction is not as simple as selecting a person who has qualities that are pleasing. An individual's dating history, familial history, own college major and many other factors can have an impact on whether or not a respondent found the potential romantic partner to be an attractive partner. In future studies, asking more questions about the respondents' histories and personal lives to include as independent variables could help to increase the adjusted R-squared values and provide greater insight into the factors that have the most and least impact on how people rate attractiveness.

In addition, using different dependent variables in the form of additional or different scales to measure attraction could also help to increase adjusted R-squared values and provide greater insight into attraction patterns and the effect of gender roles. The scales used in this study have been used by other researchers and do provide a good starting point. Moving forward, asking more specific questions about the respondents feelings about the potential romantic partners' college majors, hobbies or personality may help to really get at respondents' feelings about very specific aspects of the potential romantic partner rather than the general perceptions.

While the current models do not have a lot of predictive power based on their adjusted Rsquared values, the results do indicate that gender roles have an effect on college students' ratings of attractiveness of a potential romantic partner, particularly for female respondents. Female respondents had statistically significant results for all scales with both ANOVA and regression analysis. Male respondents showed some statistically significant results but only with 
regression testing and at a much lower rate than female respondents. The implications of the gendered differences in the results will be further detailed in the discussion section that follows.

\section{DISCUSSION}

This study sought to connect previous literature in a new way in order to evaluate if role congruence, incongruence or neutrality had an effect on peer perceptions of attraction. It looked to answer the question: does role congruity between gender and college major and/or personality characteristics affect peer evaluations of potential romantic partner attractiveness? Previous research suggests that role incongruence has a negative impact on how attractive a person is in the eyes of their peers (Thomae and Houston, 2015; Travaglia et al., 2009; Schaffer and Johnson, 1980; Zillman et al., 1986). However, some research has found that role incongruence makes a person more attractive in the eyes of their peers (Chappetta and Barth, 2016).

In order to answer this question and examine the effect gender role congruence, incongruence or neutrality has on attraction, a vignette experiment was conducted. College students at a large research university were asked to answer survey questions in order to determine their levels of romantic attraction, non-romantic attraction and their desire for a short and long term relationship with a hypothetical potential romantic partner. Their responses were analyzed using ANOVA and regression. 


\section{Support for Hypotheses}

Hypothesis 1

H1: Respondents will be most attracted to completely gender role congruent partners.

Hypothesis 1 was not supported. The completely role congruent potential romantic partners (vignettes 1 and 10) were not rated the highest on any of the scales by either male or female respondents. Specifically, for female respondents on the Campbell Romantic Attraction Scale vignette 1 (entirely role congruent) had a mean score of 23.67 points whereas the highest mean score was vignette 6 (role incongruent major, neutral personality) at 24.44 points. For male respondents, vignette 10 (entirely role congruent) had a mean score of 24.42 points whereas the highest mean score was vignette 14 (entirely role incongruent) at 25.44 points. Hypothesis 2

H2: Respondents will be least attracted to completely gender role incongruent partners.

The second hypothesis was also not supported. The completely gender role incongruent potential romantic partners (vignettes 5 and 14) were not rated the lowest by either male or female respondents on any of the five scales. Specifically, on the Campbell Romantic Attraction Scale females gave vignette 9 (entirely gender neutral) the lowest mean score being 20.67 as compared to the mean score of 22.23 points for vignette 5 (entirely role incongruent). Male respondents gave the lowest mean score of 22.68 points to vignette 12 (role congruent major, neutral personality) whereas the mean score for vignette 14 (entirely role incongruent) was actually the highest 25.44 points. 


\section{Hypothesis 3}

H3: When potential partners exhibit both gender role congruent and gender role incongruent or gender neutral characteristics, respondents will find this potential partner more attractive than the partners that were completely gender role incongruent, but not as attractive as those that were completely gender role congruent.

This hypothesis was not supported. The following figure has the mean scores for all five scales for the two entirely role congruent vignettes (1 and 10), the two entirely role incongruent vignettes (5 and 14) and the four vignettes that were a combination of role congruent and role incongruent $(2,4,11$ and 13). The highest and lowest scores for male respondents and female respondents for each scale are in italics. For both male and female respondents in no cases were the entirely role congruent vignette rated the highest on average and the entirely role incongruent vignette rated the lowest on average. In only two cases were the entirely role congruent vignette even rated the highest of the four and that was for male respondents on the Reysen scale (56.64 points) and the Thomae Short-Term scale (30.76 points). In only one case was the entirely role incongruent vignette rated the lowest and that was for female respondents on the Campbell scale (22.40 points). In fact, in the case of the Reysen scale mean scores for female respondents are the exact opposite of the hypothesized result. The entirely role congruent vignette (1) was rated the lowest (51.50 points) and the entirely role incongruent vignette (5) was rated the highest (59.83 points). 
Table 14: Mean scores for entirely role congruent, entirely role incongruent and combinations of congruent and incongruent vignettes for each of the five scales. The italic text indicates the highest and lowest mean scores for each scale.

\begin{tabular}{|l|l|l|l|l|l|l|}
\hline \multirow{5}{*}{ Females } & Campbell & Reysen & Thomae & $\begin{array}{l}\text { Thomae } \\
\text { Short }\end{array}$ & $\begin{array}{l}\text { Thomae } \\
\text { Long }\end{array}$ \\
\hline \multirow{5}{*}{} & $\begin{array}{r}\text { Vignette 1 } \\
\text { MRC/PRC }\end{array}$ & 23.50 & 51.50 & 56.74 & 26.66 & 30.09 \\
\cline { 2 - 7 } & $\begin{array}{r}\text { Vignette 2 } \\
\text { MRC/PRI }\end{array}$ & 22.92 & 57.02 & 56.37 & 27.80 & 28.58 \\
\cline { 2 - 7 } & $\begin{array}{r}\text { Vignette 4 } \\
\text { MRI/PRC }\end{array}$ & 24.20 & 57.68 & 60.06 & 28.77 & 31.29 \\
\cline { 2 - 7 } & $\begin{array}{r}\text { Vignette 5 } \\
\text { MRI/PRI }\end{array}$ & 22.40 & 59.83 & 59.06 & 28.46 & 30.60 \\
\hline \multirow{5}{*}{ Males } & $\begin{array}{r}\text { Vignette 10 } \\
\text { MRC/PRC }\end{array}$ & 24.48 & 56.64 & 61.21 & 30.76 & 30.45 \\
\cline { 2 - 7 } & $\begin{array}{r}\text { Vignette 11 } \\
\text { MRC/PRI }\end{array}$ & 24.81 & 55.43 & 64.21 & 30.48 & 33.74 \\
\cline { 2 - 7 } & $\begin{array}{r}\text { Vignette 13 } \\
\text { MRI/PRC }\end{array}$ & 24.46 & 54.72 & 58.10 & 29.00 & 29.10 \\
\cline { 2 - 7 } & $\begin{array}{c}\text { Vignette 14 } \\
\text { MRI/PRI }\end{array}$ & 25.75 & 55.25 & 62.58 & 30.43 & 32.15 \\
\hline
\end{tabular}

Hypothesis 4

H4: Gender role congruence or incongruence will have a larger effect on attraction in long-term relationships than in short-term relationships.

There were more statistically significant differences between vignette scores on the Thomae Long-Term Desire for a Relationship Scale than there were on the Thomae Desire for a Short-Term Relationship Scale for male respondents. Male respondents did not have any statistically significant results on the short-term scale whereas there were three statistically significant differences between vignettes' mean scores on the long-term scale. For females, there were ten statistically significant differences between vignettes' mean scores on the short-term scale while there were nine statistically significant differences between vignettes' mean scores on the long-term scale. This suggests that role congruence or incongruence has a larger impact on long-term attraction than on short-term attraction for males (three statistically significant 
differences compared to zero) while for women role congruence, incongruence or neutrality has about the same impact on short-term and long-term relationships (ten statistically significant differences compared to nine). This pattern may be due to females being less likely than men to be looking for a short-term relationship as compared to a long-term relationship and thus females have more similar desires for their partners regardless of duration because they have an expectation or goal of any short-term relationship becoming a long-term one (Heldman and Wade, 2010; Bradshaw et al., 2010). Men may be more likely to be looking for a short-term relationship and thus are less likely to consider long-term factors until long-term issues are specifically mentioned or tested for (Bradshaw et al., 2010).

Hypothesis 5

H5: Male respondents will find potential female romantic partners who are gender role incongruent to be more attractive than female respondents will find potential male romantic partners who are gender role incongruent to be.

This hypothesis is supported by the results. According to the Campbell Romantic Attraction Scale, male respondents gave a mean score of 25.44 points to the entirely role incongruent (vignette 14) potential romantic partner whereas female respondents gave a mean score of 22.23 points to the entirely role incongruent (vignette 5) potential romantic partner. However, female respondents gave lower Campbell scores in general with mean scores for vignettes ranging from 20.67 points to 24.44 points as compared to the male respondent range of 22.68 points to 25.44 points with three vignettes having mean scores higher than the highest mean score for female respondents. While the data supports this hypothesis in that the entirely role incongruent male potential romantic partner was rated as less attractive than the entirely role 
incongruent female potential romantic partner, female respondents tended to give male potential romantic partners lower scores than male respondents gave female potential romantic partners.

\section{Summary}

The results of this study support the notion that gender roles are changing. Both female and male respondents showed no statistically significant evidence that they were more attracted to the completely gender role congruent potential romantic partner or that they were least attracted to the completely role incongruent potential romantic partner. Male respondents showed very few statistically significant preferences for their potential romantic partner. In fact according to ANOVA testing male respondents had zero statistically significant preferences for their female potential romantic partners. On the other hand, there were a lot of statistically significant differences between vignettes' average scale scores amongst female respondents. The ANOVA testing is particularly evident of this duality. Men showed no statistically significant preferences whereas their female counterparts showed several statistically significant differences between their average scores for vignettes depending on the congruence, incongruence or neutrality of the potential romantic partner's college major or personality.

The more statistically significant results for female respondents rather than male respondents could be due to the idea that men experience greater negative consequences when they diverge from gender norms than women do (Jackson and Sullivan, 1990; Lupton, 2000). In this study, there were more statistically significant differences in ratings for the male potential romantic partners than there were for the female potential romantic partners. This gender disparity indicates that the role (in)congruity of the male potential romantic partners had a larger impact on how attractive, likable and desirable they were assessed to be by the female respondents than the impact role (in)congruity had on the assessment of female potential 
romantic partners by male respondents. The literature on role congruity supports the gender disparity in effect on peer perceptions in that men tend to be more negatively impacted when they are not gender role congruent than females are (Jackson and Sullivan, 1990; Lupton, 2000).

The female respondents' ANOVA results show very little preference for the gender neutral major, even as compared to the role incongruent feminine major. This pattern could be due to women seeking a man with an economic plan for the future (Hitsch et al., 2010). The potential romantic partners who were in a feminine or a masculine college major had a career goal and therefore an economic plan for the future while the potential romantic partner in the gender neutral college major did not have such a plan. The strong female dislike for men without a plan indicates that women find a man with a plan more desirable, as they are seeking a man that can and will provide economically. However, female respondents did not show much of a preference for whether that man was earning an income in a feminine or masculine field. What was most important was that he had a plan to earn money.

This result shows that while gender roles are loosening and it is more socially acceptable for men to be in a traditionally feminine field, such as elementary education, it is still expected that men are providers or planners in the context of heterosexual romantic relationships. The loosening of traditional gender roles could be due to the age of the respondents. College aged students grew up in an age of economic uncertainty with the Great Recession of 2008. These students saw firsthand the economy take a drastic downward turn. That could be part of the reason why a potential partner without an economic plan was so disliked by female respondents. Having seen the economic uncertainty of the recession, when looking for a potential romantic partner not having an economic plan can be a major deal breaker, particularly for women (Hitsch et al., 2010). 
According to the ANOVA testing and pretty consistently across the regression analysis as well was the fact that college major had a larger impact on female ratings of attractiveness of the male potential romantic partner than personality characteristics did. The ANOVA results suggest that for female college-aged individuals the gender role and earning potential of their potential male romantic partner had a large impact on whether or not they found him to be attractive. Personality characteristics did not have the same effect and in fact had no statistically significant results according to ANOVA analysis. For the regression analysis of female respondents, the results were very similar across most scales. Female ratings of male potential romantic partner attractiveness varied the most due to the potential romantic partner's college major rather than their personality on most scales.

On the Reysen Likability Scale however, there were more statistically significant differences between the mean vignette scores for female respondents than there were for male respondents due to the potential romantic partners' personality characteristics. The results of the regression analysis of the female respondents reveal that females were more likely to rate a male potential romantic partner as likable in a non-romantic context if he exhibited at least one feminine characteristic, whether that be college major or personality. In fact, female ratings of male potential romantic partner's on the Reysen Likability Scale had the most statistically significant differences between mean scores of any of the five scales due to personality characteristics.

This result could be due to the fact that many of the characteristics on this Likert scale questionnaire have a feminine connotation to them - is this person warm, would you ask this person for advice, et cetera — thus the more feminine vignettes, the male vignettes with feminine characteristics or the female vignettes on the whole, were seen as more likable overall on this 
scale. That could be why the male vignettes that had at least one role congruent characteristic (masculine) were rated statistically significantly lower than the male vignettes with at least one role incongruent (feminine) characteristic. There are gendered differences in friendships. The Reysen Likability Scale measured liking in a non-romantic, therefore friendship, context. According to Ryle (2018), women's friendships tend to rest on shared intimacies, self-revelation, nurturance and emotional support whereas men's friendships are characterized by shared activities and conversations that center on work, sports or exercise. The gendered differences in friendships could be why women rated the more feminine male potential romantic partners to be more likable on the Reysen Likability Scale because they were responding positively to the qualities that they seek in friendships which are more feminine in nature.

The overall results of this study indicate that gender role (in)congruity may not have as big of an impact on levels of attraction as it used to (Zillman et al., 1986, Shaffer and Johnson, 1980; Thomae and Houston, 2015). There were still significant differences in ratings on the scales, but these differences may be due to considerations other than gender role congruity such as economic concerns or due to changing definitions of gender roles. The definition of what it means to be "gender role congruent" or "gender role incongruent" may be different for today's college students than they were for college students of previous generations. The results of this study show that as researchers we may want to reconsider our definitions of what it means to be “gender role (in)congruent" for today's college students taking into consideration the loosening of gender norms, the economic circumstances in which they grew up and a plethora of other factors that have an impact on the definition of "gender role (in)congruity". By contextualizing Role Congruity Theory so that it is more applicable to and better reflects the attitudes, practices 
and opinions of the population that is being researched, more accurate and relevant studies can be completed to look at the changing impact of gender roles.

\section{Limitations}

A limitation of this study is that studies such as this, which involve an entirely hypothetical dating situation, may suffer from a lack of predictive validity in real life dating situations. Eastwick and Finkel (2008) compared individuals stated partner preferences to reallife preferences in a speed dating situation and found that stated preferences did not reflect their real-life preferences. This result suggests that in a real-life dating situation partner preferences may be significantly different than previously stated preferences. However that does not mean that the results of this study are not valid. The results may not precisely predict individuals' attraction to romantic partners but they do represent overall patterns of attraction and gender roles among college students.

Another limitation of this study is the fact that the potential romantic partners with the gender neutral college major did not have an occupational/economic plan associated with them. If they had a plan for the future, the results of the study may have been different. Female respondents' ANOVA results in particular suggest that the gender neutral college major was least attractive amongst the college majors. The female respondents' ANOVA results may suggest that gender role congruity or incongruity may not be as important as being goal-oriented. Based on this study, it is not entirely clear if being goal-oriented is associated with masculinity, femininity or gender neutrality (required of everyone), a point that would require more research to determine. More research should also be done to determine if having vignettes with a gender neutral major but also a plan changes the patterns of attraction seen in this study. 


\section{Directions for Future Research}

In the future, it would be interesting to further test to see if there is an interaction effect between the respondents' own masculinity/femininity, the congruence of the potential romantic partner and their subsequent attraction ratings of them. Previous research suggests that the more strongly a person embraces traditional gender roles in their own life the more they seek them out in their potential romantic partners (Thomae and Houston, 2015; D’Agostino and Day, 19991; Travaglia et al., 2009). Data was collected on the respondents' level of masculinity/femininity in the form of the slider bar question about themselves however, due to time constraints, the interaction between respondent levels of masculinity/femininity and potential romantic partners was not analyzed but it can be in the future.

It would also be interesting in the future to recreate this experiment with college majors that have a gendered connotation but that are matched on future earning potential. Previous research indicates that attraction patterns may be moving away from being determined by strict gender roles and towards being determined by economic considerations (Hitsch et al., 2010). The results of this study indicate that women are particularly concerned with their potential romantic partners' economic plan as indicated by their disinterest in the potential romantic partner in the gender neutral college major. He did not have a plan for the future, thus he did not have a plan for how he was going to earn money and he received the lowest average ratings from women according to ANOVA testing on the Campbell Romantic Attraction Scale (21.66 points), the Thomae Desire for a Relationship Scale (52.17 points) and both the short-term (25.88 points) and long-term (26.28 points) scales. Male respondents did not show the same type of preference which indicates that they may not be as affected by the earning potential of their potential romantic partners' as women are, a result that was also found by Hitsch et al. (2010). Additional 
research in which all three college majors had career goals/plans that were matched in regards to income would help to better determine if it is the gender congruence/incongruence/neutrality that is having an effect on peer ratings of attraction or if it is due to economic factors.

In addition, it would be interesting to conduct this experiment again specifically within the LGBTQ population in order to determine if attraction patterns and preferences for partner roles are the same or different than the heterosexual population. Due to a limited sample size (92) there were not enough responses to make any strong statements regarding their attraction patterns. A follow-up study specifically targeting LGBTQ respondents would be needed in order to compare their results to the current study of heterosexual students. This follow-up study would show if and how gender roles and gender role congruence/incongruence impacts the LGBTQ population and if this impact is different than in the heterosexual population. It would allow for a better understanding of LGBTQ attraction and partnering patterns as well.

\section{CONCLUSION}

Gender roles are very pervasive and powerful forces that exist within almost every aspect of society to a point where they are even forced upon children before they are born. However, society is changing and gender roles are being challenged, reconstituted and altered every day. This study assessed the level of impact of gender roles still have on attraction patterns.

Respondents were asked to rate a potential romantic partner who exhibited a combination of gender role congruent, gender role incongruent, and gender role neutral characteristics. The results indicate that gender roles are changing and, in heterosexual romantic contexts, individuals are not solely concerned with finding a mate who is completely traditionally masculine or completely traditionally feminine. Attraction is a complicated issue and cannot be fully reduced 
to gender roles, but the results of this study still have power in that they represent the current state of gender roles amongst college-aged individuals. More research needs to be done to fully tease out this complicated issue. This study hopes to point research into the future in order to further understand the complexities and changes of gender roles and how they impact individuals every day of their lives. 


\section{APPENDICES}

\section{APPENDIX 1: Vignettes}

Note: $\mathrm{M}$ refers to College Major (a proxy for occupational status), P refers to Personality Traits, $\mathrm{RC}$ refers to Gender Role Congruent, Gender RI refers to Role Incongruent and N refers to Gender Role Neutral. For example: ORC PN refers to a vignette that is occupational status gender role congruent and personality trait gender role neutral.

Note: The names "Jacob" and "Jennifer" were selected due to their popularity of baby names from 1993-1999 which reflect the most likely years of birth of current undergraduate college students. These two names were selected in particular for their similarity, the fact that they have a strong gender connotation and because each allows for a realistic and gendered nickname to be used in the vignettes to make the person more realistic ("Jake" and "Jen").

\section{MALE}

$M R C P R C$

Hi my name is Jacob but everyone calls me Jake. I'm a junior with a major in mechanical engineering. I can be quite competitive but I'm also very ambitious. On the weekends, I love playing sports and video games with my friends. I'm looking forward to working as an engineer, even though it will be a lot of hard work and time spent away from my home and family, the payoff will be worth it.

\section{$M R C P R I$}

Hi my name is Jacob but everyone calls me Jake. I'm a junior with a major in mechanical engineering. I can be quite shy, but I'm also very cheerful. On the weekends I love baking and going shopping with my friends. I'm looking forward to working as an engineer, even though it will be a lot of hard work and time spent away from my home and family, the payoff will be worth it.

\section{$M R C P N$}

Hi my name is Jacob but everyone calls me Jake. I'm a junior with a major in mechanical engineering. I can be quite unpredictable, but I'm also very genuine. On the weekends, I enjoy listening to music and watching movies with friends. I'm looking forward to working as an engineer, even though it will be a lot of hard work and time spent away from my future kids and home, the payoff will be worth it.

\section{MRI PRC}

Hi my name is Jacob but everyone calls me Jake. I'm a junior with a major in elementary education. I can be quite competitive but I'm also very ambitious. On the weekends, I love playing sports and video games with my friends. I'm looking forward to working as a teacher, even though it will be a lot of hard work, having a schedule that will allow me to take care of my future kids and home will be worth it. 


\section{MRI PRI}

Hi my name is Jacob but everyone calls me Jake. I'm a junior with a major elementary education. I can be quite shy, but I'm also very cheerful. On the weekends I love baking and going shopping with my friends. I'm looking forward to working as a teacher, even though it will be a lot of hard work, having a schedule that will allow me to take care of my future kids and home will be worth it.

\section{MRI PN}

Hi my name is Jacob but everyone calls me Jake. I'm a junior with a major in elementary education. I can be quite unpredictable, but I'm also very genuine. On the weekends, I enjoy listening to music and watching movies with friends. I'm looking forward to working as a teacher, even though it will be a lot of hard work, having a schedule that will allow me to take care of my future kids and home will be worth it.

\section{MN PRC}

Hi my name is Jacob but everyone calls me Jake. I'm a junior with a major in sociology. I can be quite competitive but I'm also very ambitious. On the weekends, I love playing sports and video games with my friends. I'm not quite sure what I am going to do when I graduate. I can either pursue a job with the government which would mean long hours away from my future family but a big payoff or I can work as a career counselor at a high school which would give me time to take care of my future kids and home. Both are possibilities, I'm just working on figuring out which is best for me.

\section{MN PRI}

Hi my name is Jacob but everyone calls me Jake. I'm a junior with a major in sociology. I can be quite shy, but I'm also very cheerful. On the weekends I love baking and going shopping with my friends. I'm not quite sure what I am going to do when I graduate. I can either pursue a job with the government which would mean long hours away from my future family but a big payoff or I can work as a career counselor at a high school which would give me time to take care of my future kids and home. Both are possibilities, I'm just working on figuring out which is best for me.

\section{$M N P N$}

Hi my name is Jacob but everyone calls me Jake. I'm a junior with a major in sociology. I can be quite unpredictable, but I'm also very genuine. On the weekends, I enjoy listening to music and watching movies with friends. I'm not quite sure what I am going to do when I graduate. I can either pursue a job with the government which would mean long hours away from my future family but a big payoff or I can work as a career counselor at a high school which would give me time to take care of my future kids and home. Both are possibilities, I'm just working on figuring out which is best for me. 


\section{FEMALE} $M R C P R C$

Hi my name is Jennifer but everyone calls me Jen. I'm a junior with a major in elementary education. I can be quite shy, but I'm also very cheerful. On the weekends I love baking and going shopping with my friends. I'm looking forward to working as a teacher, even though it will be a lot of hard work, having a schedule that will allow me to take care of my future kids and home will be worth it.

\section{$M R C P R I$}

Hi my name is Jennifer but everyone calls me Jen. I'm a junior with a major in elementary education. I can be quite competitive but I'm also very ambitious. On the weekends, I love playing sports and video games with my friends. I'm looking forward to working as a teacher, even though it will be a lot of hard work, having a schedule that will allow me to take care of my future kids and home will be worth it.

\section{$M R C P N$}

Hi my name is Jennifer but everyone calls me Jen. I'm a junior with a major in elementary education. I can be quite unpredictable, but I'm also very genuine. On the weekends, I enjoy listening to music and watching movies with friends. I'm looking forward to working as a teacher, even though it will be a lot of hard work, having a schedule that will allow me to take care of my future kids and home will be worth it.

\section{MRI PRC}

Hi my name is Jennifer but everyone calls me Jen. I'm a junior with a major in mechanical engineering. I can be quite shy, but I'm also very cheerful. On the weekends I love baking and going shopping with my friends. I'm looking forward to working as an engineer, even though it will be a lot of hard work and time spent away from my home and family, the payoff will be worth it.

\section{MRI PRI}

Hi my name is Jennifer but everyone calls me Jen. I'm a junior with a major in mechanical engineering. I can be quite competitive but I'm also very ambitious. On the weekends, I love playing sports and video games with my friends. I'm looking forward to working as an engineer, even though it will be a lot of hard work and time spent away from my home and family, the payoff will be worth it.

\section{MRI PN}

Hi my name is Jennifer but everyone calls me Jen. I'm a junior with a major in mechanical engineering. I can be quite unpredictable, but I'm also very genuine. On the weekends, I enjoy listening to music and watching movies with friends. I'm looking forward to working as an engineer, even though it will be a lot of hard work and time spent away from my home and family, the payoff will be worth it. 
$M N P R C$

Hi my name is Jennifer but everyone calls me Jen. I'm a junior with a major in sociology. I can be quite shy, but I'm also very cheerful. On the weekends I love baking and going shopping with my friends. I'm not quite sure what I am going to do when I graduate. I can either pursue a job with the government which would mean long hours away from my future family but a big payoff or I can work as a career counselor at a high school which would give me time to take care of my future kids and home. Both are possibilities, I'm just working on figuring out which is best for me.

\section{MN PRI}

Hi my name is Jennifer but everyone calls me Jen. I'm a junior with a major in sociology. I can be quite competitive but I'm also very ambitious. On the weekends, I love playing sports and video games with my friends. I'm not quite sure what I am going to do when I graduate. I can either pursue a job with the government which would mean long hours away from my future family but a big payoff or I can work as a career counselor at a high school which would give me time to take care of my future kids and home. Both are possibilities, I'm just working on figuring out which is best for me.

\section{$M N P N$}

Hi my name is Jennifer but everyone calls me Jen. I'm a junior with a major in sociology. I can be quite unpredictable, but I'm also very genuine. On the weekends, I enjoy listening to music and watching movies with friends. I'm not quite sure what I am going to do when I graduate. I can either pursue a job with the government which would mean long hours away from my future family but a big payoff or I can work as a career counselor at a high school which would give me time to take care of my future kids and home. Both are possibilities, I'm just working on figuring out which is best for me. 


\section{APPENDIX 2: Dependent Variable Scales}

\section{Reysen's Likability Scale}

Please select how strongly you agree or disagree with each statement in regards to the person you just read about.

\begin{tabular}{lcccc}
\multicolumn{3}{c}{$\begin{array}{c}\text { Neither } \\
\text { agree }\end{array}$} \\
Strongly \\
disagree Disagree & $\begin{array}{c}\text { Somewhat } \\
\text { disagree }\end{array}$ & nor \\
disagree & $\begin{array}{c}\text { Somewhat } \\
\text { agree }\end{array}$ Agree $\begin{array}{c}\text { Strongly } \\
\text { agree }\end{array}$
\end{tabular}

This person is friendly.

This person is likable.

This person is warm.

This person is approchable.

I would ask this person for advice.

I would like this person as a coworker.

I would like this person as a roommate.

I would like to be friends with this person.

This person is physically attractive.

This person is similar to me.

This person is knowledgeable.

$\begin{array}{ll}0 & 0 \\ 0 & 0 \\ 0 & 0 \\ 0 & 0 \\ 0 & 0 \\ 0 & 0 \\ 0 & 0 \\ 0 & 0\end{array}$
○

O

O

O

O

is

is

s




\section{Thomae's Desire for a Relationship Scale}

Please select how strongly you agree or disagree with each statement in regards to the person you just read about.

\begin{tabular}{lcccc}
\multicolumn{5}{c}{$\begin{array}{c}\text { Neither } \\
\text { agree }\end{array}$} \\
$\begin{array}{l}\text { Strongly } \\
\text { disagree Disagree }\end{array}$ Somewhat $\begin{array}{c}\text { nor } \\
\text { disagree }\end{array}$ disagree & $\begin{array}{c}\text { Somewhat } \\
\text { agree }\end{array}$ Agree & $\begin{array}{c}\text { Strongly } \\
\text { agree }\end{array}$
\end{tabular}

I would be interested in dating a person like this.

I would be interested in having a sexual relationship with a person like this.

I could imagine having a long-term romantic relationship with a person like this.

I could imagine marrying a person like this.

I can see a person like this being a parent of my children.

I can picture growing old with a person like this.

Their aims in life are similar to my aims.

I can imagine living with a person like this.

I don't like the attitudes of people like this.

Dealing with a person like this would probably cause lots of problems and result in many fights.

I dislike people like this.

I think a person like this would be a good match for me in a romantic relationship.

$\begin{array}{ll}0 & 0 \\ 0 & 0 \\ 0 & 0 \\ 0 & 0 \\ 0 & 0 \\ 0 & 0 \\ 0 & 0 \\ 0 & 0 \\ 0 & 0 \\ 0 & 0 \\ 0 & 0 \\ 0 & 0\end{array}$




\section{Campbell's Romantic Attraction Scale}

How attractive do you find this person?

Not at all attractive

Moderartley unattractive

Somewhat unattractive

Neither unattractive nor attractive

Somewhat attractive

Moderately attractive

Very attractive

How desirable would you find this person as a dating partner?

Not at all desirable

Moderatley undesirable

Somewhat undesirable

Neither undesirable nor desirable

Somewhat desirable

Moderately desirable

Extremely desirable 
How much would you actually like to date this person?

Dislike a great deal

Dislike a moderate amount

Dislike a little

Neither like nor dislike

Like a little

Like a moderate amount

Like a great deal

How would you feel about yourself if you were dating this person?

Extremely dissatisfied

Moderately dissatisfied

Slightly dissatisfied

Neither satisfied nor dissatisfied

Slightly satisfied

Moderately satisfied

Extremely satisfied 
Extremely displeased

Moderately displeased

Slightly displeased

Neither pleased nor displeased

Slightly pleased

Moderately pleased

Extremely pleased 


\section{REFERENCES}

Arnett, J. J. 2000. "Emerging Adulthood: A Theory of Development From the Late Teens Through Twenties." American Psychologist. 45(1):145-155.

Arnett, J. J. 2004. Emerging Adulthood: The Winding Road from the Late Teens Through the Twenties. New York, New York: Oxford University Press.

Arum, R., J. Roksa, and M. J. Budig. 2008. "The Romance of College Attendance: Higher Education Stratification and Mate Selection." Research in Social Stratification and Mobility. 26:107-121.

Bem, S. L. 1981. The Bem Sex Role Inventory: A Professional Manual. Palo Alto, CA: Consulting Psychologists Press.

Bradshaw, C., A. S. Kahn and B. K. Saville. 2010. “To Hook Up or Date: Which Gender Benefits?" Sex Roles. 62:661-669.

Campbell, W. 1999. "Narcissism and Romantic Attraction.” Journal of Personality and Social Psychology. 77(6):1254-1270.

Chappetta, K. C. and J. M. Barth. 2016. "How Gender Role Stereotypes Affect Attraction in an Online Dating Scenario." Computers in Human Behavior. 63:738-746.

Cohn, D., J. S. Passel, W. Wang and G. Livingston. 2011. "Barely Half of U.S. Adults Are Married-A Record Low." Pew Social and Demographic Trends.

D’Agostino, J. V. and S. K. Day. 1991. “Gender-role Orientation and Preference for an Intimate Partner." The Psychological Record. 41(3):321-328.

DeLamater, J. D., D. J. Myers and J. L. Collett. 2014. Social Psychology, $8^{\text {th }}$ edition. Boulder, CO: Westview Press.

Diekman, A. B. and A. H. Eagly. 2008. "Of Men, Women, And Motivation: A Role Congruity Account." Pp. 434-47 in Handbook of Motivation Science, edited by J. Y. 
Shah and W. L. Gardner.

Diekman, A. B. and M. C. Schneider. 2010. “A Social Role Theory Perspective on Gender Gaps in Political Attitudes." Psychology of Women Quarterly. 34:486-497.

Eagly, A. H. 1987. Sex Differences in Social Behavior: A Social-Role Interpretation. Hillsdale, NJ: Lawrence Erlbaum.

Eagly, A. H., P. W. Eastwick and M. Johannesen-Schmidt. 2009. "Possible Selves in Marital Roles: The Impact of the Anticipated Division of Labor on the Mate Preferences of Women and Men.” Personality and Social Psychology Bulletin 35(4): 403-414.

Eagly, A. H. and S. J. Karau. 2002. "RCT of Prejudice Toward Female Leaders.” Psychological Review 109(3):573-98.

Eagly, A. H. and W. Wood. 2002. "A Cross-Cultural Analysis of the Behavior of Women and Men: Implication for the Origins of Sex Differences." Psychological Bulletin 128(5):699727.

Eagly, A. H., W. Wood, and A. B. Diekman. 2000. "Social Role Theory of Sex Differences and Similarities: A Current Appraisal.” In T. Eckes and H. M. Trautner (Eds.), The Developmental Social Psychology of Gender (pp. 123-174). Mahwah, NJ: Lawrence Erlbaum Associates, Inc.

Eastwick, P. W., A. H. Eagly, P. Glick, M. C. Johannesen-Schmidt, S. T. Fiske, A. B. Blum, et al. 2006. "Is Traditional Gender Ideology Associated with Sex-typed Mate Preferences? A Test in Nine Nations.” Journal of Personality and Social Psychology 101:993-1011. Eastwick, P. W. and E. J. Finkel. 2008. "Sex Differences in Mate Preferences Revisited: Do People Know What They Initially Desire in a Romantic Partner?” Journal of Personality and Social Psychology 94(2):245-264. 
Elliott, D. B., K. Krivickas, M. W. Brault, and R. M. Kreider. 2012. "Historical Marriage Trends from 1890-2010: A Focus on Race Differences." Annual Meeting of the Population Association of America, San Francisco, California, May 3-5, 2012. United States Census Bureau, United States.

Fiske, A. P., N. Haslam and S. T. Fiske. 1991. "Confusing One Person with Another: What Errors Reveal about the Elementary Forms of Social Relations.” Journal of Personality and Social Psychology 60:656-674.

Fox, R. L. and Z. M. Oxley. 2003. “Gender Stereotyping in State Executive Elections: Candidate Selection and Success." The Journal of Politics. 65(3):833-850.

Garcia-Retamero, R. and E. López-Zafra. 2006. "Prejudice Against Women in MaleCongenial Environments: Perceptions of Gender Role Congruity in Leadership.” Sex Roles 55:51-61.

Gol, J. (2016, September 12). Kurdish 'Angelina Jolie' devalued by media hype. Retrieved September 16, 2016, from http://www.bbc.com/news/world-middle-east-

\section{$\underline{37337908 \text { ?ocid=socialflow_facebook }}$}

Gonzaga, G. C., S. Carter, and J. Buckwalter. 2010. “Assortative Mating, Convergence, and Satisfaction in Married Couples.” Personal Relationships 17:634-644.

Heilman, M. E. 2012. “Gender Stereotypes And Workplace Bias.” Research in Organizational Behavior 32:113-35.

Heldman, C. and L. Wade. 2010. "Hook-Up Culture: Setting a New Research Agenda." Sex Res Soc Policy. 7:323-333.

Henry, J., H. W. Helm Jr., and N. Cruz. 2013. "Mate Selection: Gender and Generational Differences." North American Journal of Psychology 15(1):63-70. 
Hitsch, G., A. Hortaçsu, and D. Ariely. 2010. "What Makes You Click?-Mate Preferences in Online Dating." Quantitative Marketing and Economics 8(4):393-427.

Jackson, L. A. and L. A. Sullivan. 1990. "Perceptions Of Multiple Role Participants.” Social Psychology Quarterly 53(3):274-82.

James, S. D. (2013, March 25). Why Men Don't Teach Elementary School. Retrieved September 16, 2016, from http://abcnews.go.com/Health/men-teach-elementary$\underline{\text { school/story? } \mathrm{id}=18784172}$

Lindsey, E. A. and W. R. Zakahi. 1996. "Women Who Tell and Men Who Ask: Perceptions of Men and Women Departing From Gender Stereotypes During Initial Interaction.” Sex Roles. 34(11):767-786.

Lippa, R. 2005. “How Do Lay People Weight Information About Instrumentality, Expressiveness, and Gender-Typed Hobbies When Judging Masculinity-Femininity in Themselves, Best Friends, and Strangers?" Sex Roles. 53(1), 43-55.

Lupton, B. (2000). “Maintaining Masculinity: Men who do 'Women's Work'.” British Journal of Management Br J Management. 11(Special Issue), 33-48.

Martin, C. L. 1987. “A Ratio Measure of Sex Stereotyping.” Journal of Personality and Social Psychology. 52:3(489-499).

McGrimmon, T.S. and L.M. Dilks. 2016. "Role Congruity and Crime Clearance: The Effect of Gendered Expectations for Crime."

Moss, J. H. 2010. “The Role of Similar Humor Styles in Initial Romantic Attraction.” (Unpublished Master's Thesis). University of North Carolina Wilmington. Retrieved October 5, 2016, from http://dl.uncw.edu/etd/2010-1/mossj/justinmoss.pdf

N.A. (n.d.). Digest of Education Statistics-Digest of Education Statistics - Home. Retrieved 
November 01, 2016, from http://nces.ed.gov/programs/digest/2014menus_tables.asp

O'Neil, J., Helms, B., Gable, R., David, L., \& Wrightsman, L. (1986). “Gender-Role Conflict Scale: College Men's Fear of Femininity." Sex Roles. 14(5), 335-350.

Porter, S. R. and P. D. Umbach. 2006. “College Major Choice: An Analysis of PersonEnvironment Fit." Research in Higher Education 47(4):429-449.

Reysen, S. 2005. "Construction of a New Scale: The Reysen Likability Scale." Social Behavior and Personality. 33(2):201-208.

Ryle, R. 2018. Questioning Gender: A Sociological Exploration Third Edition. Thousand Oaks, CA: SAGE Publications.

Schaffer, D. R. and R. D. Johnson. 1980. "Effects of Occupational Choice and Sex-role Preferences on the Attractiveness of Competent Men and Women." Journal of Personality. 48(4):505-519.

Siebler, F., S. Sabelus and G. Bohner. 2008. "A Refined Computer Model of Ambivalent Sexism and Gender Differences in Romantic Partner Preferences." Psychology of Women Quarterly. 35:303-317.

Simpson, R. 2004. "Masculinities at Work: The Experiences of Men in Female Dominated Occupations." Work, Employment and Society. 18(2):349-368.

Smith, A., \& Anderson, M. 2016, February 29. “5 Facts About Online Dating.” Retrieved October 05, 2016, from http://www.pewresearch.org/fact-tank/2016/02/29/5-facts-aboutonline-dating/ Internet American Life Project

Thomae, M. and D. M. Houston. 2015. “The Impact of Gender Ideologies on Men's and Women's Desire for a Traditional of Non-Traditional Partner." Personality and Individual Differences. 95:152-158 
Travaglia, L. K., N. C. Overall and C. G. Sibley. 2009. "Benevolent and Hostile Sexism and Preferences for Romantic Partners." Personality and Individual Differences. 47:599-604.

Zillmann, D., J. B. Weaver, N. Mundorf and C. F. Aust. 1986. "Effect of an Opposite-Gender Companion's Affect to Horror on Distress, Delight, and Attraction." Journal of Personality and Social Psychology. 51(3):586-594. 